\title{
Inhibition of spawning in zebrafish (Danio rerio): Adverse outcome pathways of quinacrine and ethinylestradiol
}

\author{
By \\ Madelyne M. Cosme \\ A thesis \\ presented to \\ The University of Guelph
In partial fulfillment of requirements
for the degree of
Master of Science
in
Integrative Biology (Toxicology)

Guelph, Ontario, Canada

(C) Madelyne M. Cosme, August 2014 


\section{INHIBITION OF SPAWNING IN ZEBRAFISH (Danio rerio): ADVERSE OUTCOME PATHWAYS OF QUINACRINE AND ETHINYLESTRADIOL}

\section{Madelyne Cosme University of Guelph, 2014}

\section{Advisor: Professor. Glen Van Der Kraak}

This study examined the effects of estrogen receptor agonist, ethinylestradiol, and the phospholipase $A_{2}$ inhibitor, quinacrine, on the pathways controlling follicular recruitment, steroidogenesis, oocyte maturation and ovulation and spawning success in the adult zebrafish. Ethinylestradiol and quinacrine both inhibit spawning but did so through different adverse outcome pathways. Ethinylestradiol affected follicular recruitment (reduced ovarian size and reduction in the proportion of cortical alveolus, vitellogenic and mature follicle stages), steroidogenesis (reduced expression of aromatase) maturation (reduced luteinizing hormone receptor expression) and ovulation (reduced expression of cytosolic phospholipase A2 and the nuclear progesterone receptor). Quinacrine targeted ovulation via a reduction of the steroid $17 \alpha, 20 \beta$ dihydroxy-4-prenen-3-one and expression of the prostaglandin metabolizing enzyme cyclooxygenase 2 . Collectively, these studies suggest that a targeted assessment of reproductive endpoints can be used effectively to identify the adverse outcome pathways by which toxicants can impact reproductive fitness. 


\section{ACKNOWLEDGEMENTS}

I would like to take the time to thank all those who have helped me during the past couple years. Firstly I would like to thank my advisor, Dr. Glen Van Der Kraak, for all his help, guidance and patience throughout my graduate studies. I would like to express my gratitude to my advisory committee, Dr. Mark Servos and Dr. Andreas Heyland for their advice and recommendations during committee meetings. I would also like to express my appreciation to Andrea Lister and Jacquie Matsumoto for their assistance in running experiments and guidance in the lab. I am grateful for all the support provided by the members of the Van Der Kraak lab; their assistance was invaluable, especially during early morning sampling. I also want to thank the members of the Servos lab for their help in processing and analyzing water samples. Finally I would like to thank my family and friends for their continued support and encouragement during my graduate studies. 


\section{TABLE OF CONTENTS}

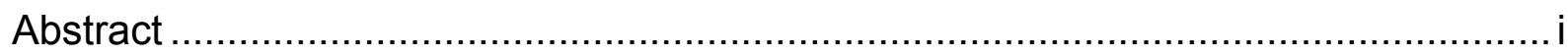

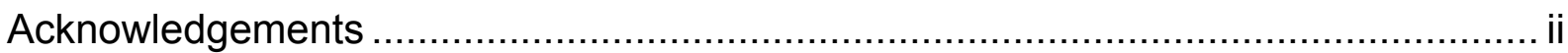

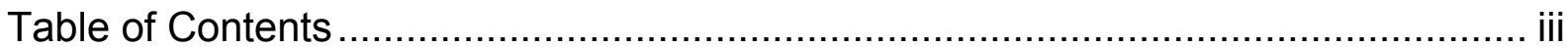

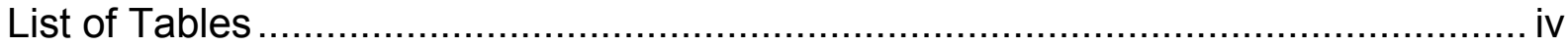

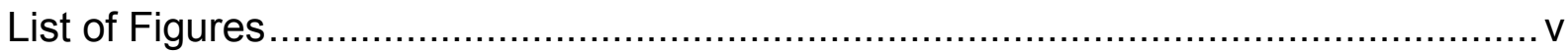

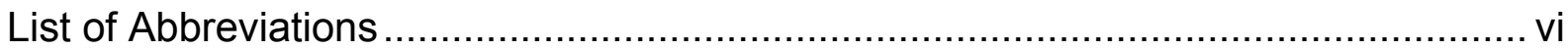

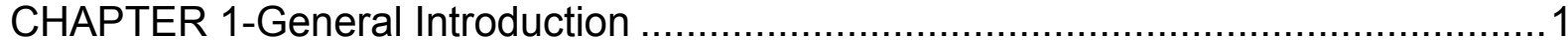

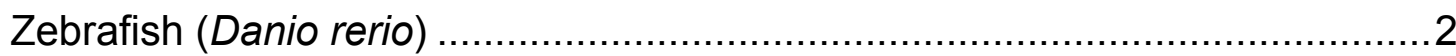

Endocrine disrupting chemicals and adverse outcome pathways .................16

Thesis Objective and Outline .......................................................... 22

CHAPTER 2-Inhibition of spawning in zebrafish: Adverse outcome pathways of

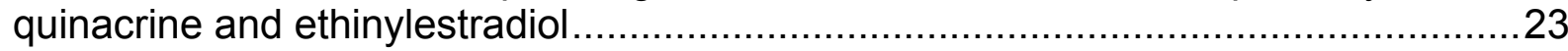

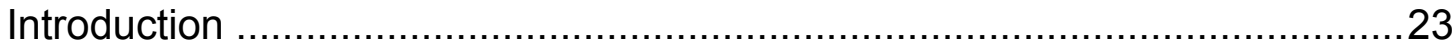

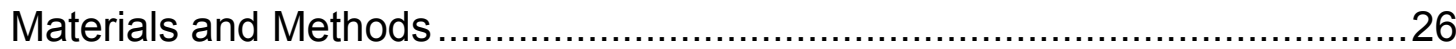

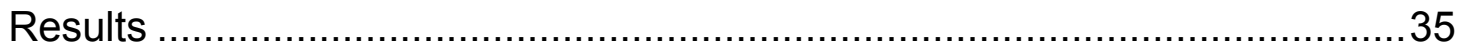

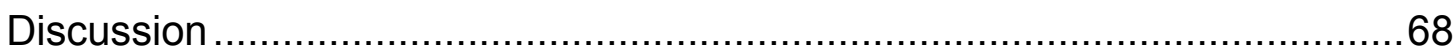

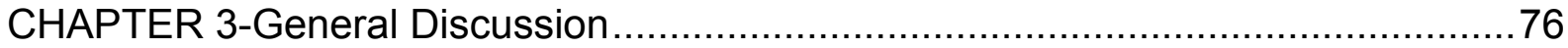

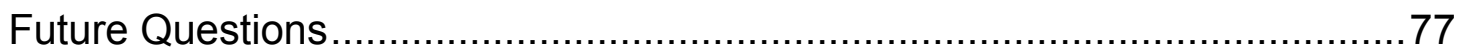

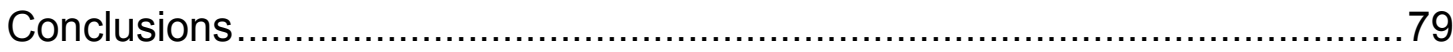

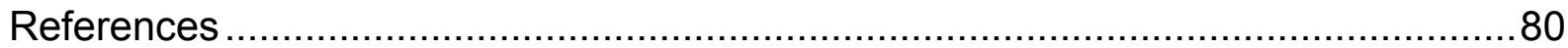




\section{LIST OF TABLES}

\section{CHAPTER 2}

Table 1: List of primers and their sequences used in this study .67

Table 2: Adverse outcome pathways of QUIN and $E_{2}$ that result in the inhibition of spawning in zebrafish. 


\section{LIST OF FIGURES}

\section{CHAPTER 1}

Figure 1: Stages of zebrafish follicular development ........................................

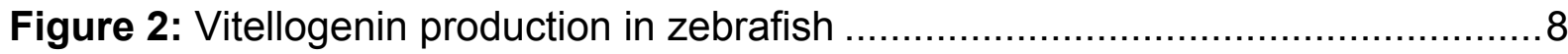

Figure 3: Steroidogenic pathways of follicle growth and oocyte maturation .............10

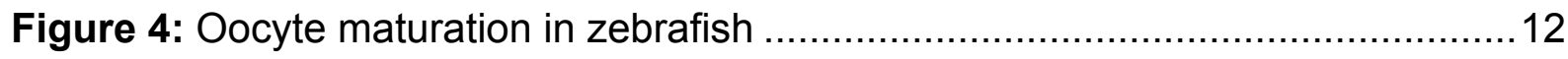

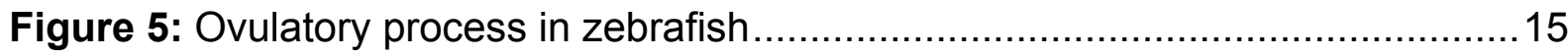

Figure 6: AOP for spawning success in zebafish ...........................................21

\section{CHAPTER 2}

Figure 1: Cumulative egg production by groups of zebrafish over an 8-day period (4 day pre-treatment, 4 days of treatment) exposed to QUIN (100 $\mu \mathrm{g} / \mathrm{L})$ or well water (control). Data represents the cumulative number of eggs spawned in 4 to 5 tanks per treatment.....

Figure 2: Average number of eggs per treatment produced by each female during the 4-day pre-treatment period and 4-day treatment to QUIN $(100 \mu \mathrm{g} / \mathrm{L})$ or well water (control). Data represents mean \pm S.E.M. of 4 to 5 tanks per treatment. Different letters indicate a significant difference between time and treatments $(p<0.05$; ANOVA, Tukey's).

Figure 3: In vivo effects of QUIN (100 $\mu \mathrm{g} / \mathrm{L})$ on ovarian levels of $17 \alpha, 20 \beta-P$. Results were expressed as pg of $17 \alpha, 20 \beta \mathrm{P}$ per mg of tissue (approximately $25 \pm$ $5 \mathrm{mg}$ ). Values represent the mean \pm S.E.M of 17 to 24 individuals. Different letters indicate a significant difference between time and treatments $(p<0.05$; ANOVA, Tukey's).....

Figure 4: Ovarian expression of cyclooxygenase-2 (COX-2) in fish exposed to QUIN (100 ug/L). The expression levels were normalized to that of elongation factor- $1 \alpha$ and expressed as a fold change relative to gene expression in the controls. Values represent the mean \pm S.E.M of 17 to 24 individuals. Different letters indicate a significant difference between time and treatments $(p<0.05$; ANOVA, Tukey's). 
Figure 5: Cumulative egg production by groups of zebrafish over a 14-day period (6-day pre-treatment, 8-day treatment) exposed to QUIN (100 $\mu \mathrm{g} / \mathrm{L}), \mathrm{EE}_{2}(25 \mathrm{ng} / \mathrm{L})$ or ethanol (control). Data represents the cumulative number of eggs spawned in 4 tanks per treatment.

Figure 6: Average number of eggs per treatment produced by each female during the 6-day pre-treatment and 8-day treatment with QUIN (100 $\mu \mathrm{g} / \mathrm{L}), \mathrm{EE}_{2}(25 \mathrm{ng} / \mathrm{L})$ or ethanol (control). Data represents mean \pm S.E.M. of 4 tanks per treatment. Different letters indicate a significant difference between treatments $(p<0.05$; ANOVA, Tukey's).

Figure 7: Gonadal somatic index of female fish after an 8-day treatment with QUIN $(100 \mu \mathrm{g} / \mathrm{L}), E_{2}(25 \mathrm{ng} / \mathrm{L})$ or ethanol (control). Data represents mean $\pm S . E . M . ~ o f ~ 4$ tanks per treatment. Different letters indicate a significant difference between treatments $(p<0.05$; ANOVA, Tukey's).

Figure 8: Representative histology of the ovarian tissue from fish exposed to (a) ethanol (b) QUIN (100 $\mu \mathrm{g} / \mathrm{L})$ (c) $\mathrm{EE}_{2}(25 \mathrm{ng} / \mathrm{L})$ for 8 days and sampled at 00:00. Pg, primary growth; $\mathrm{Ca}$, cortical alveolus; $\mathrm{V}$, vitellogenic; $\mathrm{M}$, mature.

Figure 9: Percent distribution of early stage (primary growth) follicles and later stage follicles (cortical alveolus, vitellogenic and mature) in ovarian tissue of fish exposed for 8 days to QUIN (100 $\mu \mathrm{g} / \mathrm{L})$, $\mathrm{EE}_{2}(25 \mathrm{ng} / \mathrm{L})$ or ethanol (control) and sampled at 00:00 on the morning of the $9^{\text {th }}$ day of treatment. Data represents mean \pm S.E.M of 3-4 individuals per treatment. Different letters indicate a significant difference between treatments ( $p<0.05$; ANOVA, Tukey's).

Figure 10: Ovarian expression of (a) aromatase (Arom-A) (b) luteinizing hormone receptor (LHr) (c) cytosolic phospholipase $\mathrm{A}_{2}\left(\mathrm{CPLA}_{2}\right)$ (d) nuclear progestin receptor (nPR) of fish exposed for 8 days to QUIN (100 $\mu \mathrm{g} / \mathrm{L}), \mathrm{EE}_{2}(25 \mathrm{ng} / \mathrm{L})$ or ethanol (control) and sampled at 00:00, 03:00, 06:00 and 09:00 on the morning of the $9^{\text {th }}$ day of treatment. Data represents the mean \pm S.E.M. of 5-15 individual samples. Different letters indicate a significant difference between time and treatments $(p<0.05$; ANOVA, Tukey's).

Figure 11: Vitellogenin expression in the livers of (a) female and (b) male fish exposed for 8 days to QUIN (100 $\mu \mathrm{g} / \mathrm{L}), \mathrm{EE}_{2}(25 \mathrm{ng} / \mathrm{L})$ or ethanol (control) and sampled at 00:00, 03:00, 06:00 and 09:00 on the morning of the $9^{\text {th }}$ day of treatment. Data represents the mean \pm S.E.M. of 5-16 individual samples. Different letters indicate a significant difference between time and treatments $(p<0.05$; ANOVA, Tukey's).

Figure 12: Cumulative egg production by groups of zebrafish over an 11-day period (5-day pre-treatment, 2 and 6-day treatment) exposed to $\mathrm{EE}_{2}(25 \mathrm{ng} / \mathrm{L})$ or to ethanol (control). Data represents the cumulative number of eggs spawned in 3 tanks per treatment. 
Figure 13: Average number of eggs per treatment produced by each female during the 5-day pre-treatment, and a 2 and 6-day treatment with $17 \alpha$-ethinylestradiol $\left(\mathrm{EE}_{2} ; 25 \mathrm{ng} / \mathrm{L}\right)$ or ethanol (control). Data represents mean \pm S.E.M. of 3 tanks per treatment. Different letters indicate a significant difference between time and treatments $(p<0.05$; ANOVA).

Figure 14: Gonadal somatic index of female fish after 2 and 6-day treatment with $\mathrm{EE}_{2}(25 \mathrm{ng} / \mathrm{L})$ or ethanol (control). Data represents mean \pm S.E.M. of 3 tanks per treatment. Different letters indicate a significant difference between time and treatments $(p<0.05$; ANOVA, Tukey's).

Figure 15: Representative histology of ovarian tissue from fish exposed to (a) ethanol and (b) $E_{2}(25 \mathrm{ng} / \mathrm{L})$ after 2 days of treatment and (c) ethanol and (d) $E_{2}$ $(25 \mathrm{ng} / \mathrm{L})$ after 6 days of treatment. All groups were sampled at 05:00. Pg, primary growth; Ca, cortical alveolus; $\mathrm{V}$, vitellogenic; $\mathrm{M}$, mature.

Figure 16: Percent distribution of early stage (primary growth) follicles and later stage follicles (cortical alveolus, vitellogenic and mature) in ovarian tissue of fish exposed to $\mathrm{EE}_{2}(25 \mathrm{ng} / \mathrm{L})$ or ethanol (control) and sampled at 05:00 on the morning of the $2^{\text {nd }}$ and $6^{\text {th }}$ day of treatment. Data represents mean \pm S.E.M of 9 individuals per treatment. Different letters indicate a significant difference between time and treatments $(p<0.05$; ANOVA, Tukey's).

Figure 17: Relative expression of (a) aromatase (Arom-A) (b) luteinizing hormone receptor (LHr) (c) cytosolic phospholipase $\mathrm{A}_{2}\left(\mathrm{CPLA}_{2}\right)$ and (d) nuclear progestin receptor (nPR) in cortical alveolus, vitellogenic and mature follicles from fish exposed to $25 \mathrm{ng} / \mathrm{L}$ of $E_{2}$ for 2 and 6 days and sampled at 05:00. Data represents the mean \pm S.E.M. of 3 tanks per treatment. Different letters denote statistical significance ( $p<0.05$; ANOVA, Tukey's).

Figure 18: Ovarian expression of (a) aromatase (Arom-A) (b) luteinizing hormone receptor ( $\mathrm{LHr}$ ) (c) cytosolic phospholipase $\mathrm{A}_{2}\left(\mathrm{CPLA}_{2}\right)$ and (d) nuclear progestin receptor $(\mathrm{nPR})$ in fish exposed to $\mathrm{EE}_{2}(25 \mathrm{ng} / \mathrm{L})$ or ethanol (control) for 2 and 6-days and sampled at 05:00. Data represents the mean \pm S.E.M. of 3 tanks per treatment. Different letters indicate a significant difference between time and treatments $(p<0.05$; ANOVA, Tukey's). 


\section{LIST OF ABBREVIATIONS}

\begin{tabular}{ll}
\hline Abbreviation & Proper Name \\
\hline $17 \alpha, 20 \beta-P$ & $17 \alpha, 20 \beta$-dihydroxy-4-pregnen-3-one \\
$17 \alpha-H P$ & $17 \alpha$-hydroxy-progesterone \\
$17 \beta$ HSD & $17 \beta$-Hydroxysteroid dehydrogenase \\
AA & Arachidonic acid \\
Arom-A & Aromatase \\
ARP & Acidic ribosomal protein \\
AOP & Adverse outcome pathway \\
Bax & BCL2-Associated X Protein \\
Bcl-2 & B-cell CLL/Lymphoma 2 \\
COX-1 & Cyclooxygenase-1 \\
COX-1 & Cyclooxygenase-2 \\
cPLA ${ }_{2}$ & Cytosolic phospholipase A2 \\
EDC & Endocrine disrupting chemicals \\
$E_{2}$ & Estradiol \\
EDTA & ethylenediaminetetraacetic acid \\
EE 2 & 17a-ethinylestradiol \\
EIA & Enzyme Immunoassay \\
FSH & Follilce stimulating hormone \\
GnRH & Gonadotropin-releasing hormone \\
GPR30 & G protein coupled receptor 30 \\
GSI & Gonadal somatic index \\
GV & Germinal vesicle \\
HPRT & Hypoxanthine-guanine phosphoribosyltransferase \\
INDO & indomethacin \\
LH & Luteinizing hormone \\
MPF & Maturation promoting factor \\
mPR & Membrane progestin receptor \\
mRNA & Messenger ribonucleic acid \\
nPR & Nuclear progestin receptor \\
p53 & Tumor protein 53 \\
PGF & Prostaglandin F2 $\alpha$ \\
PGH & Prostaglandin H \\
qPCR & Quantitative polymerase chain reaction \\
StAR & Steroid acute regulatory protein \\
& Terminal deoxynucleotidyl transferase (TdT)-mediated dUTP nick \\
TUNEL & Vitellogenin \\
Vtg & Quinacrine \\
QUIN &
\end{tabular}




\section{CHAPTER 1}

\section{GENERAL INTRODUCTION}

In recent years much progress has been made in defining the endocrine pathways and events that mediate reproduction in vertebrates. Advances in diagnostic techniques and increased understanding of the molecular targets affected in disease states, has resulted in a more detailed examination of the relationship between cause and effect. In the field of toxicology, there has been much interest in describing how a toxicant interacts with a biological target and contributes to adverse effects at a whole organism/population level (Ankley et al., 2010). In 2010 Ankley coined the term, adverse outcome pathway (AOP), a term that encompasses the impacts of a toxicant from the initial event of exposure to an adverse effect at higher levels of biological organization, such as a whole organism or a population level. This is not a radical concept in toxicology, but merely a defined approach that can be utilized to effectively collect and organize information about a toxicant's effects (Ankley et al., 2010). These so called AOPs may be particularly useful in defining the bridge between initial toxicant exposure and significant responses at the apical level such as gonadal growth, ovulation and fertility (Kramer et al., 2011).

The objective of this thesis was to examine the mechanisms of action of two pharmaceuticals, quinacrine (QUIN) and $17 \alpha$-ethinylestradiol $\left(\mathrm{EE}_{2}\right)$, which are known to inhibit spawning in fish (Van den Belt, Verheyen, \& Witters, 2001; Van den Belt et al., 2002). The AOP framework will be utilized in order to determine if it is useful in 
connecting the impacts of these substances on cellular and organ responses to the final outcome of spawning inhibition. This chapter will provide a review on the use of zebrafish as a model species in biological studies and take a detailed look at the structure and function of the zebrafish ovary. Different aspects of the reproductive pathways and how they contribute to the development, maturation, ovulation and eventual spawning of eggs will also be investigated. A description of what an AOP is and how this framework can be utilized to understand the complete mechanism of action of toxicants will be examined. The objective and outline for the rest of the thesis will also be discussed.

\section{Zebrafish (Danio rerio)}

Zebrafish (Danio rerio) are a tropical freshwater fish that belong to the Cyprinidae family (Zhang, Willett, \& Fremgen, 2003). The zebrafish is widely used as a model species for vertebrate development studies and more recently has become embraced for use in the area of reproductive toxicology (Selderslaghs, Van Rompay, De Coen, \& Witters, 2009; Alsop, Brown, \& Van Der Kraak, 2007; Lister, Regan, Van Zwol, \& Van Der Kraak, 2009). Large numbers of zebrafish can be housed in comparatively small spaces, which is beneficial as it is cost effective in terms of maintenance (Teraoka, Dong \& Hiraga, 2003). Zebrafish have been utilized in a variety of scientific studies since the 1930's (Laale, 1977), which has resulted in a large amount of morphological, biochemical and physiological information, including a fully sequenced genome (Hill, Teraoka, Heideman, \& Peterson, 2005). Additionally, genes identified in the zebrafish model are well conserved among other vertebrates (Hill et al., 2005). Zebrafish are especially useful when investigating aspects of reproduction as they have the ability to 
reproduce year round, with females spawning between 50-200 eggs every few days. Also much is known of the processes of oocyte final maturation, ovulation and spawning in zebrafish. Maturation occurs between 01:00 and 04:00, ovulation begins about an hour before the beginning of a light cycle, followed by spawning within the first hour of light exposure after a dark period (Blanco-Vives \& Sánchez-Vázquez, 2009; Lister \& Van Der Kraak, 2008). Under laboratory conditions, the timing of these processes can be manipulated as zebrafish reproductive behavior is strongly dependent on photoperiod, allowing researchers to select sampling times in order to focus on a particular process (Blanco-Vives \& Sánchez-Vázquez, 2009).

Zebrafish have asynchronous ovaries, meaning that follicles of all development stages are present within the ovary (Niimi \& LaHam, 1974). Zebrafish follicles consist of a large oocyte encased by a zona radiata with a surrounding follicular layer composed of an outer layer of theca cells separated by a basement membrane from an inner layer of granulosa cells (Clelland \& Peng, 2009). In adult zebrafish, follicular development primarily occurs in two stages, growth and maturation, which are predominantly controlled through the action of hormones. Gonadotropin-releasing hormone $(\mathrm{GnRH})$ is produced in the preoptic area of the hypothalamus and acts on the pituitary to stimulate the production of the gonadotropins follicle-stimulating hormone $(\mathrm{FSH})$ and luteinizing hormone (LH) (Van Der Kraak, 2009). These gonadotropins regulate folliculogenesis and promote the synthesis of peptide growth factors, sex steroids and prostaglandins in the ovary. FSH is responsible for controlling the growth stage of follicles while LH influences the maturation stage (Patino, Yoshhizaki, Thomas \& Kagawa, 2001; Nagahama et al., 1994; Nagahama et al., 1995). The development of follicles is also 
regulated, in part, by dynamic changes in the expression of various genes that control aspects of steroidogenesis and follicular recruitment, maturation and ovulation. The oocyte's transition from primary growth cell to a mature egg has been studied extensively in zebrafish. Selman, Wallace and Sarka (1993) were the first to identify the five stages of follicle growth in zebrafish, the development of which takes place over a 10-day period (Figure 1) (Wang \& Ge, 2002, 2004). 
I. primary growth stage II. Cortical alveolus stage

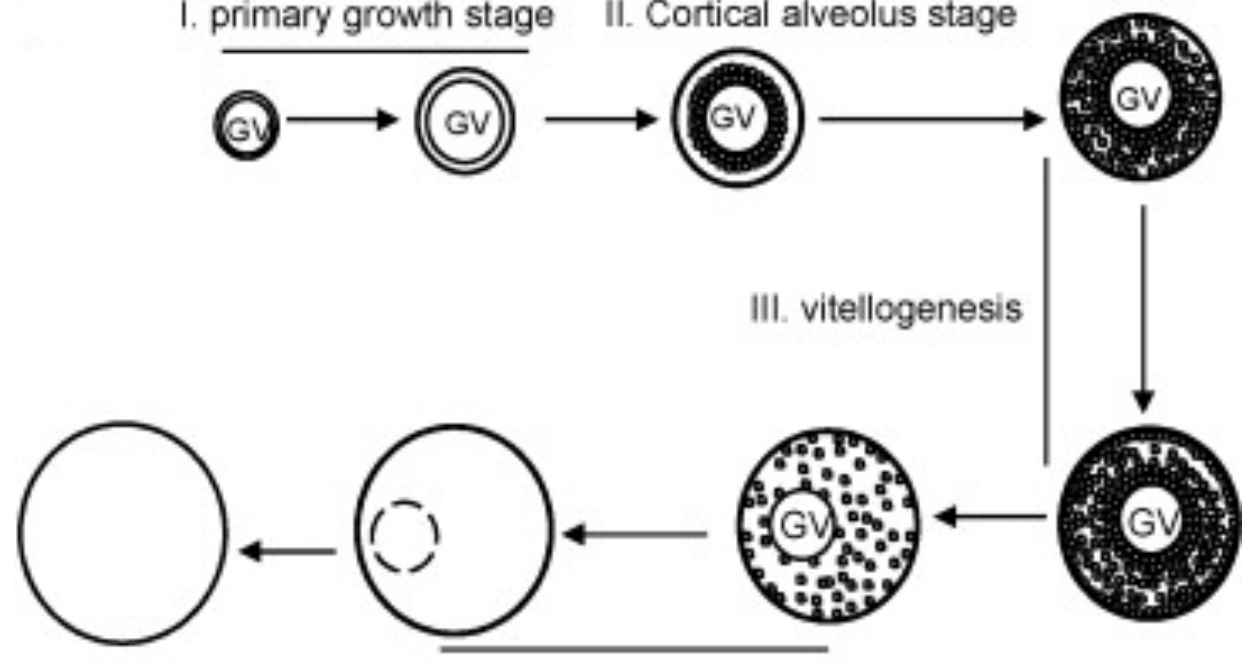

V. mature egg IV. oocyte maturation

Figure 1: Stages of zebrafish follicular development. Illustration of the five stages of follilcular development is based on Selman et al. (1993). In the primary growth stage oocytes begin to grow and follicles form. When cortical alveoli start to accumulate in the oocyte, this is referred to as the cortical alveolus stage. In the vitellogenic stage, oocytes experience a major growth period as follicles uptake vitellogenin. Oocyte maturation follicles are undergoing maturation, in which meiosis resumes and the germinal vesicle (GV) moves to the periphery of the oocyte and the nuclear membrane begins to breaks down. The mature eggs are ovulated and can be spawned. Modified from Clelland \& Peng, 2009. 
In the primary growth stage, oocytes enlarge and follicles start to form. The oocytes advance through the first meiotic division and are halted in prophase I. In the cortical alveolus stage, yolk vesicles are formed in the oocyte. Oocytes in the vitellogenenic stage experience an increase in size due to receptor-mediated endocytosis of vitellogenin, the precursor of the egg-yolk protein (Wang, Yan, Tan, \& Gong, 2000). Early vitellogenic follicles are considered to be maturationally incompetent, as they are unable to respond to progestin hormones (see below), which function as maturational hormones (Wu et al., 2000). Mature oocytes undergo maturation, where the oocyte is released from prophase 1 and meiosis is resumed. The germinal vesicle then migrates to the perimeter of the oocyte and the nuclear membrane begins to break down. These events are followed by vitellogenin cleaving into yolk proteins, the ooplasm clearing and finally hydration of the oocyte. The oocyte then progresses to metaphase II, where the extrusion of the first polar body occurs and the oocyte is expelled. The ovulated mature egg is now ready for spawning (Selman et al., 1993).

Steroid hormones have long been recognized as the key regulators of ovarian development (Clelland \& Peng, 2009). Nagahama et al. $(1994,1995)$ proposed a twocell model for follicular recruitment which begins with FSH binding to a G-protein coupled receptor in the theca cells to stimulate the synthesis of estradiol $17 \beta\left(E_{2}\right)$. The production of $E_{2}$ begins with a sequence of enzymatic events that take place in the theca cells, transforming cholesterol into testosterone. Testosterone is then released from the theca cells, passively diffuses to the granulosa cells and is converted into $E_{2}$ through the action of aromatase (Arom-A) (Clelland \& Peng, 2009). This is the 
beginning of the major growth phase in follicles, which occurs in vitellogenic follicles and accordingly the expression of Arom-A has been found to be highest in this stage (GotoKazeto, Kight, Zohar, Place, \& Trant, 2004). $E_{2}$ is transported to the liver through the bloodstream where it diffuses into hepatocytes and binds to nuclear receptors. The receptors then complex to estrogen responsive elements found in the promoter region of the vitellogenin gene, initiating vitellogenin production. Follicles then uptake vitellogenin though receptor mediated endocytosis, becoming opaque in appearance (Figure 2) (Wang, Tan, Emelyanov, Korzh, \& Gong, 2005). 


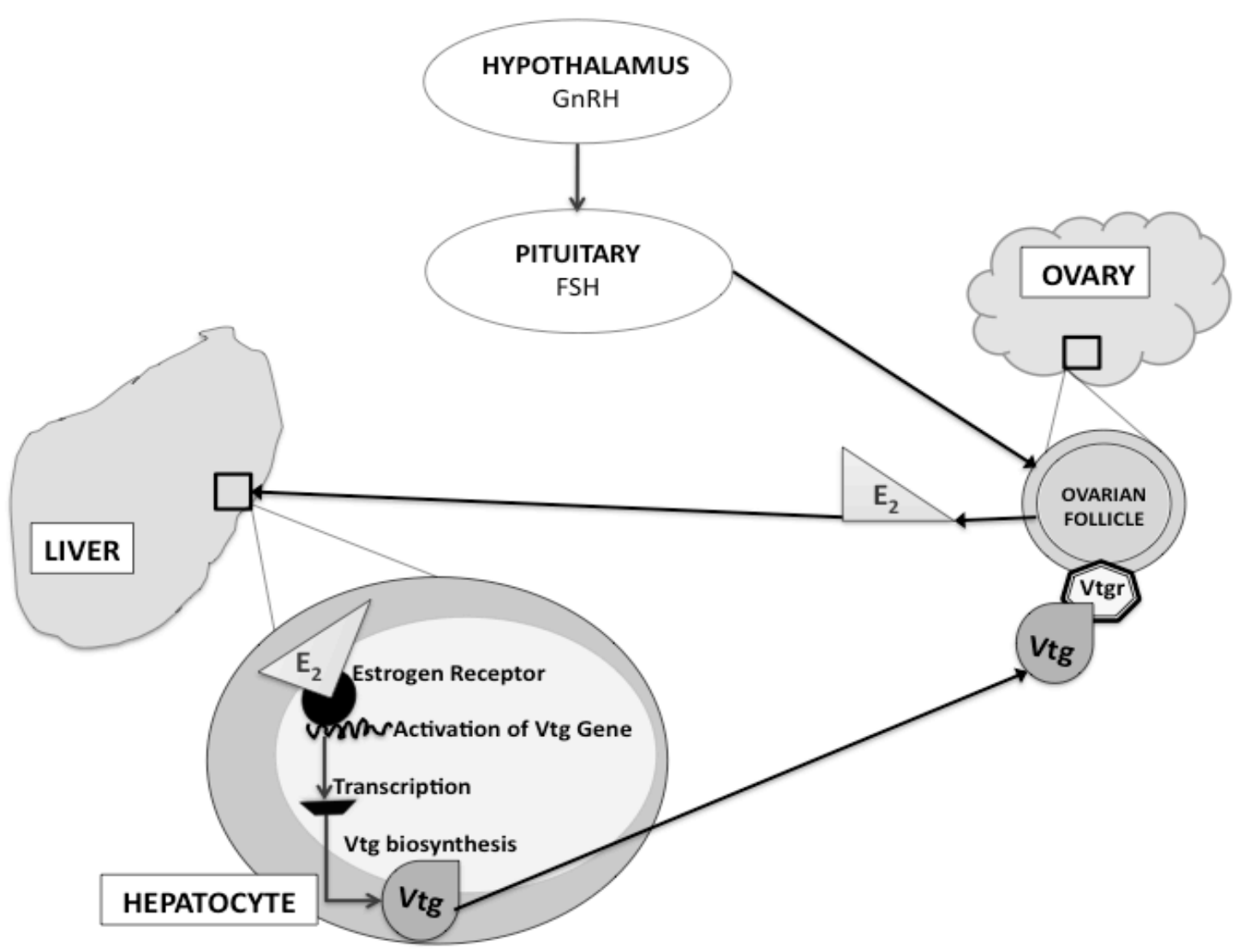

Figure 2: Vitellogenin production in the zebrafish. Gonadotropin-releasing hormone $(\mathrm{GnRH})$ stimulates the production of the follicle stimulating hormone $(\mathrm{FSH})$ in the pituitary, which then acts on the ovary to produce estradiol $\left(E_{2}\right) . E_{2}$ is then transferred through the bloodstream, to hepatocytes, where it binds to nuclear receptors, initiating the production of vitellogenin $(\mathrm{Vtg})$. Vitellogenin is then taken up by the follicles through receptor-mediated endocytosis. 
Studies have found that the G protein coupled receptor (GPR30) may be acting as an estrogen receptor and playing a role in maintaining oocyte meiotic arrest (Pang, Dong \& Thomas, 2008; Pang \& Thomas, 2010). A study that looked at a strain of GPR30 knockdown zebrafish determined that this protein mediated the inhibitory effect of $E_{2}$ on $17,20 \beta P$-induced oocyte maturation. The results of this study suggests the high levels of $E_{2}$ that occur during oocyte growth may be acting through GPR30 to prevent follicle maturation (Pang et al., 2008; Pang \& Thomas, 2010). Prior to maturation there is a shift in the steroidogenic pathway from the production of $E_{2}$ to $17 \alpha, 20 \beta$-dihydroxy4-pregnen-3-one $(17,20 \beta \mathrm{P})$, the maturation inducing hormone in zebrafish (Figure 3) (Nagahama \& Yamashita, 2008). With lower levels of $E_{2}$ there would be reduced GPR30 activity, enabling follicles to advance to the maturation stage (Clelland \& Peng, 2009). 


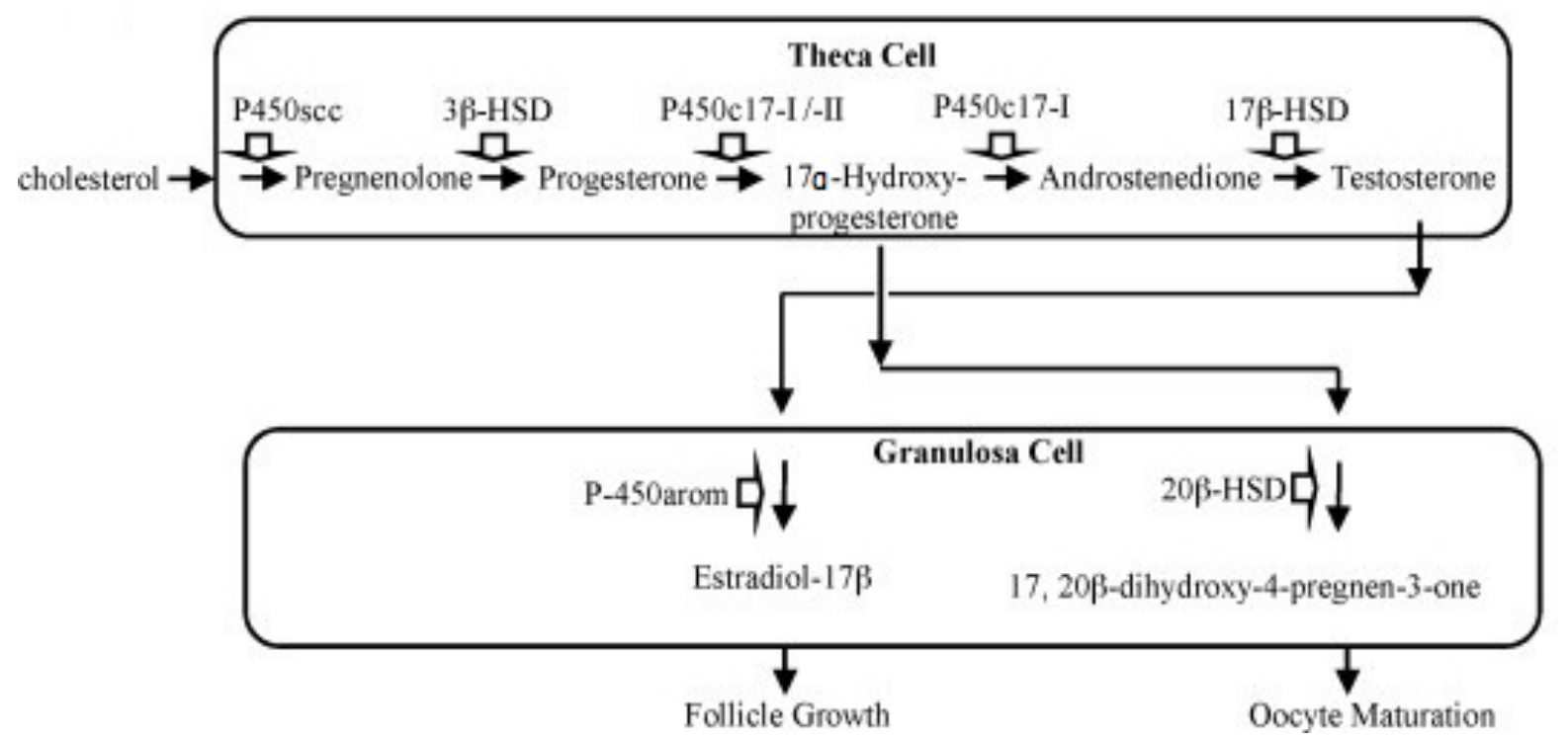

Figure 3: The steroidogenic pathways of follicle growth and oocyte maturation in zebrafish. The follicular growth pathway results in the production of estradiol-17 $\beta$ and the pathway leading to oocyte maturation produces the maturation inducing hormone in zebrafish 17 $\alpha, 20 \beta$-dihydroxy-4-pregnen-3-one. Adapted from Clelland \& Peng, 2009. 
The resumption of meiosis is a defining event during oocyte maturation and is believed to commence with LH stimulating the production of 17,20ßP (Nagahama \& Yamashita, 2008). A combination of transcriptional and translational events allows granulosa cells to develop the ability to produce $17,20 \beta \mathrm{P}$ and to become maturationally competent during which time the oocyte gains the ability to respond to $17,20 \beta \mathrm{P}$ (Kagawa, Tanaka, Okuzawa \& Kobayashi, 1998; Pang \& Ge, 2002a,b; Patiño \& Thomas, 1990). LH has

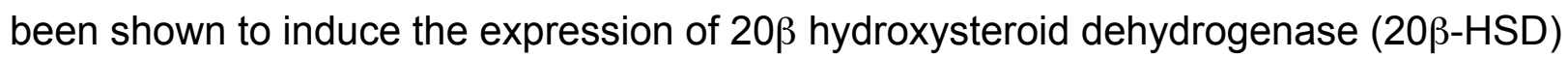
which mediates the conversion of $17 \alpha$-hydroxy-progesterone $(17 \alpha-\mathrm{HP})$ to $17,20 \beta \mathrm{P}$ (Kohli, Clelland, \& Peng, 2005). LH has also has been shown to trigger the expression of membrane bound progestin receptors (mPRs) and consequently levels of mPR expression are highest in mature follicles, which are in the process of undergoing maturation (Tan, Zagrodny, Bernaudo, \& Peng, 2009). mPRs are thought to be responsible for oocytes gaining maturational competence (Tan et al., 2009). Treatment with growth factors known to stimulate (activin) and prevent (BMP-15, TGF- $\beta$ ) maturation, increased or decreased the expression of mPRs respectively, providing further evidence for the role of mPRs in maturation (Tan et al., 2009). 17,20ßP also acts via mPRs to trigger production of the maturation promoting factor (MPF), which is responsible for releasing follicles from prophase 1 arrest (Figure 4) (Tokumoto, Tokumoto, \& Nagahama, 2005). 


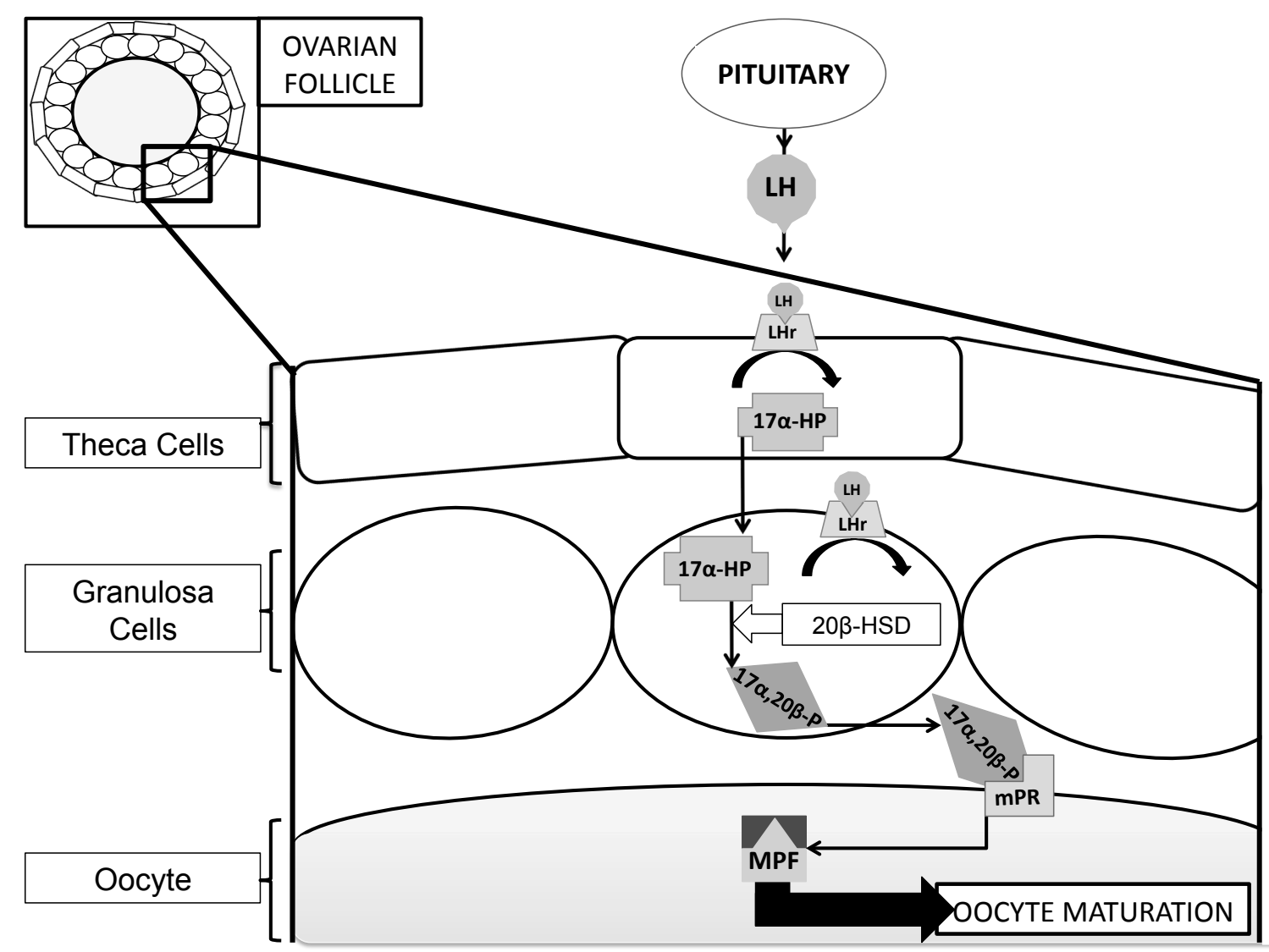

Figure 4:The process of oocyte maturation in zebrafish. The pituitary produces luteinizing hormone (LH), which binds to the luteinizing hormone receptor $(\mathrm{LHr})$ stimulating the production of $17 \alpha$-hydroxy-progesterone (17 $\alpha-\mathrm{HP}) .17 \alpha-\mathrm{HP}$ is then converted to $17 \alpha, 20 \beta-\mathrm{P}$, the maturation inducing hormone in zebrafish via the actions of the enzyme 20B-HSD. $17 \alpha, 20 \beta-P$ then acts via a membrane progestin receptor (mPR) to activate the maturation promoting factor (MPF), which releases follicles from prophase 1 arrest resulting in oocyte maturation. Model based on (Clelland \& Peng, 2009 and the work of Tokumoto et al., 2005) 
Immediately prior to ovulation, the microvillous connections between the oocyte and the granulosa cells degrade. The follicular layer surrounding the oocyte is then digested by proteolytic enzymes, causing the follicle to rupture and release the egg, this process is referred to as ovulation (Ogiwara, Takano, Shinohara, Murakimu \& Takahashi, 2005). The ovulatory pathway distinctly differs from that of maturation as ovulation requires the synthesis of new mRNA, while maturation entails only translational activity (Nagahama \& Yamashita, 2008). Accordingly the expression of genes involved in the induction of ovulation are highest in follicles undergoing this process (Clelland \& Peng, 2009). Though the molecular mechanisms involved in ovulation have been investigated, there are still aspects of this process that are unknown (Patiño \& Sullivan, 2003). Several studies have identified prostaglandins, a product of the arachidonic acid (AA) cycle, as a trigger for the induction of ovulation in zebrafish (Nagahama \& Yamashita, 2008; Lister \& Van Der Kraak, 2008). Prostaglandin synthesis begins with cytosolic phospholipase $A_{2}\left(C P L A_{2}\right)$ releasing $A A$ from the membrane phospholipids (Lister et al., 2009). Cyclooxygenases, COX-1 and COX-2 then transform $\mathrm{AA}$ into Prostaglandin $\mathrm{H}_{2}\left(\mathrm{PGH}_{2}\right)$, the prostaglandin precursor. $\mathrm{PGH}_{2}$ is converted to functional prostaglandins through the actions of prostaglandin synthases (Lister \& Van Der Kraak, 2008). Prostaglandin $F_{2 a}\left(P G F_{2 a}\right)$ has been found to stimulate ovulation in carp, goldfish, yellow perch and the Atlantic croaker (reviewed in Yaron \& Sivan, 2006). In breeding zebrafish, ovarian levels of $\mathrm{PGF}_{2 a}$ are highest during ovulation (Lister \& Van Der Kraak, 2008), providing further evidence for $\mathrm{PGF}_{2 a}$ 's role in ovulation in zebrafish. Studies have also determined that prostaglandins can stimulate egg-laying behavior and are also thought to induce spawning behavior in male fish (Stacey, 
Choinacki, Narayanan, Cole \& Murphy., 2003). $17 \alpha, 20 \beta-P$ is believed to play a role in the induction of ovulation by acting through a nuclear receptor (nPR) to initiate the synthesis of new mRNA (Figure 5) (Nagahama \& Yamashita, 2008). A study performed by Melnyk \& Van Der Kraak (2011) showed that vitellogenic zebrafish follicles treated with $17 \alpha, 20 \beta-P$ demonstrated a significant increase in the expression of $c P L A_{2}$, supporting the role of $17 \alpha, 20 \beta-\mathrm{P}$ in stimulating the transcriptional activity required for ovulation. Studies using nPR knockout mouse showed that nPRs are required specifically for LH-dependent induction of ovulation (Lydon et al., 1995). The results of a study examining ovulation in the medaka agree with these findings as an increase in nPR mRNA was found after in vitro induction of ovulation (Ogiwara et al., 2005). 


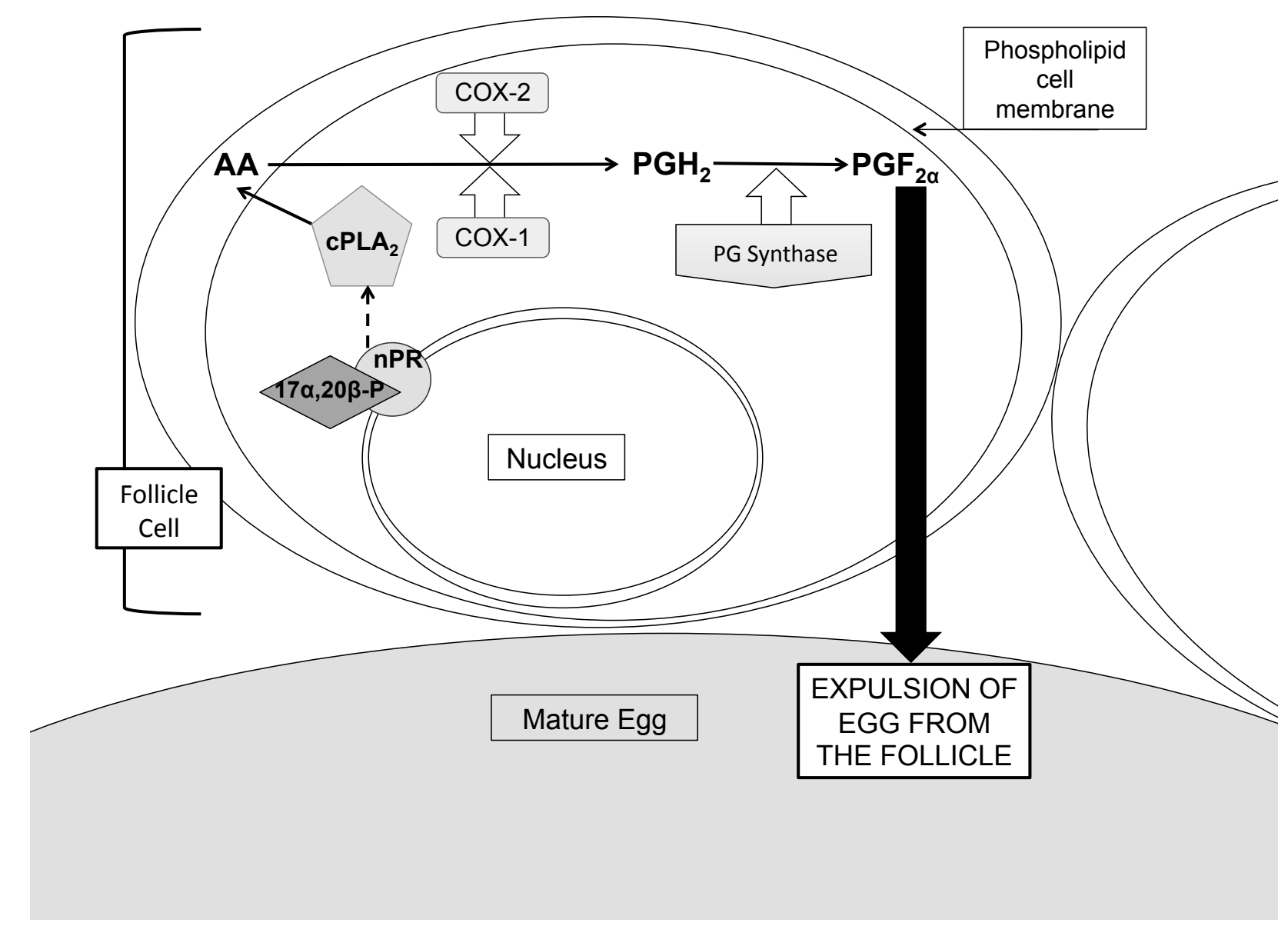

Figure 5: Ovulatory process in zebrafish. $17 \alpha, 20 \beta-\mathrm{P}$ is thought to act via nuclear progestin receptors $(\mathrm{nPR})$ in the follicles to stimulate the expression of $\mathrm{CPLA}_{2}$ (denoted by the dashed line). cPLA 2 releases arachidonic acid (AA) from the phospholipid membrane, which is then converted to $\mathrm{PGH}_{2}$ through the actions of $\mathrm{COX}-1$ and $\mathrm{COX}-2$. Prostaglandin synthase then transforms $\mathrm{PGH}_{2}$ into prostaglandin $\mathrm{F}_{2^{a}}\left(\mathrm{PGF}_{2^{a}}\right)$, which is believed to induce ovulation in zebrafish. Model based on the works of Lister \& Van Der Kraak, 2008; Nagahama \& Yamashita, 2008, Melnyk \& Van Der Kraak, 2011. 


\section{Endocrine disrupting chemicals and adverse outcome pathways}

Endocrine disruptors are exogenous substances or mixtures that alter the function of the endocrine system resulting in adverse heath effects for an organism, its offspring or the resulting generations (WHO-IPCS, 2002). Endocrine disrupting chemicals (EDCs) possess the ability to disrupt hormone synthesis and metabolism, imitate the effect of endogenous hormones, antagonize hormone action or impact the hormone receptors levels. These actions can alter the hormone pathways that control reproductive functions (Mills \& Chichester, 2005). EDCs are widely distributed in marine, estuarine and freshwater habitats throughout the world (Heberer, 2002). Industrial, municipal and sewage treatment effluent, are a major source of natural hormones, pharmaceuticals, industrial chemicals, pesticides and plant derived chemicals, all substances which have the potential to act as endocrine disruptors.

My studies are focusing on the effect of EDCs on fish due to their high likelihood of exposure and sensitivity to estrogenic substances (Segner et al., 2003). Fish are commonly utilized as a model species when investigating the impact of EDCs and consequently the effects of exposure on fish have been well documented (Ankley et al., 2009). A variety of reproductive impacts are associated with EDC exposure in fish populations including alteration of gonad structure, decreased gonadal somatic index (GSI) and altered sex hormone levels (Mills \& Chichester, 2005); however, one of the most common effects is an inhibition of spawning (Söffker \& Tyler, 2012). One EDC that has been shown to inhibit spawning in fish is $\mathrm{EE}_{2}$ (Van den Belt et al., 2001; Van den Belt et al., 2002). 
$E E_{2}$, is an EDC of foremost concern in regards to the health of freshwater aquatic environments as wastewater effluent, one of the major sources of biologically active $E_{2}$, is commonly discharged into natural waterways (Metcalfe et al., 2013). $E_{2}$ is a synthetic estrogen commonly used in contraceptives, hormonal replacement therapies and livestock reproduction management (Zuo, Zhang, \& Zhou, 2013). EE $E_{2}$ is one of the top 15 most prescribed pharmaceuticals and approximately 1 ton of $\mathrm{EE}_{2}$ is consumed annually worldwide (Vosges, Braguer, \& Combarnous, 2008). $\mathrm{EE}_{2}$ is a hydrophobic substance with low volatility (Yin, Kookana, \& Ru, 2002) and is less prone to biodegradation than natural estrogenic steroids (Zuo et al., 2013) making it a persistent pollutant in the environment. A study looking at the concentration of $E_{2}$ in shorthead redhorse suckers (Moxostoma macrolepidotum) collected near a wastewater treatment plant also confirmed $\mathrm{EE}_{2}$ as a probable candidate for bioaccumulation (Al-Ansari et al., 2010). $E_{2}$ is an estrogen receptor agonist and exposure is a major environmental concern due to its ability to induce estrogenic effects at low concentrations (> $10 \mathrm{ng} / \mathrm{L}$ ) (Kidd et al., 2007; Lange et al., 2009; Parrott \& Blunt, 2005). Many studies have looked at the effects of $\mathrm{EE}_{2}$ on fish fecundity in both laboratory and field settings. A whole lake experiment conducted in northwestern Ontario exposed a population of fathead minnows (Pimephales promelas) to 5-6 $\mathrm{ng} / \mathrm{L}_{\text {of }} \mathrm{EE}_{2}$. They found that after seven years, a near extirpation of the species had occurred due to an inhibition of spawning (Kidd et al., 2007). A decrease in GSI and an altered ovarian structure is another welldocumented effect of $\mathrm{EE}_{2}$ exposure that has been observed in the fathead minnow (Kidd et al., 2007), the wild roach (Rutilus rutilus) (Lange et al., 2009), rare minnow (Gobiocypris rarus) (Zha, Wang, Wang, \& Ingersoll, 2007) and the zebrafish (Van den 
Belt et al., 2002). Several studies have shown that zebrafish are sensitive to the effects of $E_{2}$ which are mediated by impacts on a variety of reproductive pathways (Segner et al., 2003). Exposure to $E_{2}$ reduces the expression of steroid acute regulatory protein (StAR), 17 $\beta$-hydroxysteroid dehydrogenase (17 $\beta$ HSD) and aromatase (Arom-A) all of which are involved in the steroidogenic pathway (Urbatzka et al., 2012). Other studies have found an absence of mature follicles in the ovaries of fish exposed to $E_{2}$ (Van den Belt et al., 2001) as well as a downregulation of the LH receptor (Carnevali et al., 2010; Liu, Wu, \& Ge, 2013), which suggests that $\mathrm{EE}_{2}$ is having an adverse impact on the processes of follicular recruitment or the final stages of development. A decrease in COX-2 expression has also been demonstrated in the ovaries of zebrafish exposed to $E_{2}$, which implies that $E_{2}$ also affects the ovulatory process (Carnevali et al., 2010). A number of different responses to $\mathrm{EE}_{2}$ exposure have been well documented, however, the relationship between these responses and a connection to the apical endpoint of reproductive failure have yet to be clearly defined (Werner \& Palace, 2006).

As mentioned above, prostaglandins are important regulators of ovulation and spawning in fish. QUIN is a drug that disrupts the AA pathway by intercalating into the membrane phospholipids, inhibiting $\mathrm{CPLA}_{2}$ binding and activity. The downstream effect of this interruption is decreased levels of leukotrienes, prostanoids and eicosanioid activity (Ehsanian, Van Waes, \& Feller, 2011). QUIN has historically been used as a treatment for malaria, rheumatoid arthritis, and mild to moderate systemic lupus erythematosus and more recently, the neurodegenerative disease CreutzfeldtJakb disease (Vogtherr et al., 2003). Due to its ability to interrupt the AA pathway it has been utilized in reproductive studies investigating the ovulatory pathway in fish. 
Treatment with $1.0 \mathrm{mM}$ of QUIN has been shown to inhibit spontaneous ovulation in brook trout (Berndtson \& Goetz, 1986). At this time there is no evidence that QUIN is of environmental concern.

In the field of reproductive toxicology, researchers have always been interested in the mechanisms by which toxicants impact pathways regulating reproductive processes. More recently there has been a focus in organizing these effects into molecular, cellular, whole organism and population levels in order to create a complete picture of a toxicant's biological impacts, this framework has been defined as an AOP. AOPs are a chronological depiction of events that occur after the initial exposure to a toxicant leading to an observable effect at a top level of biological organization (Ankley et al., 2010). The core concept of AOPs is not a new one, but this term was developed in order to differentiate the idea behind AOPs from that of toxicity pathways. A toxicity pathway is defined as the cellular responses that occur directly after an initiating event; however, an AOP is a comprehensive examination of the effects of a toxicant at a molecular, cellular and organ level, including linkages from the initiating event to an adverse effect at an organism or population level (Ankley et al., 2010).

From a regulatory perspective, risk assessments of environmental contaminants presently focus primarily on the apical responses of exposure with little consideration to the AOP that leads to the harmful effect (Ankley et al., 2009). With stricter legislation concerning the manufacturing and management of chemicals and the quality of food and drinking water, pressure on risk assessors has increased to evaluate a greater number of new and emerging substances that have the potential for adverse effects, conversely there is a demand for these tasks to be completed utilizing fewer resources, 
(Ankley et al., 2010). The AOP framework has the potential to assist in this endeavor as a detailed understanding about a toxicant's AOP can be used as a starting point for extrapolation concerning additional impacts on molecular, cellular organ and whole organism responses as well as estimate potential effects on different species (Kramer et al., 2011).

In order to thoroughly investigate the effect of a toxicant on reproduction, an examination of the processes involved, including impacts on the cellular and organ responses should be made. With spawning as the apical endpoint of exposure, the next biological level of interest would be the organ response; therefore GSI and proportion of follicle stages present within the ovary will be examined and will determine if a toxicant is having an effect on follicular recruitment and development. Cellular responses will be analyzed by examining the levels of hormones and gene expression involved in steroidogenesis and follicular recruitment, maturation and ovulation to determine what reproductive pathways are being affected (Figure 6). 


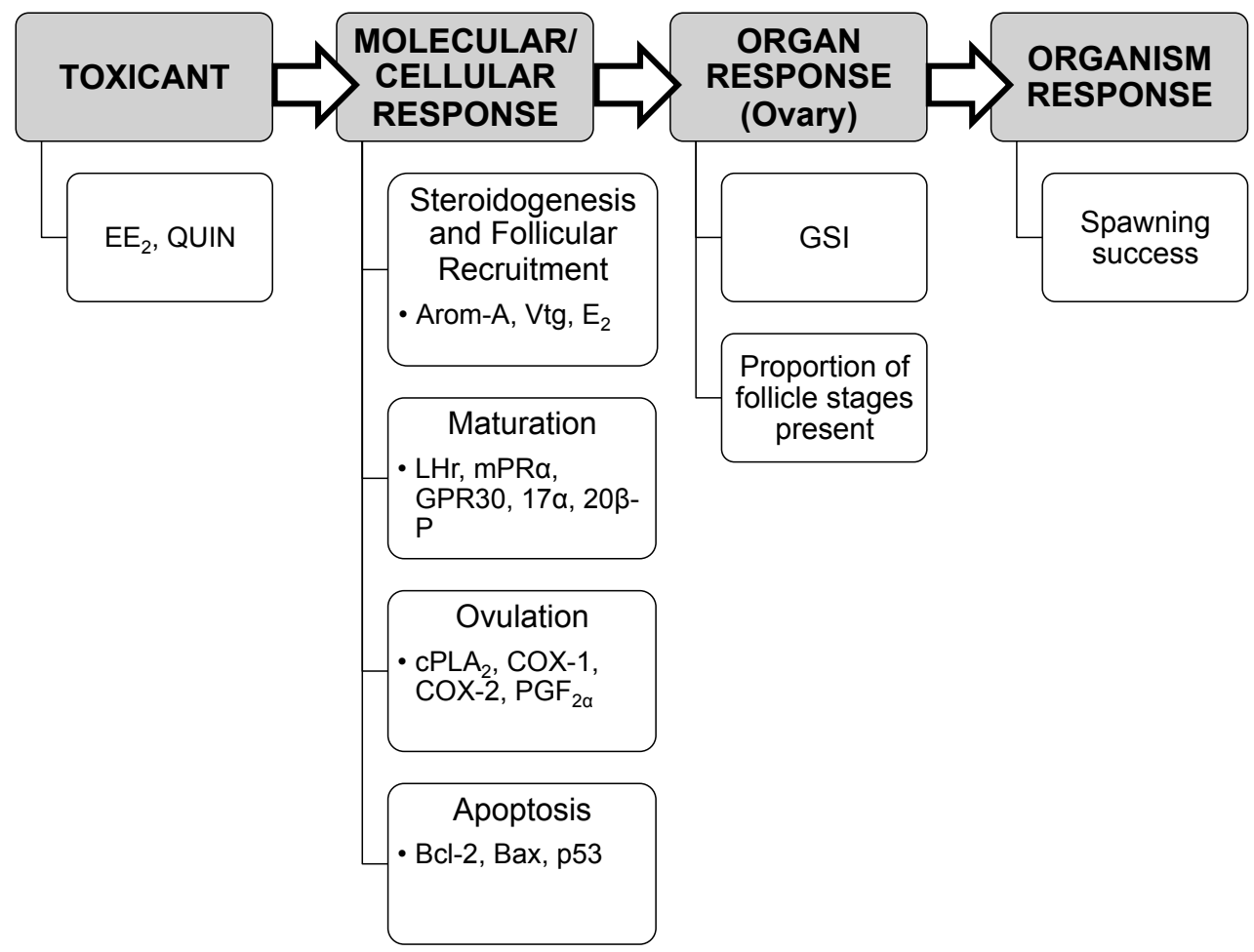

Figure 6: AOP for spawning success in zebrafish. A summary of the major pathways that may be affected by QUIN or $\mathrm{EE}_{2}$ and would be predicted to impact spawning success. 


\section{Thesis Objectives and Outline}

The goals of this thesis were to investigate the mechanisms of action of two EDCs, QUIN and $E_{2}$, that are known to inhibit spawning and to determine if an AOP framework would be helpful in making connections between the impacts seen at lower biological level to those at higher biological levels. The study involves testing the chemicals for effects in spawning adult zebrafish focusing on follicular recruitment and steroidogenesis, maturation and ovulation. A variety of tools, including gonadal histology and the measurement of hormone and gene expression levels involved in reproduction, were used to determine the cellular and organ responses and establish if linkages could be drawn between these impacts and spawning inhibition. Further examination of $E_{2}$ 's $A O P$ was also completed to determine if $E_{2}$ 's impact on gene expression was due to changes in the proportion of follicle stages within the ovary or an alteration of gene expression in follicles at specific stages of follicle development. The final chapter of this thesis provides a general discussion that integrates the results of the current study into the existing body of knowledge of reproductive endocrinology. 


\section{CHAPTER 2}

\section{Inhibition of spawning in zebrafish: Adverse outcome pathways of quinacrine and ethinylestradiol}

\section{INTRODUCTION}

Zebrafish are widely used as a lab model for toxicological studies assessing the effects of various wastewater effluents (Parker et al., 2014), pulp mill effluents (Van den Heuvel et al., 2010) and pharmaceuticals (Lister et al., 2009; Söffker \& Tyler, 2012) on reproductive success. There are a variety of methods available to study the aspects involved in the reproductive processes in zebrafish including, hormone measurement by EIA, gene expression via qPCR (Zhang et al., 2003), histological methods such as assessing the recruitment of ovarian follicles to the ovulatory pool and counting the number of egg spawned (Van den Belt et al., 2002; Weber, Hill, \& Janz, 2003). These tools afford the opportunity to begin to describe how compounds acting as reproductive toxicants affect the reproductive pathways. Indeed there is considerable interest in describing AOPs to draw connections between impacts observed at the molecular, cellular and organ level up to a whole organism/population response (Ankley et al., 2010).

Steroidogenesis and follicular recruitment, maturation and ovulation are key reproductive processes responsible for spawning success in fish (Clelland \& Peng, 2009); therefore examining aspects of these pathways, including molecular, cellular and organ responses, would be useful in describing how a toxicant affects reproduction. 
During follicular recruitment, the primary product of the steroidogenic pathway is $E_{2}$. Arom-A acts on testosterone, converting it to $E_{2}$, which is transported to the liver where it binds to nuclear receptors. This binding triggers the production of vitellogenin, which is ultimately sequestered in the ovarian follicle, resulting in an increase in size (Wang, et al., 2005). The levels of Arom-A gene expression are highest in vitellogenic follicles, the developmental stage where follicles experience the most growth (Goto-Kazeto et al., 2004). $E_{2}$ is also thought to work through the membrane estrogen receptor GPR30 located on the oocyte surface, where it acts to prevent follicles from maturing (Pang et al., 2008).

Prior to maturation, a surge of $\mathrm{LH}$ is believed to change the steroidogenic pathway from the production of $E_{2}$ to $17 \alpha, 20 \beta-P$, the maturation-inducing hormone in zebrafish, reducing GPR30 activity (Pang et al., 2008). Mature follicles, which are undergoing maturation, have demonstrated an increased expression of mPRs and it is thought that $17 \alpha, 20 \beta-P$ acts through these receptors to stimulate the production of MPF. MPF is responsible for releasing follicles from prophase 1 arrest, allowing for the resumption of meiosis (Kazeto, Goto-Kazeto, \& Trant, 2005; Tan, et al, 2009).

Prostaglandins, a product of the AA pathway, have been identified in several studies as being responsible for triggering ovulation in zebrafish (Lister \& Van Der Kraak, 2008; Nagahama \& Yamashita, 2008). An increase in the expression of genes involved in the AA pathway has also been observed in mature follicles (Carnevali et al., 2010). $C P L A_{2}$ is responsible for releasing AA from the phospholipid membrane where it is metabolized to stable prostaglandins by cyclooxygenases, COX-1 and COX-2 (Lister \& Van Der Kraak, 2008). In zebrafish, levels of $\mathrm{PGF}_{2 \star}$ have been shown to significantly 
increase in the ovaries of spawning zebrafish around the time of ovulation (Lister \& Van Der Kraak, 2008; Nagahama \& Yamashita, 2008). It has been also been proposed that $17 \alpha, 20 \beta-P$ works through $\mathrm{nPRs}$ to trigger the transcriptional activity and mRNA synthesis required for the induction of ovulation (Lydon et al., 1995; Nagahama \& Yamashita, 2008, Melynk \& Van Der Kraak, 2011).

$\mathrm{EE}_{2}$ and QUIN were chosen for this study because both toxicants have the potential to impact spawning in fish. QUIN is a phospholipase $A_{2}$ inhibitor that was initially approved for use as an anti-malaria drug (Ehsanian et al., 2011). It has more recently been utilized in biological studies examining the ovulatory process in mammals and fish due to QUIN's ability to reduce the availability of AA pathway which is the substrate for the production of prostaglandins (Espey, Stein, \& Dumitrescu, 1982; Berndtson \& Goetz, 1986;). $\mathrm{EE}_{2}$ is a synthetic estrogen that acts as an estrogen receptor agonist (Ankley et al., 2007). The effect of $\mathrm{EE}_{2}$ exposure on fish fecundity has been well documented (Rahman, Yanful, \& Jasim, 2009; Segner et al., 2003). EE 2 exposure results in reduced ovary size, altered gonadal structure (Van den Belt, et al., 2002; Versonnen \& Janssen, 2004) and a decline in expression of genes involved in the follicular recruitment and steroidogenesis, maturation and ovulation pathways (Carnevali et al., 2010; Urbatzka et al., 2012; Van den Belt et al., 2001).

The first objective of this study was to determine if $\mathrm{EE}_{2}$ and QUIN inhibit spawning through the same AOP by examining aspects of steroidogenesis and follicular recruitment, maturation and ovulation at the cellular and whole organ level. The second objective was to determine if the decrease in ovarian gene expression, following $E_{2}$ exposure, was due to $\mathrm{EE}_{2}$ 's altering the proportion of follicles within the ovary (an organ 
level effect) or on downregulation of gene expression at a specific follicle stage (a cellular level effect).

\section{MATERIALS AND METHODS}

\section{Animals}

Adult zebrafish were purchased from AQUAlity Tropical Fish Wholesalers (Mississauga, ON) and held in an environmental chamber in the Hagen Aqualab (University of Guelph, Guelph, ON). Fish were housed in an A-HAB fish containment unit (Aquatic Habitats, Apopka, $\mathrm{FL}$ ) and maintained in $28^{\circ} \mathrm{C}$ re-circulated well water. The photoperiod in the environmental chamber was set to 12 hours light: 12 hours dark. Fish were fed daily with tropical fish flakes (Nutrafin Max, Baie d'Urfé) and supplemented occasionally with frozen brine shrimp (Hakari, Hayward CA). All experiments were executed according to the animal care protocols approved by the University of Guelph Animal Care Committee on behalf of the Canadian Council on Animal Care.

\section{Chemicals}

$\mathrm{EE}_{2}$, QUIN and indomethacin were purchased from Sigma (St. Louis, MO). Ethanol was purchased from Commercial Alcohols (Brampton, ON).

\section{General experimental set-up}

All fish used in the experiment were sexually mature. Efforts were made to obtain a 2:1 female to male sex ratio. Sexually mature females were identified based on morphological features (increased abdominal size and presence of genital papilla). Water temperature was maintained at $28^{\circ} \mathrm{C}$ throughout the duration of the experiment and fish were fed twice daily. 
After an adjustment period of five days, a plastic mesh was placed at the bottom of each tank in order to separate fish from their spawned eggs. Zebrafish generally spawn in the first hours of light (Blanco-Vives \& Sánchez-Vázquez, 2009; Spence et al., 2006). Under the experimental conditions in the Hagen Aqualab, lights came on in the environmental chamber at 08:00. Eggs were collected and counted every morning after spawning had occurred. Once it had been established that all tanks were producing approximately the same number of eggs, treatment began the following morning. Eggs continued to be counted daily.

\section{Exposures}

Experiment 1-QUIN time course exposure:

The first experiment was performed in order to determine if exposure to the phospholipase $A_{2}$ inhibitor, QUIN, would inhibit spawning and to identify potential pathways responsible for these effects. This experiment was conducted under static conditions in which groups of 18 fish were randomly distributed into nine-20L tanks containing $17 \mathrm{~L}$ of Hagen Aqualab well-water. Water temperature was maintained with aquarium heaters placed in the individual tanks. A stock solution of QUIN was prepared in ultrapure water and a $100 \mu \mathrm{L}$ aliquot was added to each treatment tank for a final concentration of $100 \mu \mathrm{g} / \mathrm{L}$. Stock solutions were stored at $-20^{\circ} \mathrm{C}$ for the duration of the exposure. Water was changed daily in control and treatment tanks. Treatment tanks were dosed with QUIN and thoroughly mixed to ensure an even distribution of the drug before fish were added. In eight of the tanks, misidentification of sex resulted in a female to male ratio ranging between 2.6.1 and 1:2.6. After four days of treatment, two control tanks and two treatment tanks were sampled at 00:00 and three control tanks 
and two treatment tanks were sampled at 06:00 in order to capture the temporal changes in hormone and gene expression that occur prior to spawning. Experiment 2-QUIN and $E_{2}$ time course exposure:

A second experiment was performed in order to identify the mechanisms by which $\mathrm{EE}_{2}$ inhibits spawning and to further investigate the mode of action of QUIN. This experiment tested whether these two compounds affect spawning through the same AOPs by monitoring the expression of selected genes and hormones involved in reproduction. This experiment was conducted under flow through conditions in order to reduce potential differences in treatment concentration associated with dosing individual tanks and to maintain water quality parameters. In this experiment groups of 27 fish were randomly distributed into twelve-20L tanks. We increased the number of fish used in this experiment in the hopes of capturing more fish undergoing maturation and ovulation in the control group in order to get an accurate measurement of the gene and hormone levels in the period before spawning. An attempt was made to obtain a 2:1 female to male sex ratio. Misidentification of sex resulted in a female to male ratio ranging from 3:1 to 1:2. Heated Hagen Aqualab well-water was pumped by a MD3 Mag drive 350GPH pump (Fish Farm Supply Woolwich, ON) from a 246L stock tank, through manifolds that fed three to four $20 \mathrm{~L}$ aerated tanks. This set up was repeated for each treatment group. Flow was set at a rate of $0.04 \mathrm{~L} /$ minutes for a total of two-tank turnovers/day. Aquarium heaters in the stock tanks maintained the water temperature and fish were fed twice daily. Stock solutions of QUIN and EE $E_{2}$ were prepared in ultrapure water and ethanol respectively. Then $100 \mu \mathrm{L}$ aliquots of stock solution were added daily to $236 \mathrm{~L}$ of Hagen Aqualab well water to create the required concentrations 
for the $25 \mathrm{ng} / \mathrm{L}$ of $\mathrm{EE}_{2}$, and $100 \mu \mathrm{g} / \mathrm{L}$ for the QUIN group. The control stock tanks received $100 \mathrm{uL}$ of ethanol. On the eighth day of exposure, single tanks belonging to the control, $\mathrm{EE}_{2}$, and QUIN groups were sampled at 00:00, 03:00, 06:00 and 09:00 in order to examine the fluctuation in hormone and gene expression levels that occur during maturation, ovulation and spawning. Female fish at the 00:00 timepoint had enough ovarian tissue to examine gene expression and histology; therefore a portion of ovarian tissue from three fish from each treatment group was used for histological examination. Experiment 3-EE $E_{2}$ time course exposure:

Experiment 3 was completed in order to determine if the changes in gene expression observed after exposure to $\mathrm{EE}_{2}$ were associated with alterations in the proportion of different follicles stages within the ovary. This experiment also provided more details regarding the AOP responsible for the inhibition of spawning by $E_{2}$.

Using the flow through set-up described in Experiment 2, groups of 27 fish were randomly distributed into twelve-20L tanks. An attempt was made to obtain a 2:1 female to male sex ratio. Misidentification of sex resulted in a female to male ratio between $0.8: 1$ and 1.7:1. The aquaria were randomly divided into six control and six $\mathrm{EE}_{2}(25$ $\mathrm{ng} / \mathrm{L}$ ) treatment groups. After three days of treatment, three tanks from each group were sampled at 05:00 before spawning occurred, so that follicles of all stages could be collected. Whole ovaries from three fish from each tank were used for histology. Treatment of the remaining six aquaria continued until a significant decrease in spawning was observed in fish exposed to $\mathrm{EE}_{2}$ compared with the controls, which was noted after the daily egg count on the fifth day. Subsequently, the aquaria were sampled 
the next morning at 05:00. Whole ovaries from three fish from each tank were used for histology.

\section{General Sampling Protocol}

All the fish used in the following experiments were sexually mature. Fish were anaesthetized with MS-222 (Syndel Laboratories Inc, Vancouver, BC) and killed by cervical transection prior to sampling. The bodies and ovaries were weighed, snap frozen in dry ice and then stored at $-80^{\circ} \mathrm{C}$ until further analysis.

In Experiment 2 a portion of ovarian tissue was removed from females whose ovaries weighed more than $25 \mathrm{mg}$. In Experiment 3 whole ovaries were removed from three fish from each tank. Ovarian tissue and whole ovaries were placed in histological cassettes, and preserved in buffered formalin (Fisher Scientific, Waltham, MA).

In Experiments 2 and 3 the intestines and associated hepatic tissue were removed from all fish and placed immediately in $100 \mu \mathrm{L}$ RNAlater@ (Ambion/Applied Biosysytems, Streetsville, ON) in $1.5 \mathrm{~mL}$ microcentrifuge tubes and placed at $4^{\circ} \mathrm{C}$ for 48 hours. To separate the livers from the intestines, tissue was placed in a 50:50 mixture of RNA later: Ultrapure water DNase/RNase free distilled water (Invitrogen, Carlsbad CA) and livers were removed with the aid of a dissecting microscope. Tissue was then removed from the RNAlater $\circledast$ and stored at $-80^{\circ} \mathrm{C}$ until analysis.

In Experiment 3, after snap freezing, a portion of the ovary from each fish was removed and placed in Ultrapure water DNase/RNase free distilled water (Invitrogen). Using a dissecting microscope the primary growth, cortical alveolus, vitellogenic and mature stage follicles were separated from each ovary. Follicle stage identification was based on descriptions by Selman et al, (1993). Follicles from two to three fish were 
pooled to ensure sufficient quantities of tissue for RNA extraction and stored at $-80^{\circ} \mathrm{C}$ until further analyses. No vitellogenic follicles were found in the ovaries of fish exposed to $E_{2}$ for six days.

\section{Determination of $\mathrm{EE}_{2}$ exposure concentrations}

Duplicate water samples were acquired from two fish tanks, chosen at random, and the stock tank of each treatment group for the measurement of $E_{2}$. In Experiment 2 water samples were taken on the seventh and eighth day of treatment. In Experiment 3 water samples were taken on the second and sixth day of treatment. Water samples were collected in $1 \mathrm{~L}$ amber glass bottles and filled to the top with water, ensuring there was no air at the top of each bottle. Each water sample was then spiked with $5 \mathrm{~mL}$ of $200 \mathrm{~g} / \mathrm{L}$ of sodium azide solution, $2.5 \mathrm{~mL}$ of $20 \mathrm{~g} / \mathrm{L}$ ascorbic acid solution and $100 \mu \mathrm{L}$ of 1mg/L d-EE2 (CDN Isotopes, Pointe-Claire, QC) in methanol. Samples were then refrigerated until further processing.

Water samples were passed through 6cc 500mg Oasis HLB cartridges (Waters, Milford, MA) according to the manufacturer's instructions using 12-port visiprep vacuum manifold (Sigma Aldrich, St. Louis, MO) and Gast oil-less diaphragm-tube pressure vacuum pump (Fisher Scientific). The final eluate was collected with $5 \mathrm{~mL}$ of methanol (Fisher Scientific) and $5 \mathrm{~mL}$ of 10/90 (v/v) of methanol/tert-butyl methyl ether (SigmaAldrich). Samples were then dried under a nitrogen gas stream. Samples were reconstituted in $500 \mu \mathrm{L}$ of methanol (Fisher Scientific), shaken on a vortex mixer and transferred to a $2 \mathrm{~mL}$ vial and stored at $-80^{\circ} \mathrm{C}$ until analysis. 
$\mathrm{EE}_{2}$ levels in water samples were measured using liquid chromatography-mass spectrometry. All analysis was completed by Mark Servos' lab at the University of Waterloo, Waterloo, Ontario.

\section{Whole body and ovarian steroid and prostaglandin levels}

Ovarian homogenates from fish in experiment 1 were prepared in a $1.5 \mathrm{~mL}$ centrifuge tube by sonicating approximately $25 \mathrm{mg}$ of ovarian tissue in $100 \mathrm{uL}$ of phosphate buffered saline (PBS) $\left(80 \mathrm{mM} \mathrm{Na}_{2} \mathrm{HPO}_{4}, 1020 \mathrm{mM} \mathrm{NaH}_{2} \mathrm{PO}_{4}, 100 \mathrm{mM} \mathrm{NaCl}\right.$; $\mathrm{pH}$ 7.4) containing $1 \mathrm{mM}$ ethylenediaminetetraacetic acid (EDTA) and $10 \mu \mathrm{M}$ indomethacin (INDO).

Whole body homogenates (minus the ovary) of fish from Experiment 2 were prepared by homogenizing the body in a $16 \mathrm{~mm} \times 10 \mathrm{~mm}$ glass tube containing $6 \mathrm{ml}$ of PBS, 1 mM EDTA and $10 \mu \mathrm{M}$ INDO for approximately 30 seconds. Then $200 \mu \mathrm{L}$ of this homogenate was then removed and placed in a $1.5 \mathrm{~mL}$ centrifuge tube.

Homogenates were kept on ice until the methanol extraction procedure had begun. Ovarian and whole body homogenate were treated with 400 and $800 \mu \mathrm{L}$ of methanol respectively. Samples were then incubated for 1 hour at $4^{\circ} \mathrm{C}$, vortexing at 20 minute intervals. The homogenate was then centrifuged at $3000 \mathrm{~g}$ for 5 minutes at $4^{\circ} \mathrm{C}$ and afterwards the pellet was snap frozen on dry ice and the upper methanol phase decanted into $7 \mathrm{~mL}$ scintillation vials. The pellet was thawed, treated with $400 \mu \mathrm{L}$ of methanol, incubated for 30 minutes at $4^{\circ} \mathrm{C}$, centrifuged for 5 minutes at $3000 \mathrm{~g}$ at $4^{\circ} \mathrm{C}$. The pellet was then snap frozen in dry ice and the upper methanol phase decanted. This procedure was repeated one more time. All three methanol phases were combined into a single vial and dried with a stream of nitrogen gas. 
Each vial was then treated with $300 \mu \mathrm{L}$ of $50 \mathrm{mM}$ acetate buffer $(2.35 \mathrm{~mL}$ glacial acetic acid, $1.23 \mathrm{~g}$ sodium acetate trihydrate in $1 \mathrm{~L} ; \mathrm{pH} 4.0$ ). These samples were passed through Amprep c-18 octadecyl mini columns (Amersham Biosciences, Little Chalfont, England), according to the manufacturer's instructions for non-polar analytes. The final eluate was collected with $2 \mathrm{~mL}$ of ethyl acetate containing $1 \%$ methanol. The ethyl acetate fraction was dried with nitrogen gas. Ovarian and whole body samples were reconstituted in 300 and $900 \mu \mathrm{L}$ of EIA buffer (Cayman Chemical, Ann, Arbour, MI) respectively and stored at $-80^{\circ} \mathrm{C} .17 \alpha, 20 \beta-\mathrm{P}$ and $\mathrm{PGF}_{2{ }^{\circ}}$ and $\mathrm{E}_{2}$ were analyzed by EIA (Cayman Chemical) as per the manufacturer's instructions. The analytes of the extracted tissue demonstrated parallelism in the EIA, which was an indication that samples did not contain compounds that interfere with the assays.

\section{Total RNA extraction, reverse transcription}

Total RNA was extracted from ovarian, liver and follicular tissue using TRIzol Reagent (Invitrogen) according to the manufacturers instruction. For RNA extraction from liver tissue, the entire liver was homogenized in TRIzol Reagent. For RNA extraction from the ovary, approximately $25 \mathrm{mg}$ of ovarian tissue was used. For RNA extraction from follicular tissue approximately 40 follicles per stage was used. Tissue was homogenized using a $3 \mathrm{~mL}$ syringe with a $21 \mathrm{G}$ needle and incubated for 5 minutes. Chloroform (Sigma) was then added to the samples and incubated for 3 minutes. Samples were centrifuged for 15 minutes at $12000 \mathrm{~g}$ and the aqueous phase removed and added to tubes of isoproponol (Sigma), and incubated for another 10 minutes. Samples were then centrifuged at $12000 \mathrm{~g}$ for 10 minutes to collect the RNA pellet. The RNA pellet was then washed with $75 \%$ ethanol and reconstituted in 10-30 uL of 
Ultrapure water DNase/RNase free distilled water (Invitrogen). Total RNA was quantified from samples using a NanoDrop 2000 (Thermo Scientific, Waltham, MA). RNA purity was determined using the $260 / 280$ absorbance ratio, all samples had a ratio of 1.8-2.2. RNA samples were then diluted to a final concentration of $500 \mathrm{ng} / \mathrm{uL}$. The methods for reverse transcription were based on those described in Nelson and Van Der Kraak (2010).

\section{Quantitative Real -Time PCR}

Relative gene expression was measured using real-time quantitative polymerase chain reaction (qPCR). The primer sequences used in these experiments and papers they were based on are shown in Table 1. Primers for vitellogenin (vtg) were designed using Primer Express software v. 2.0 (Applied Biosystems, Forster City, CA) and designed to span known exon-exon boundaries to prevent genomic DNA amplification. cDNA was diluted $31 \mathrm{X}$ for ovarian and follicular tissue and 512X for liver tissue. For the analysis, $3.75 \mathrm{uL}$ of diluted sample was added to a 96-well PCR plate with $1.875 \mu \mathrm{L}$ of forward and $1.875 \mathrm{uL}$ of reverse primers (1.6uM, Sigma) and 7.5 uL Perfecta SYBR Green Fastmix, ROX (Quanta Biosciences, Gaithersburg, MD). Samples were run in duplicate on the CFX96 Real-Time System (Bio-Rad Laboratories, Mississauga, ON). Samples were incubated at $50^{\circ} \mathrm{C}$ for 2 minutes and $95^{\circ} \mathrm{C}$ for 5 minutes. Then a cycle of 1 second at $95^{\circ} \mathrm{C}$ and 30 seconds at $60^{\circ} \mathrm{C}$ was repeated 40 times.

The housekeeping genes used in this study were chosen because there was no significant change in expression across treatment or time within the tissue being tested. It was not possible to identify a housekeeping gene to normalize expression across all the follicle stages. Therefore, gene expression of primary follicles was normalized to 
HPRT and gene expression of cortical alveolus, vitellogenic and mature follicles were normalized to ARP. Ovarian and liver samples were normalized to elongation factor-1- $\alpha$. A six point standard curve for each gene was run with a pooled sample containing all the treatment groups to quantify gene expression.

\section{Histology}

Histology cassettes were submitted to the Animal Health Histology Laboratory at the University of Guelph where ovary tissue was embedded in paraffin embedding, sliced into $5 \mu \mathrm{m}$ thick sections and stained with hematoxylin and eosin. Multiple photographs of histology slides were taken using an Olympus SZ61 Zoom Stereo Microscope (Olympus Canada Inc., Richmond Hill, ON) at 3X magnification. Photos of the slides were reviewed on a computer screen and three replicate views were evaluated blindly for each slide. The number of primary growth, cortical alveolus, vitellogenic and mature stage follicles were counted. Follicle stage identification was based on the characteristic outlined in Selman, Wallace \& Sarka, 1993.

\section{Statistical Analysis}

Egg production, gene expression, hormone and histology data were initially tested for homogeneity of variance with Levene's test and, when necessary, were log transformed or ranked to meet the requirement of further tests using parametric statistics. A one or two-way analysis of variance (ANOVA) was used to determine if there were differences between treatment groups and timepoints in egg production, ovarian gene expression and histology. A factorial ANOVA was run on follicle stage gene expression. Tukey's Honestly Significant Difference test was used to determine significance between treatment groups, timepoints and follicles group. In all statistical 
analyses, the software package SAS (v. 21) was used and the significance was set at $\alpha=0.05$ for all tests.

\section{RESULTS}

\section{Experiment 1-QUIN time course exposure:}

After four days of exposure, egg production per female was reduced almost $100 \% \pm 0.3 \%$ in the groups of fish exposed to QUIN (Figure 1). There was no significant difference in ovarian levels of $\mathrm{PGF}_{2}$ between the control and treatment group at either timepoints (data not shown). In the same fish there was no significant difference between groups in ovarian levels of $17 \alpha-20 \beta-P$ at the 00:00 timepoint, but a significant decrease in $17 \alpha-20 \beta-P$ levels was observed in the group exposed to QUIN as compared to the control at 06:00 (Figure 2). Fish exposed to QUIN exhibited no significant change in ovarian $\mathrm{CPLA}_{2}$ expression at either timepoint (data not shown). Control and QUIN exposed fish had similar ovarian COX-2 expression at 00:00, whereas COX-2 expression in QUIN exposed fish was reduced at 06:00 (Figure 3).

\section{Experiment 2-QUIN and $\mathrm{EE}_{2}$ time course exposure:}

The measured concentrations of $\mathrm{EE}_{2}$ in the fish and stock tank water was $24.5 \pm$ $0.4 \mathrm{ng} / \mathrm{L}$. Egg production per female was reduced by $44 \pm 2.2 \%$ in the group exposed to QUIN and by $64 \pm 3.1 \%$ in the group exposed to $E_{2}$ after eight days of exposure (Figure 4). The GSI of the fish exposed to $\mathrm{EE}_{2}$ was reduced by $47 \pm 1.5 \%$ and $41 \pm$ $1.0 \%$ compared to QUIN and control fish, respectively (Figure 5).

The only timepoint where fish from all treatment groups had ovaries large enough to contribute tissue for histological analysis was at 00:00. The ovaries of the fish 
exposed to $E_{2}$ were composed of $87 \pm 5.3 \%$ early stage (primary growth) follicles, which is a significantly higher proportion than the control $(63.5 \pm 4.6 \%)$ and QUIN $(74.3$ $\pm 1.1 \%$ ) group. The ovaries of fish exposed to $\mathrm{EE}_{2}$ were composed of $10.7 \pm 4.4 \%$ later stage (cortical alveolus, vitellogenic and mature) follicles, which was significantly less than that observed for the fish in the control $(34.1 \pm 4.1 \%)$ or QUIN $(25.3 \pm 0.9 \%)$ groups (Figure 6 and 7).

EIAs were performed on ovarioectomzed whole bodies, as there was not enough ovarian tissue to perform analyses on gene expression and prostaglandin and steroid levels. There was no significant difference in levels of $\mathrm{PGF}_{2_{a}, 17 \alpha-20 \beta-P}$ or $\mathrm{E}_{2}$ in any of the treatment groups at any of the timepoints (data not shown). Fish exposed to QUIN and $\mathrm{EE}_{2}$ exhibited no significant changes in ovarian expression of COX-1, COX-2, GPR30, mPR $\alpha, p 53, \mathrm{Bcl}-2$ and $\mathrm{Bax}$ (data not shown) at any of the sampling timepoints. Ovarian expression of Arom-A was significantly reduced in $\mathrm{EE}_{2}$ exposed fish compared to controls at all timepoints. In contrast, fish exposed to QUIN only exhibited a significant decrease in ovarian Arom-A expression at 06:00 (Figure 8a). Expression of $\mathrm{LHr}$ was reduced at all timepoints in fish exposed to $\mathrm{EE}_{2}$, however the changes were only significant at 00:00, 06:00 and 09:00. A significant increase in LHr expression was seen in fish exposed to QUIN at 09:00 (Figure 8b). A significant decline in $\mathrm{CPLA}_{2}$ expression was observed in the fish exposed to $\mathrm{EE}_{2}$ at 06:00 and 09:00 (Figure 8c). Levels of $n P R$ expression were significantly reduced in the $E_{2}$ fish sampled at 09:00 (Figure 8d).

Exposure to QUIN and $\mathrm{EE}_{2}$ had no effect on the liver expression of $\mathrm{Vtg}$ in female fish at any of the sampling timepoints (Figure 9a). In male fish, exposure to $E_{2}$ 
demonstrated a significant increase in liver Vtg expression at all timepoints as compared to the control and QUIN group (Figure 9b).

\section{Experiment 3-EE $E_{2}$ time course exposure:}

The average concentrations of $\mathrm{EE}_{2}$ measured in the fish and stock tank water was $23.5 \pm 0.4 \mathrm{ng} / \mathrm{L}$. After two days of exposure, $\mathrm{EE}_{2}$ had no effect on egg production (Figure 10). On day six there was no significant difference in the number of eggs produced per females in the pre and post-treatment periods in the control group, but there was $50 \pm 3.1 \% \%$ reduction in the group exposed to $E_{2}$ (Figure 10).

There was no significant difference in $\mathrm{GSI}$ between the control and $\mathrm{EE}_{2}$ groups sampled on day two. On day six, the GSI in the fish exposed to $\mathrm{EE}_{2}$ was reduced by \pm $1.7 \%$ compared to the controls (Figure 111). The ovaries of fish exposed to $E_{2}$ were composed of $76.3 \pm 3.2 \%$ (two-day exposure) and $82.4 \pm 1.2 \%$ (six-day exposure) early stage (primary growth) follicles, which is a significantly higher proportion than the control groups sampled on day two $(62.3 \pm 2.7 \%)$ and day $6(56.3 \pm 6.8 \%)$. The ovaries of fish exposed to $\mathrm{EE}_{2}$ had ovaries were composed of $23.2 \pm 2.6 \%$ (two-day exposure) and $14.2 \pm 3.2 \%$ (6-day exposure) later stage (cortical alveolus, vitellogenic and mature) follicles, which is significantly less than the control groups, two-day $(37.3 \pm 1.4 \%)$ and 6 day exposure (43.4 $\pm 1.8 \%)$ (Figure 12 and 13$)$.

There was no change in the expression of the genes of interest in primary growth follicles between treatment groups and timepoints (data not shown). The group exposed to $\mathrm{E}_{2}$ for two days demonstrated a significant decrease in Arom-A expression in vitellogenic follicles (Figure 14a). Both groups exposed to $\mathrm{EE}_{2}$ showed a significant decline in Arom-A expression in mature follicles (Figure 14a). In the group exposed to 
$\mathrm{EE}_{2}$ for six days there was a significant decrease in expression of $\mathrm{LHr}, \mathrm{cPLA} \mathrm{A}_{2}$ and $\mathrm{nPR}$ in mature follicles (Figure 14b, c, d).

Both groups of fish exposed to $\mathrm{EE}_{2}$ (two and six days) demonstrated a significant decrease in ovarian Arom-A expression (Figure 15a). Two days of $E_{2}$ exposure had no effect on $\mathrm{LHr}, \mathrm{cPLA} \mathrm{A}_{2}$ or $\mathrm{nPR}$ expression in the whole ovary. A significant decrease in ovarian expression of $\mathrm{LHr}, \mathrm{cPLA} \mathrm{A}_{2}$ and $\mathrm{nPR}$ was seen in the group exposed to $\mathrm{EE}_{2}$ for six days (Figure 15b,c,d). 


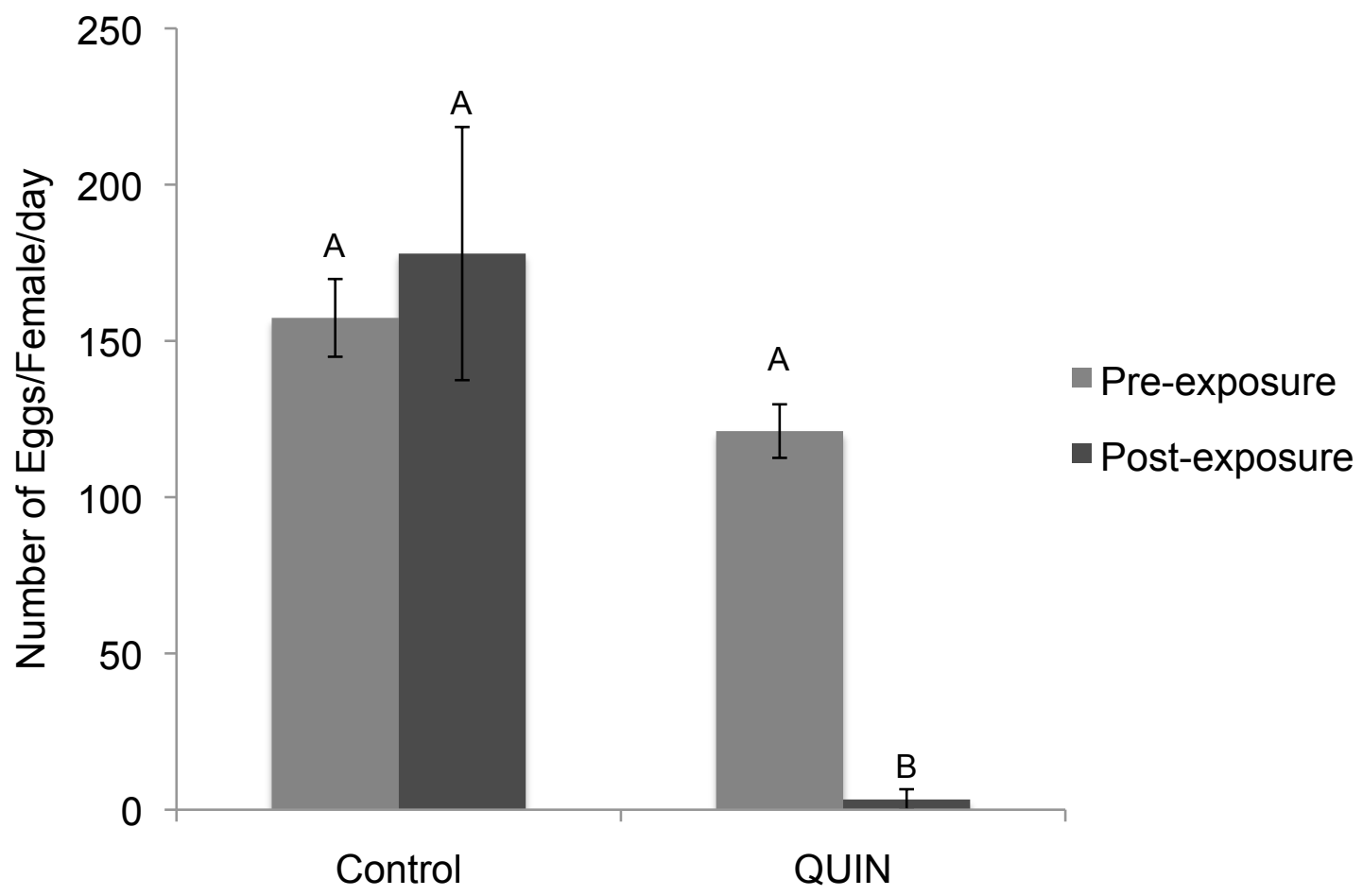

Figure 1: Average number of eggs per treatment produced by each female during the 5-day pre-treatment period and 4-day treatment to QUIN (100 $\mu \mathrm{g} / \mathrm{L})$ or well-water (control). Data represents mean \pm S.E.M. of 4 to 5 tanks per treatment. Different letters indicate a significant difference between time and treatments $(p<0.05$; ANOVA, Tukey's). 


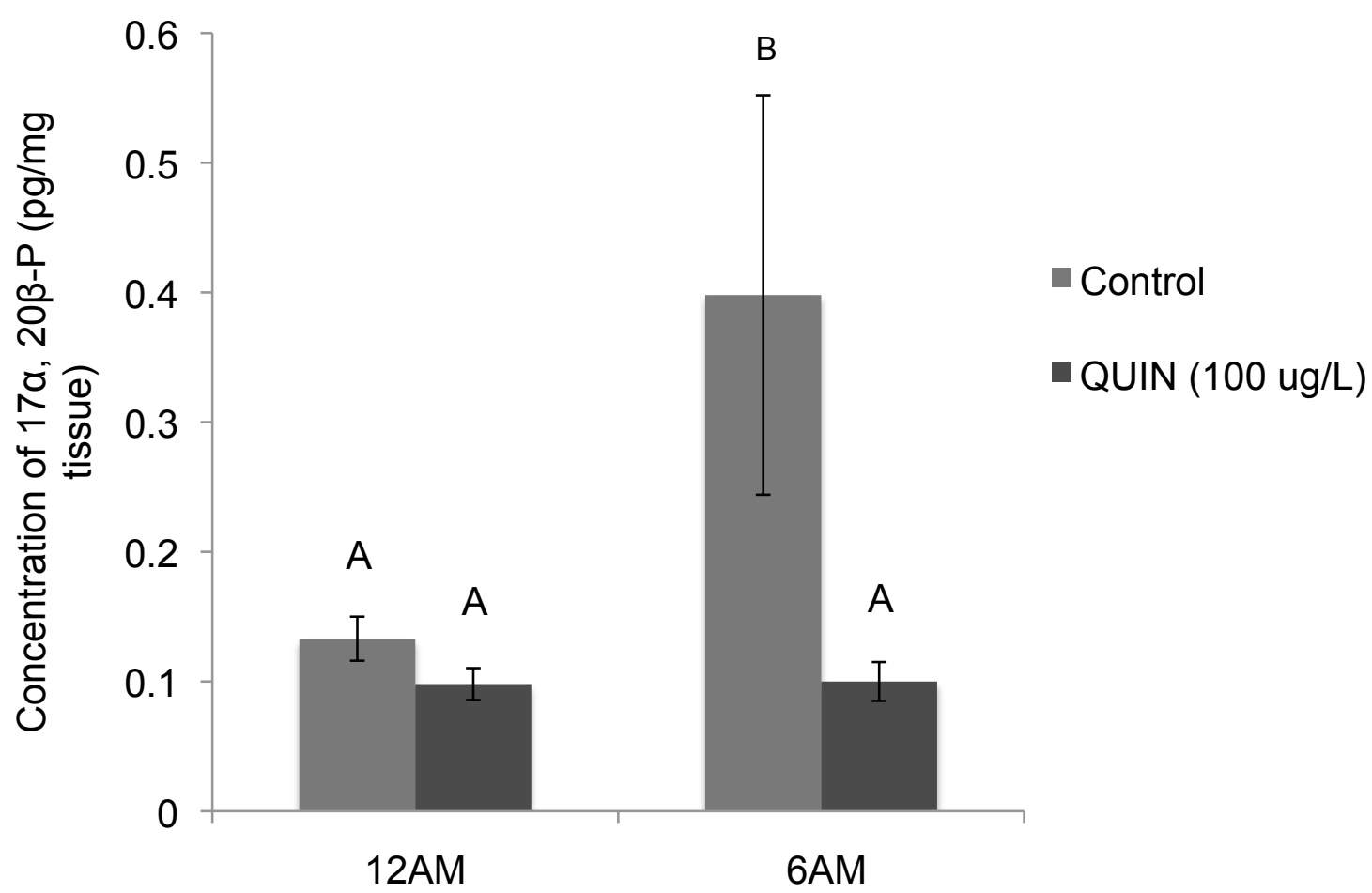

Figure 2: In vivo effects of QUIN (100 $\mu \mathrm{g} / \mathrm{L})$ on ovarian levels of $17 \alpha, 20 \beta-P$. Results were expressed as pg of $17 \alpha, 20 \beta$-P per mg of tissue (approximately $25 \pm 5 \mathrm{mg}$ ). Values represent the mean \pm S.E.M of 17 to 24 individuals. Different letters indicate a significant difference between time and treatments ( $p<0.05$; ANOVA, Tukey's). 


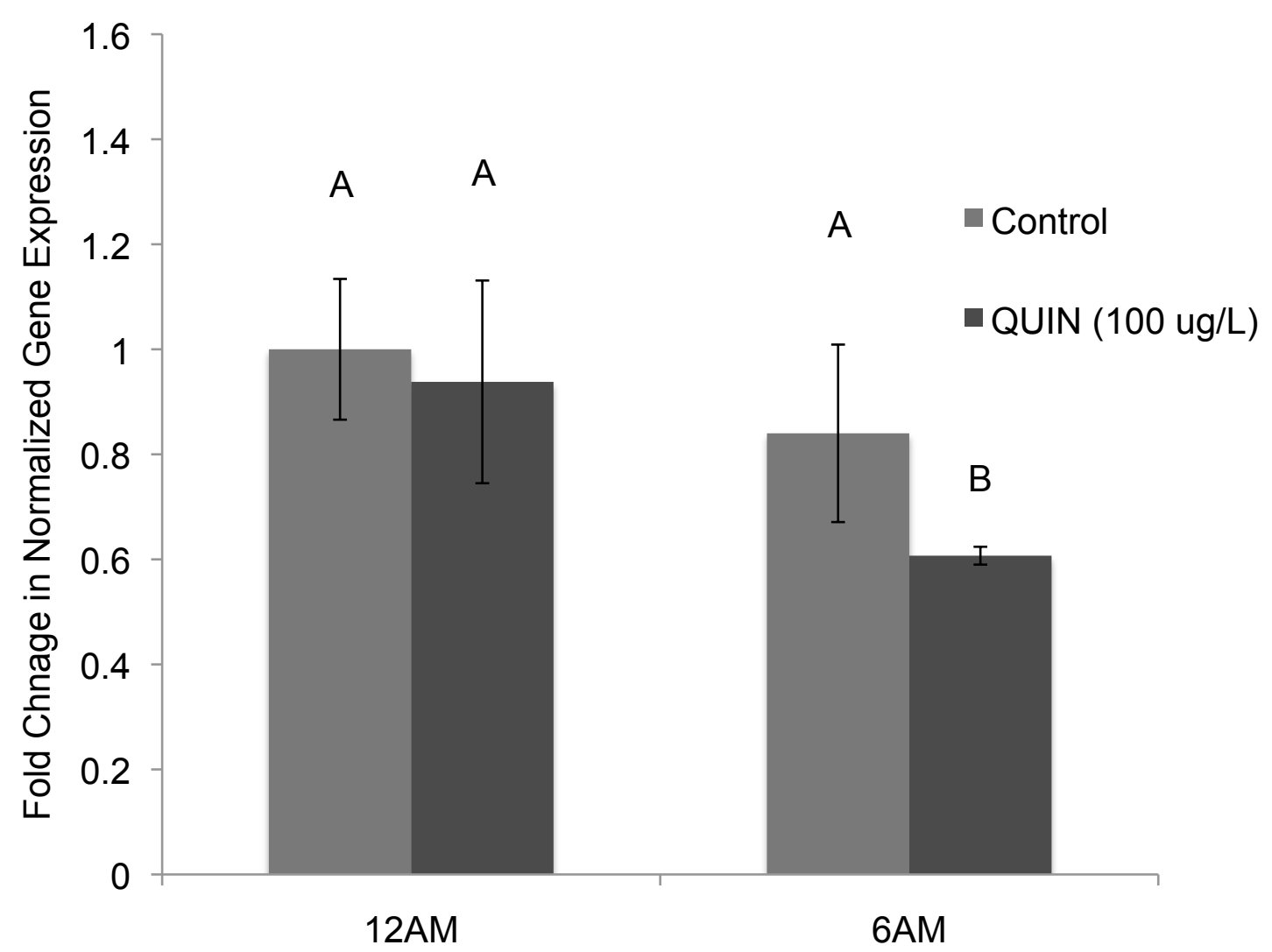

Figure 3: Ovarian expression of cyclooxygenase-2 (COX-2) in fish exposed to wellwater (control) or QUIN (100 ug/L). The expression levels were normalized to that of elongation factor- $1 \alpha$ and expressed as a fold change relative to gene expression in the controls. Values represent the mean \pm S.E.M of 17 to 24 individuals. Different letters indicate a significant difference between time and treatments $(p<0.05$; ANOVA, Tukey's). 


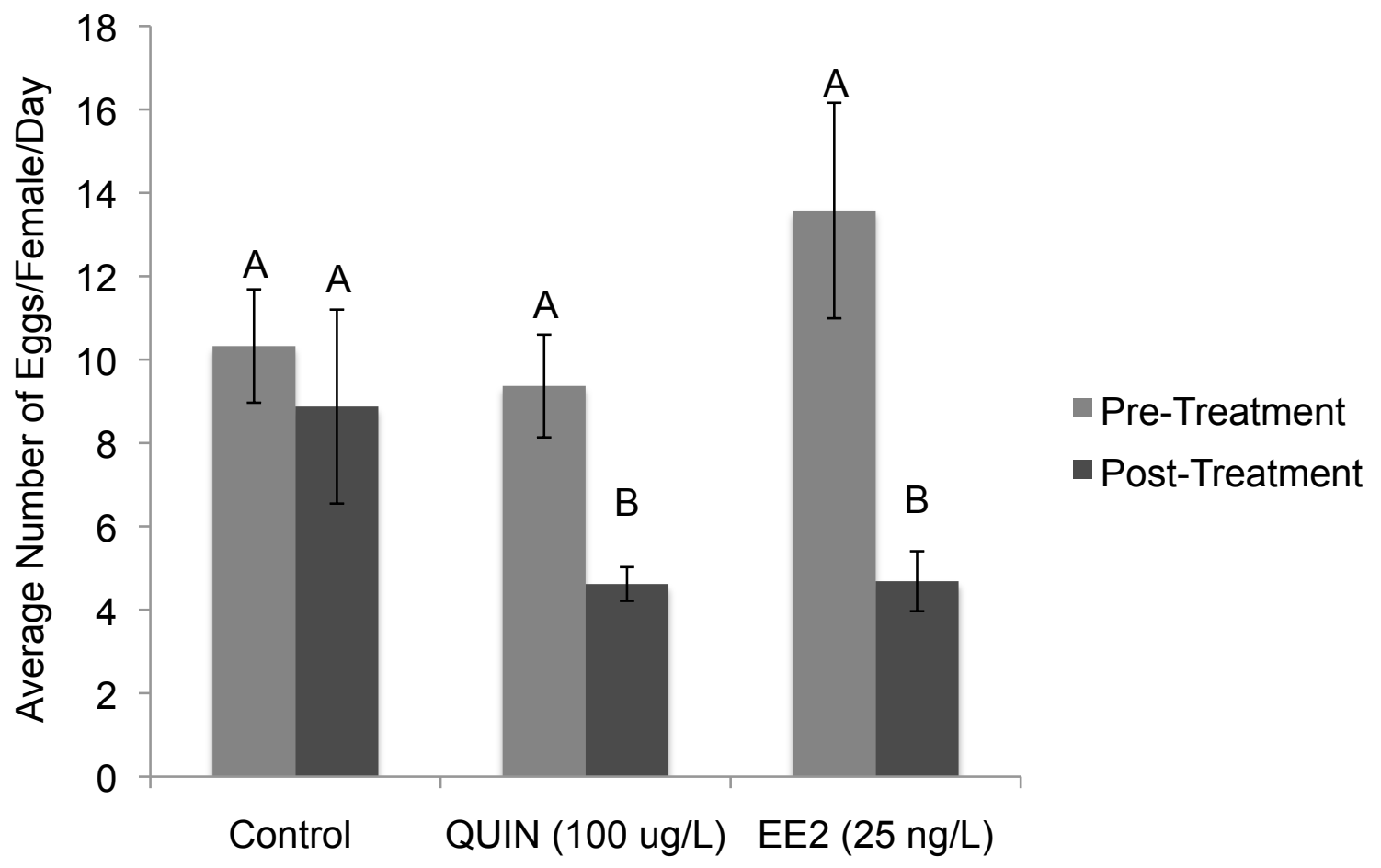

Figure 4: Average number of eggs per treatment produced by each female during the 5-day pre-treatment and 8-day treatment with QUIN (100 $\mu \mathrm{g} / \mathrm{L}), \mathrm{EE}_{2}(25 \mathrm{ng} / \mathrm{L})$ or ethanol (control). Data represents mean \pm S.E.M. of 4 tanks per treatment. Different letters indicate a significant difference between treatments ( $p<0.05$; ANOVA, Tukey's). 


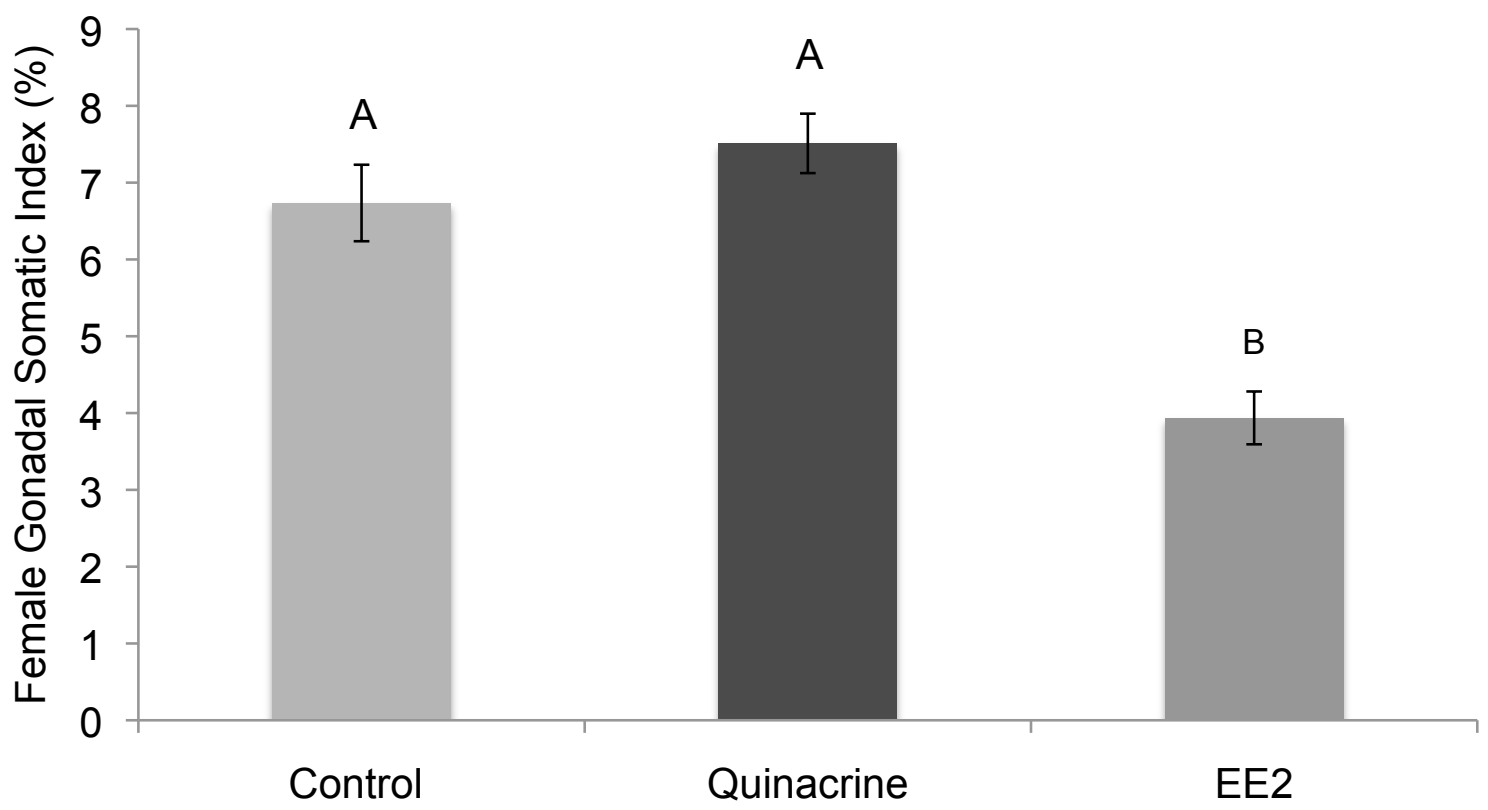

Figure 5: Gonadal somatic index of female fish after an 8-day treatment with QUIN (100 $\mu \mathrm{g} / \mathrm{L}), \mathrm{EE}_{2}(25 \mathrm{ng} / \mathrm{L})$ or ethanol (control). Data represents mean \pm S.E.M. of 4 tanks per treatment. Different letters indicate a significant difference between treatments $(p<0.05$; ANOVA, Tukey's). 
a)

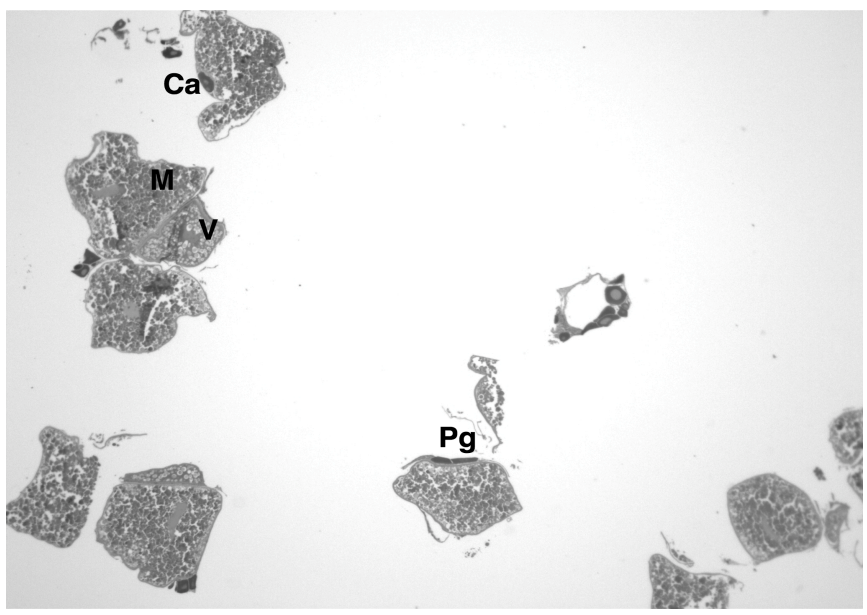

b)

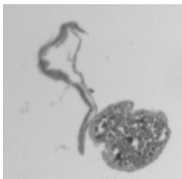

c)

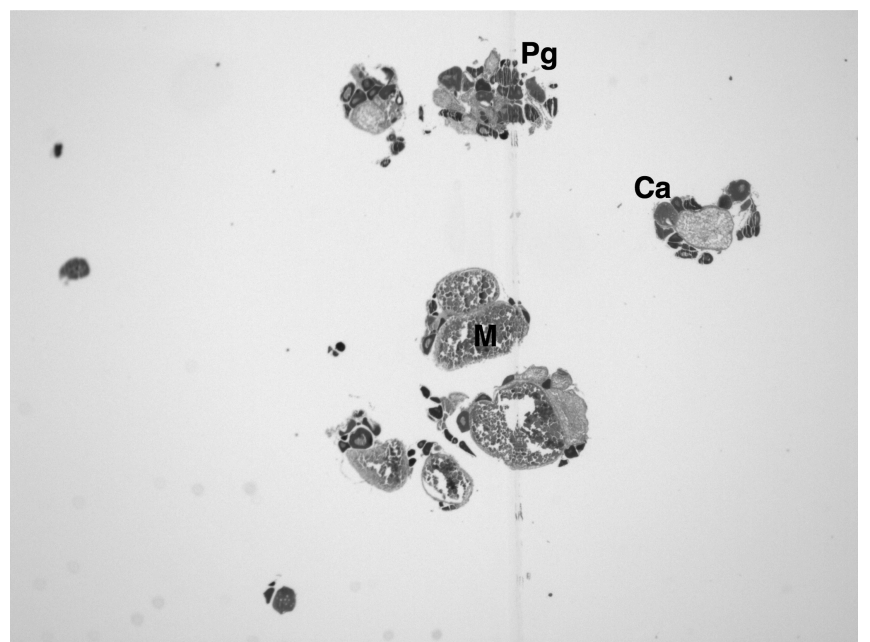


Figure 6: Representative histology of the ovarian tissue from fish exposed to (a) ethanol (b) QUIN (100 $\mu \mathrm{g} / \mathrm{L})$ (c) $\mathrm{EE}_{2}(25 \mathrm{ng} / \mathrm{L})$ for 8 days and sampled at 00:00. Pg, primary growth; $\mathrm{Ca}$, cortical alveolus; $\mathrm{V}$, vitellogenic; $\mathrm{M}$, mature. 


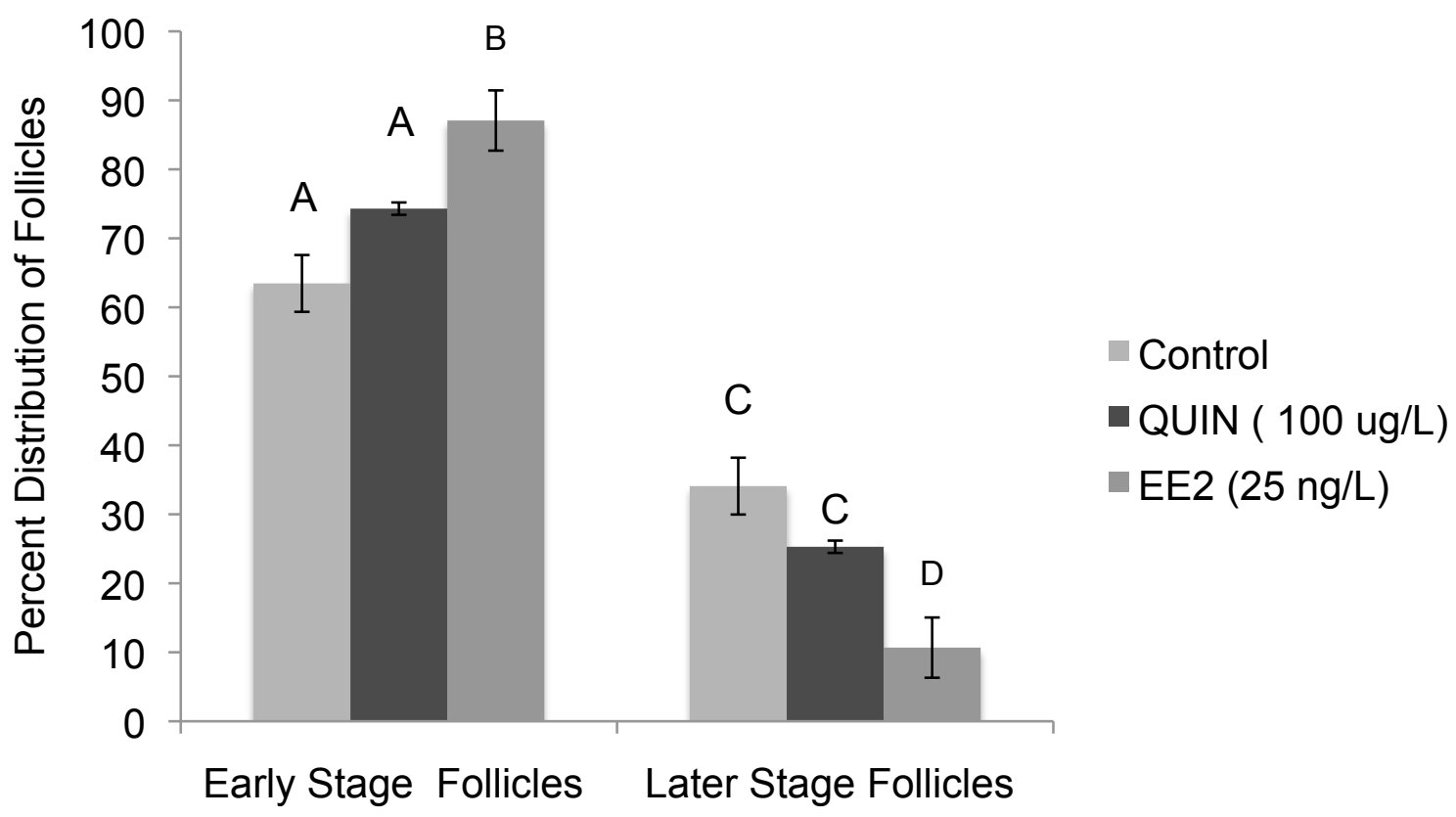

Figure 7: Percent distribution of early stage (primary growth) follicles and later stage follicles (cortical alveolus, vitellogenic and mature) in ovarian tissue of fish exposed for 8 days to QUIN (100 $\mu \mathrm{g} / \mathrm{L}), \mathrm{EE}_{2}(25 \mathrm{ng} / \mathrm{L})$ or ethanol (control) and sampled at 00:00 on the morning of the $9^{\text {th }}$ day of treatment. Data represents mean \pm S.E.M of 3-4 individuals per treatment. Different letters indicate a significant difference between treatments $(p<0.05 ;$ ANOVA, Tukey's). 
a)

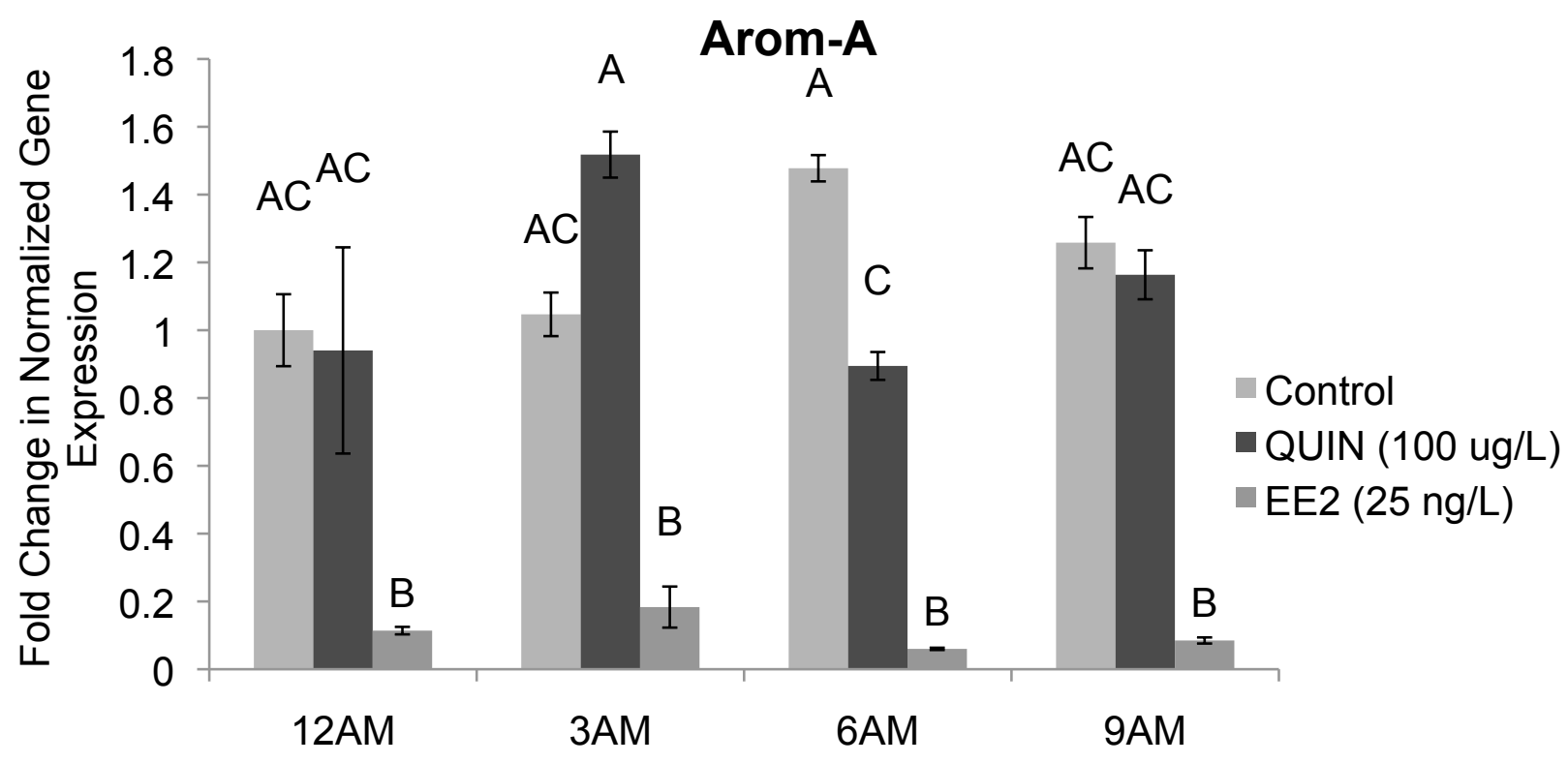

b)

\section{LHr}

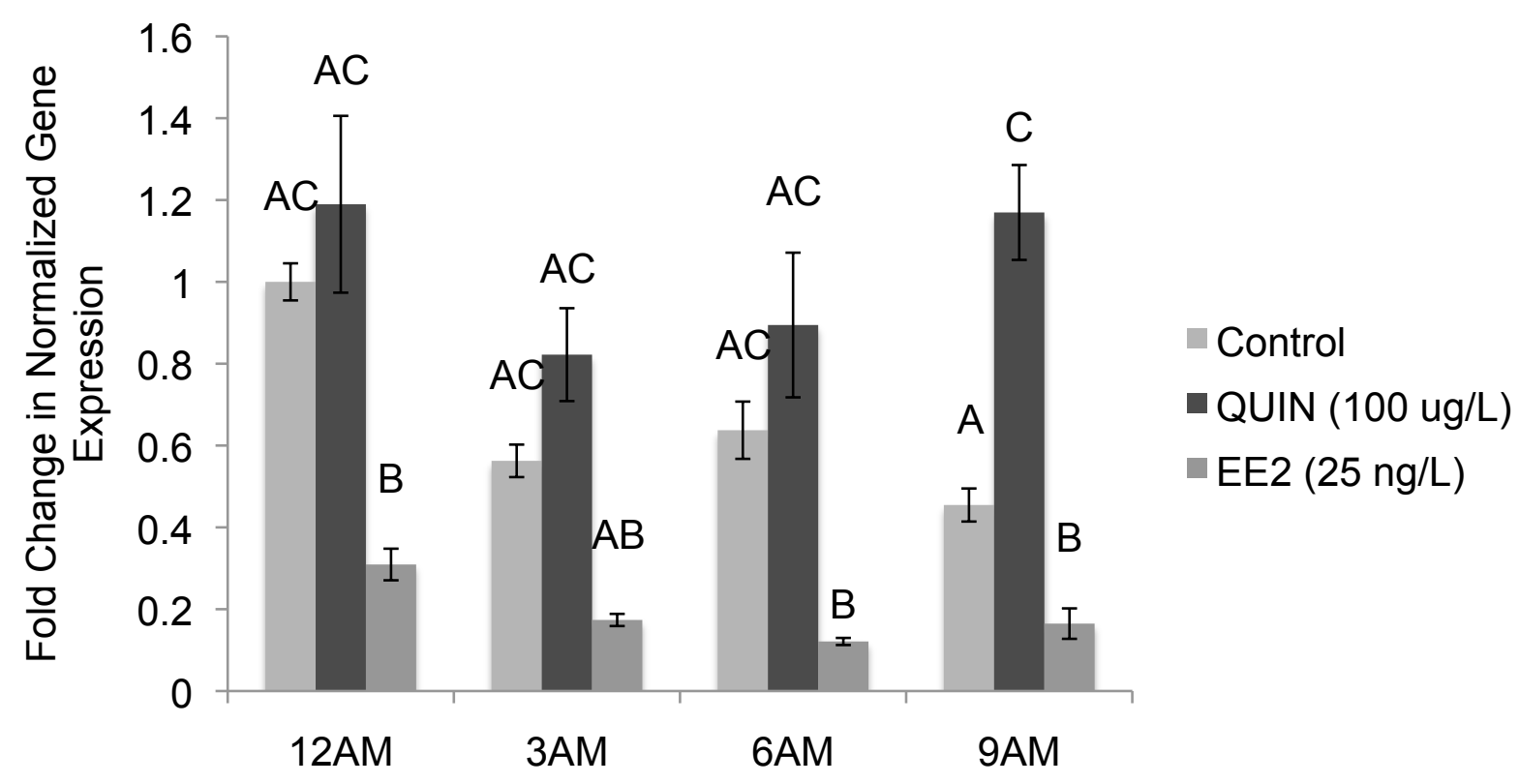


c)

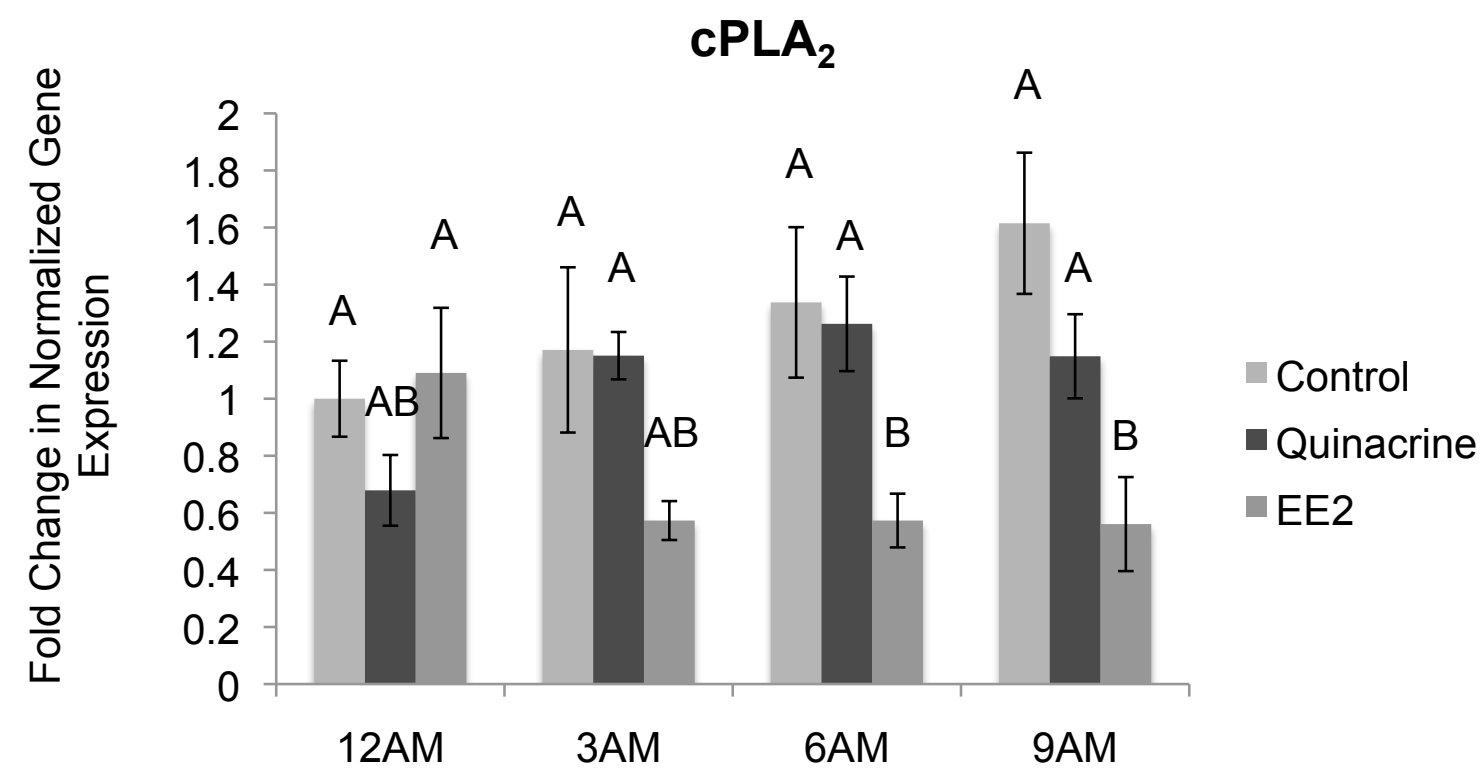

d)

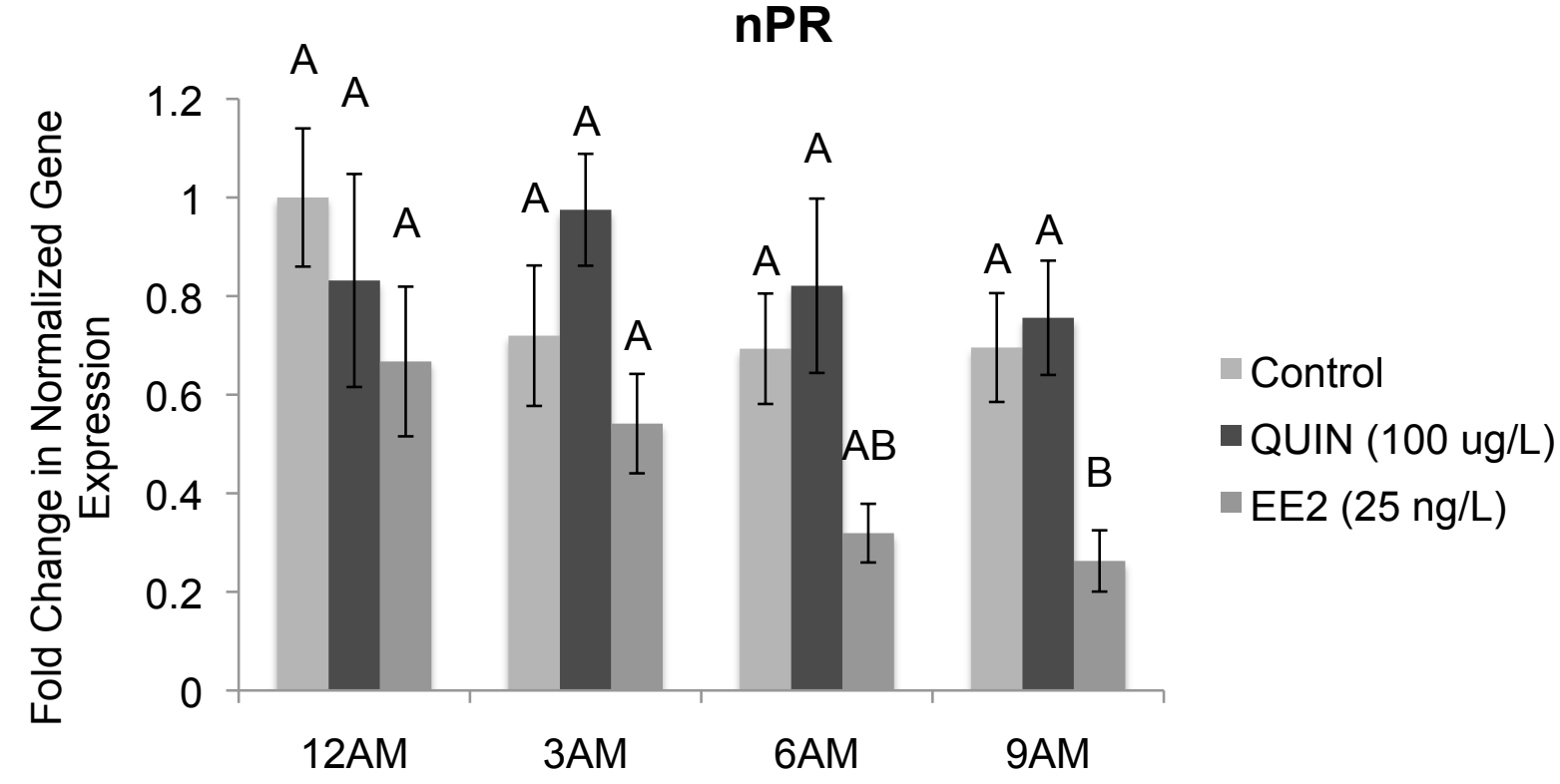


Figure 8: Ovarian expression of (a) aromatase (Arom-A) (b) luteinizing hormone receptor (LHr) (c) cytosolic phospholipase $\mathrm{A}_{2}\left(\mathrm{cPLA}_{2}\right)$ (d) nuclearprogestin receptor (nPR) of fish exposed for 8 days to QUIN (100 $\mu \mathrm{g} / \mathrm{L}), \mathrm{EE}_{2}(25 \mathrm{ng} / \mathrm{L})$ or ethanol (control) and sampled at $00: 00,03: 00,06: 00$ and $09: 00$ on the morning of the $9^{\text {th }}$ day of treatment. Data represents the mean \pm S.E.M. of 5-15 individual samples. Different letters indicate a significant difference between time and treatments $(p<0.05$; ANOVA, Tukey's). 
a)

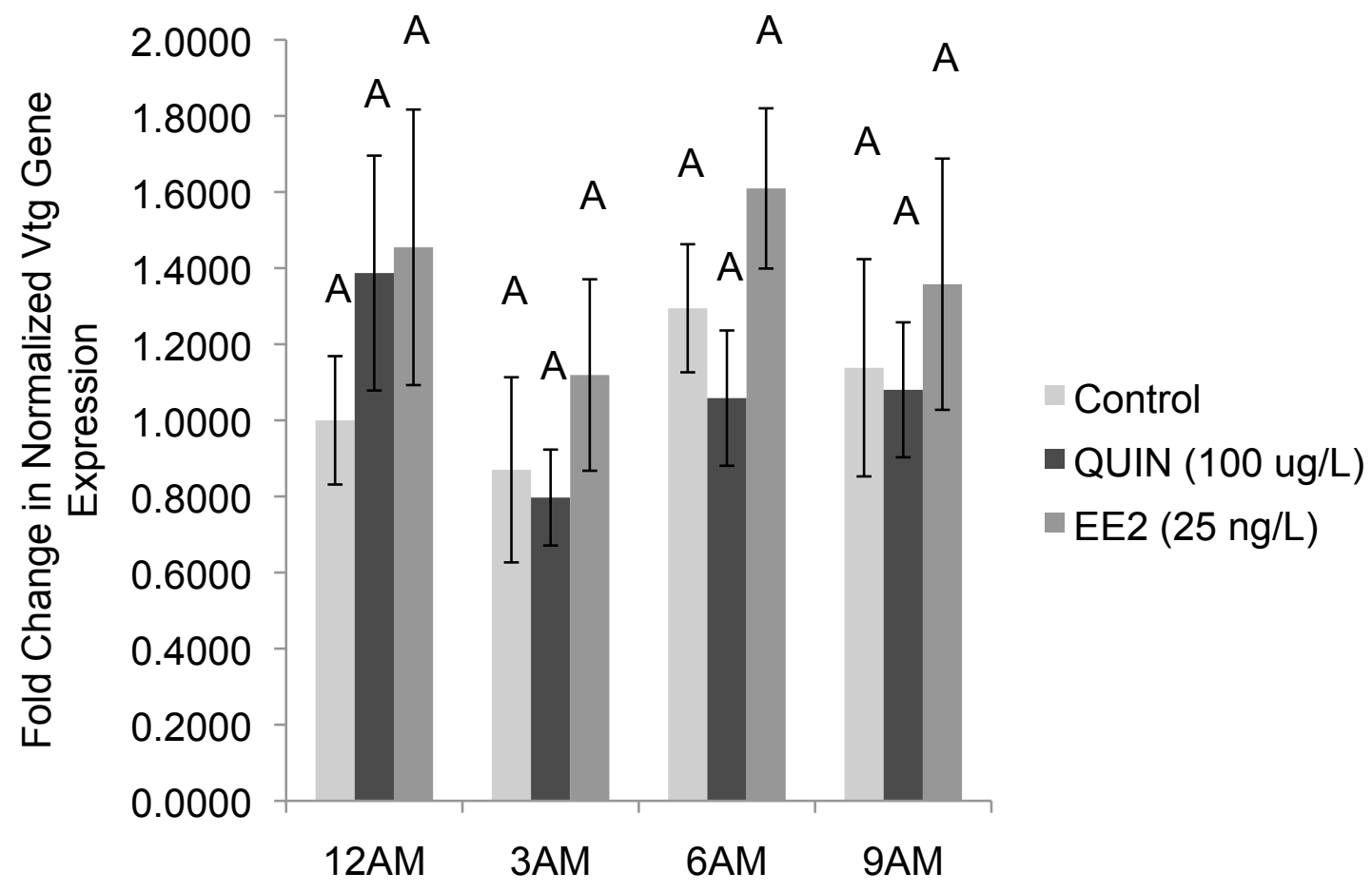

b)

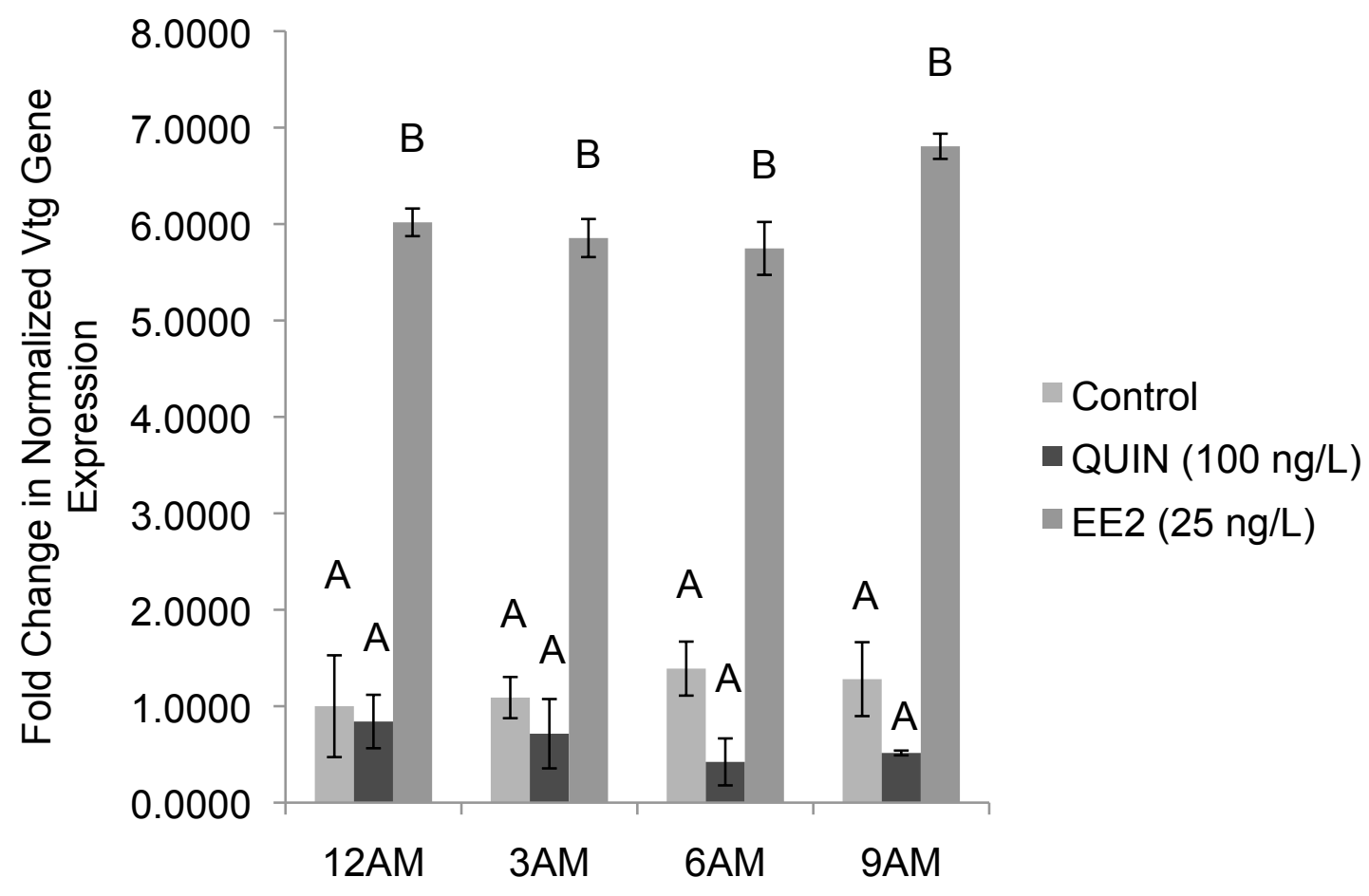


Figure 9: Vitellogenin expression in the livers of (a) female and (b) male fish exposed for 7 days to QUIN (100 $\mu \mathrm{g} / \mathrm{L})$, EE 2 ( $25 \mathrm{ng} / \mathrm{L})$ or ethanol (control) and sampled at 00:00, 03:00, 06:00 and 09:00 on the morning of the $9^{\text {th }}$ day of treatment. Data represents the mean \pm S.E.M. of 5-16 individual samples. Different letters indicate a significant difference between time and treatments $(p<0.05$; ANOVA, Tukey's). 


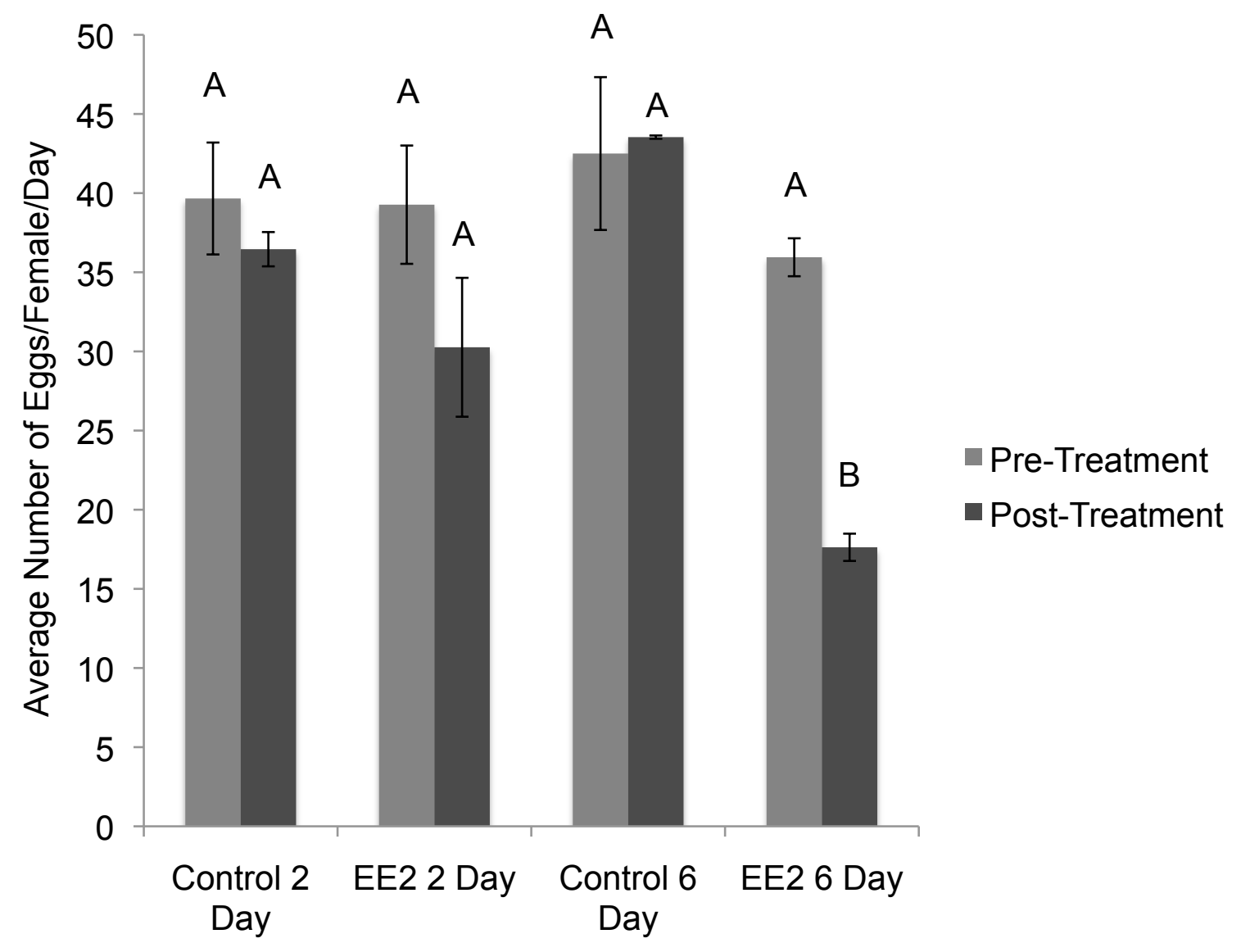

Figure 10: Average number of eggs per treatment produced by each female during the 5-day pre-treatment, and a 2 and 6-day treatment with $17 \alpha$-ethinylestradiol $\left(\mathrm{EE}_{2} ; 25\right.$ $\mathrm{ng} / \mathrm{L}$ ) or ethanol (control). Data represents mean \pm S.E.M. of 3 tanks per treatment. Different letters indicate a significant difference between time and treatments $(p<0.05$; ANOVA). 


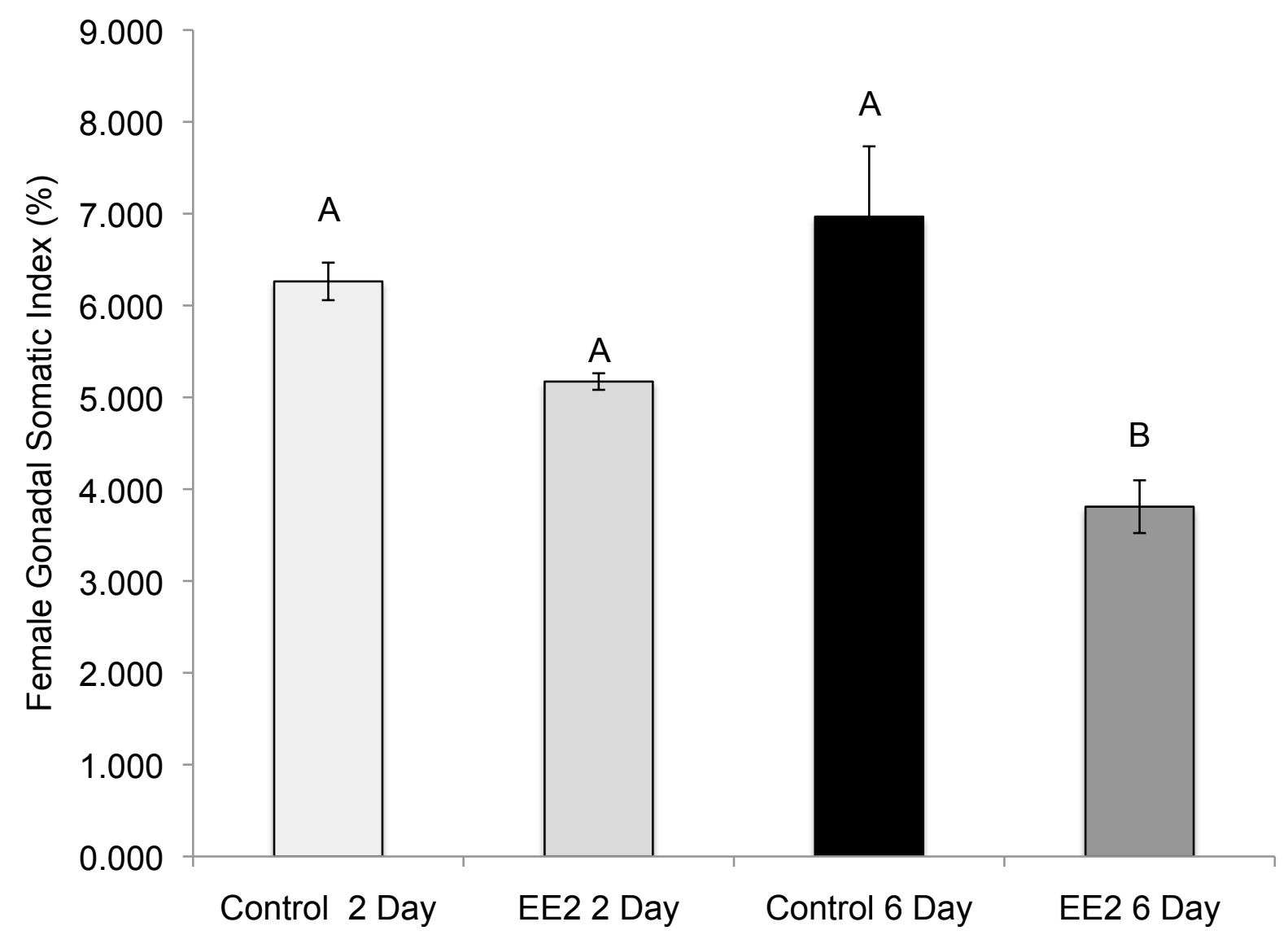

Figure 11: Gonadal somatic index of female fish after 2 and 6-day treatment with $E_{2}$ ( $25 \mathrm{ng} / \mathrm{L})$ or ethanol (control). Data represents mean \pm S.E.M. of 3 tanks per treatment. Different letters indicate a significant difference between time and treatments $(p<0.05$; ANOVA, Tukey's). 
a)

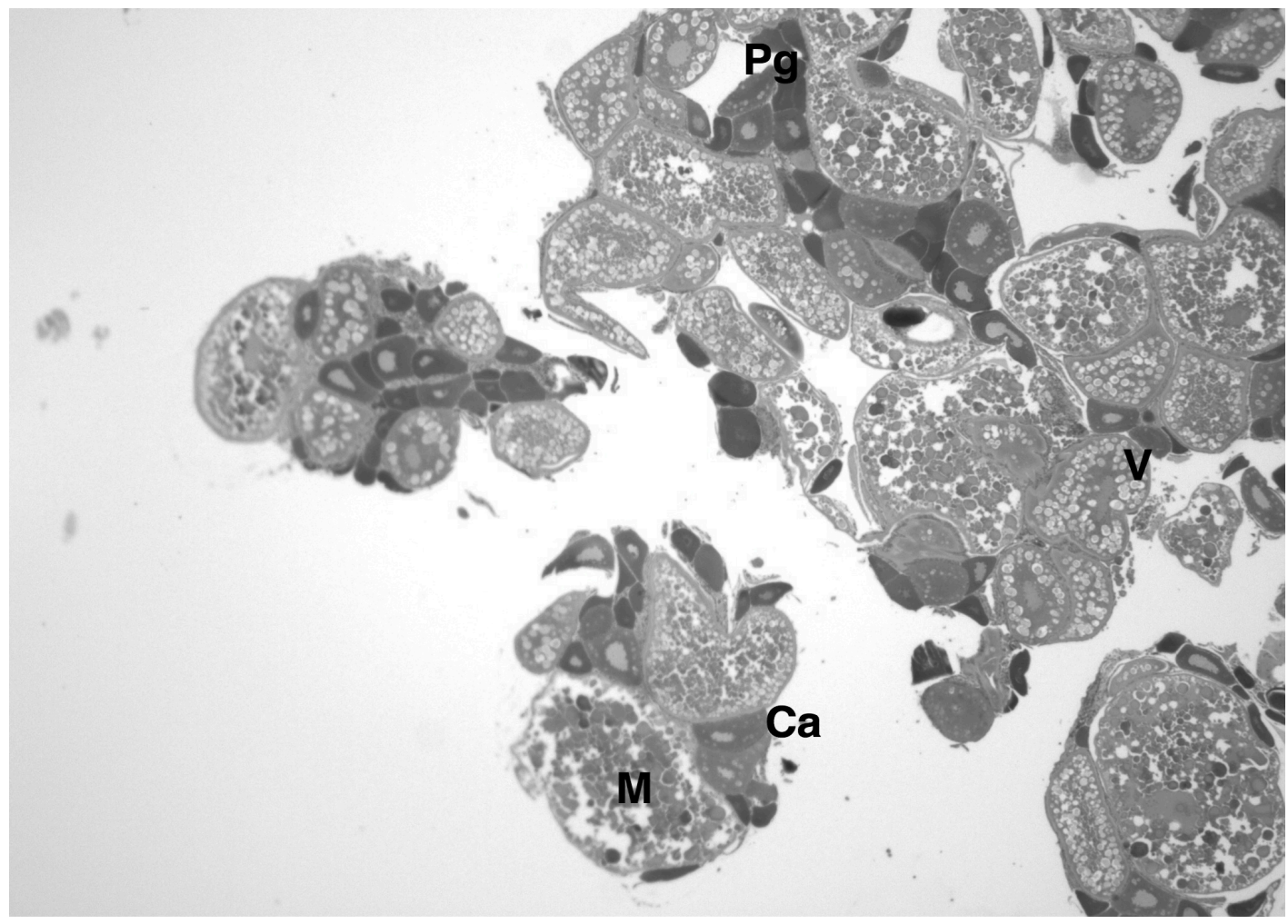

b)

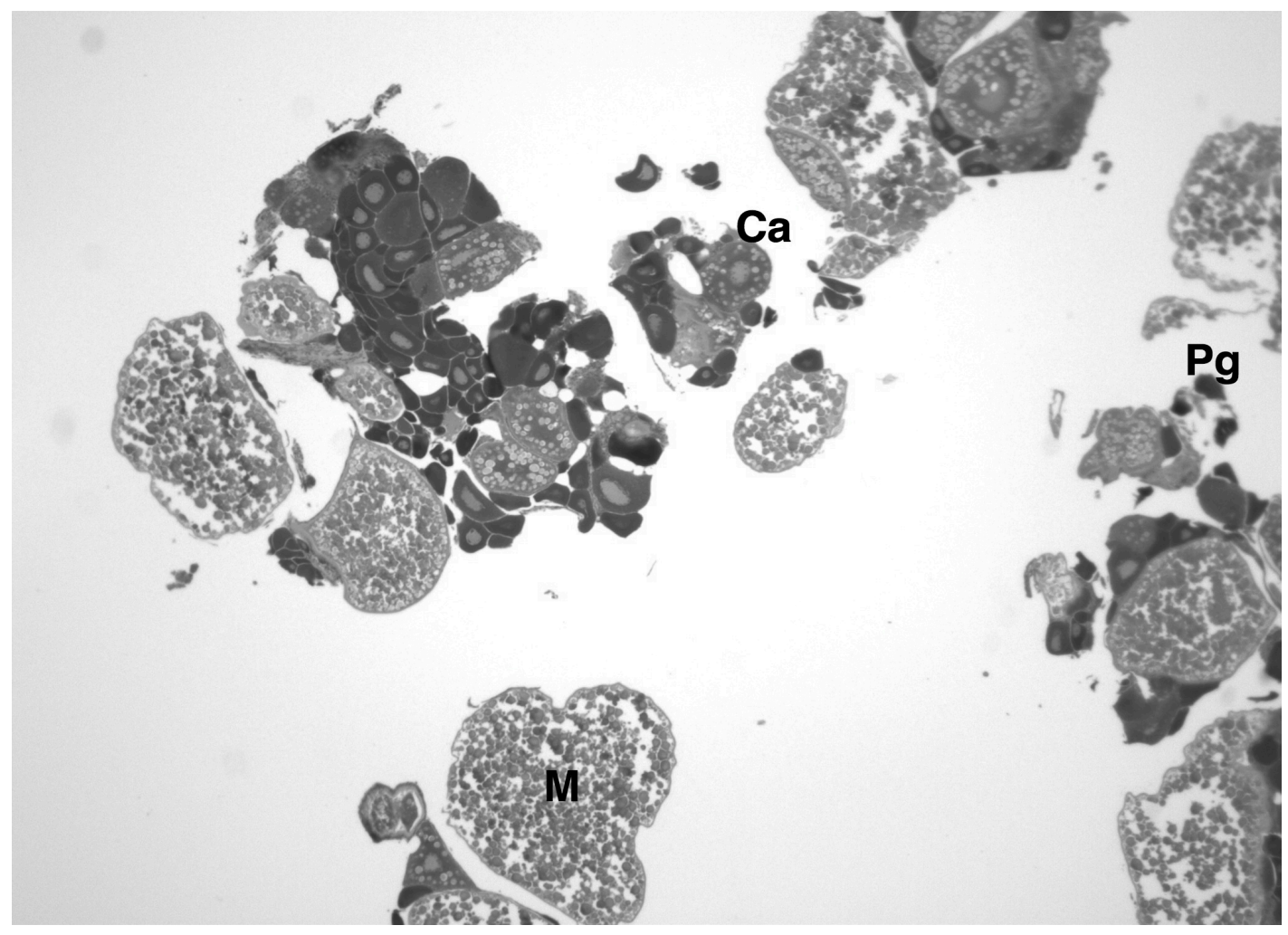


c)

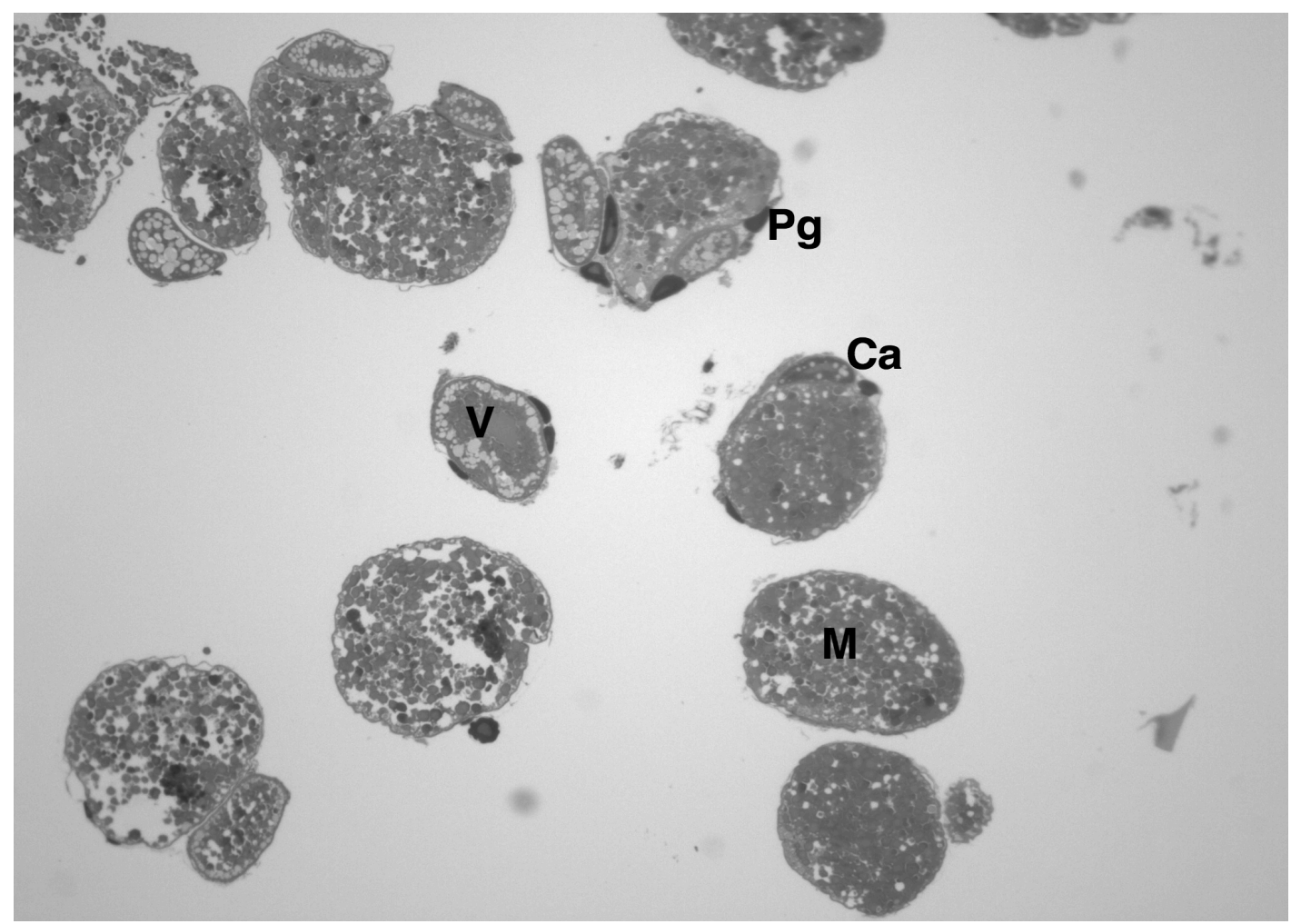

d)

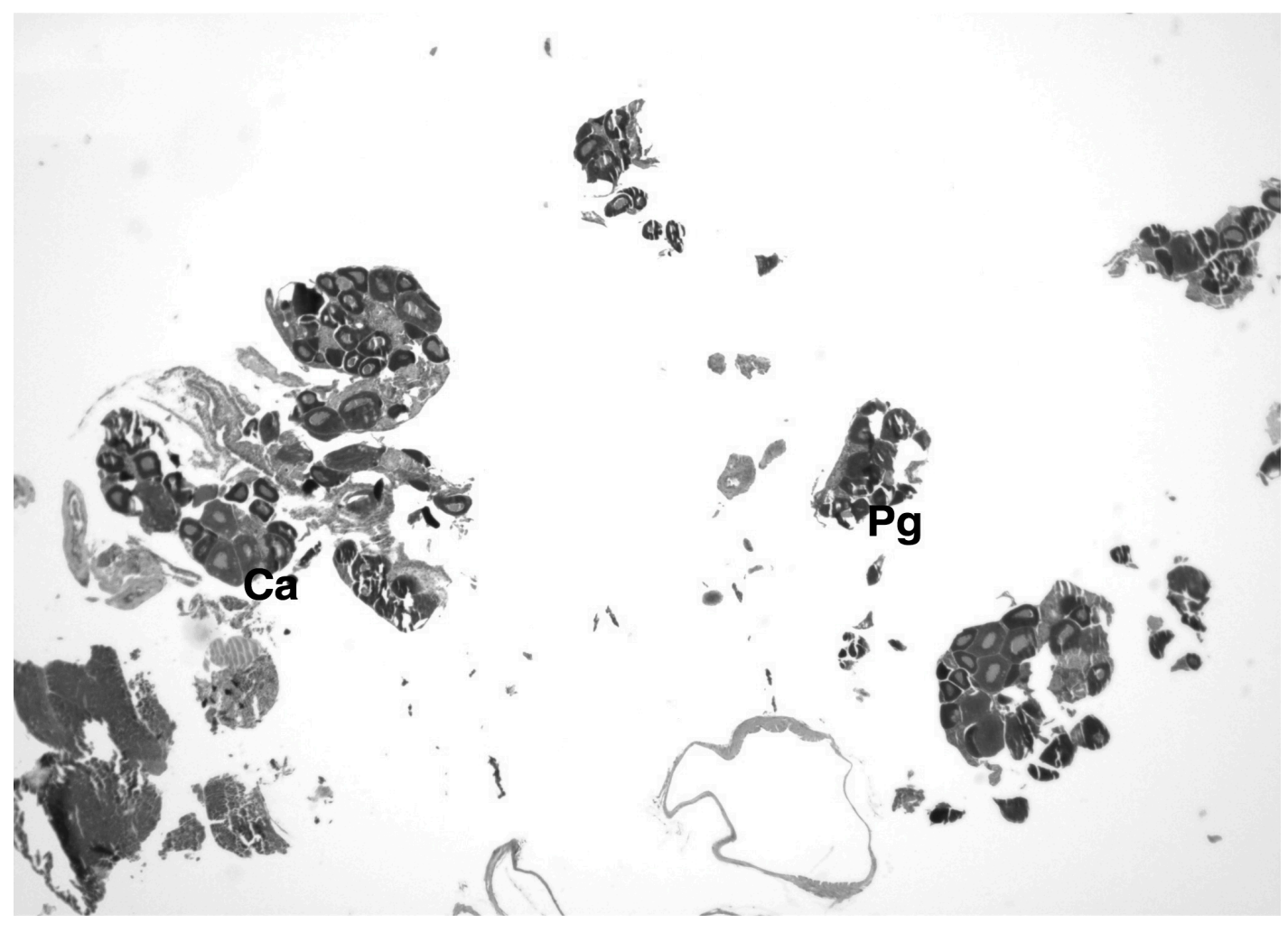


Figure 12: Representative histology of ovarian tissue from fish exposed to (a) ethanol and (b) $\mathrm{EE}_{2}(25 \mathrm{ng} / \mathrm{L})$ after 2 days of treatment and (c) ethanol and (d) $\mathrm{EE}_{2}(25 \mathrm{ng} / \mathrm{L})$ after 6 days of treatment. All groups were sampled at 05:00. Pg, primary growth; $\mathrm{Ca}$, cortical alveolus; V, vitellogenic; $\mathrm{M}$, mature. 


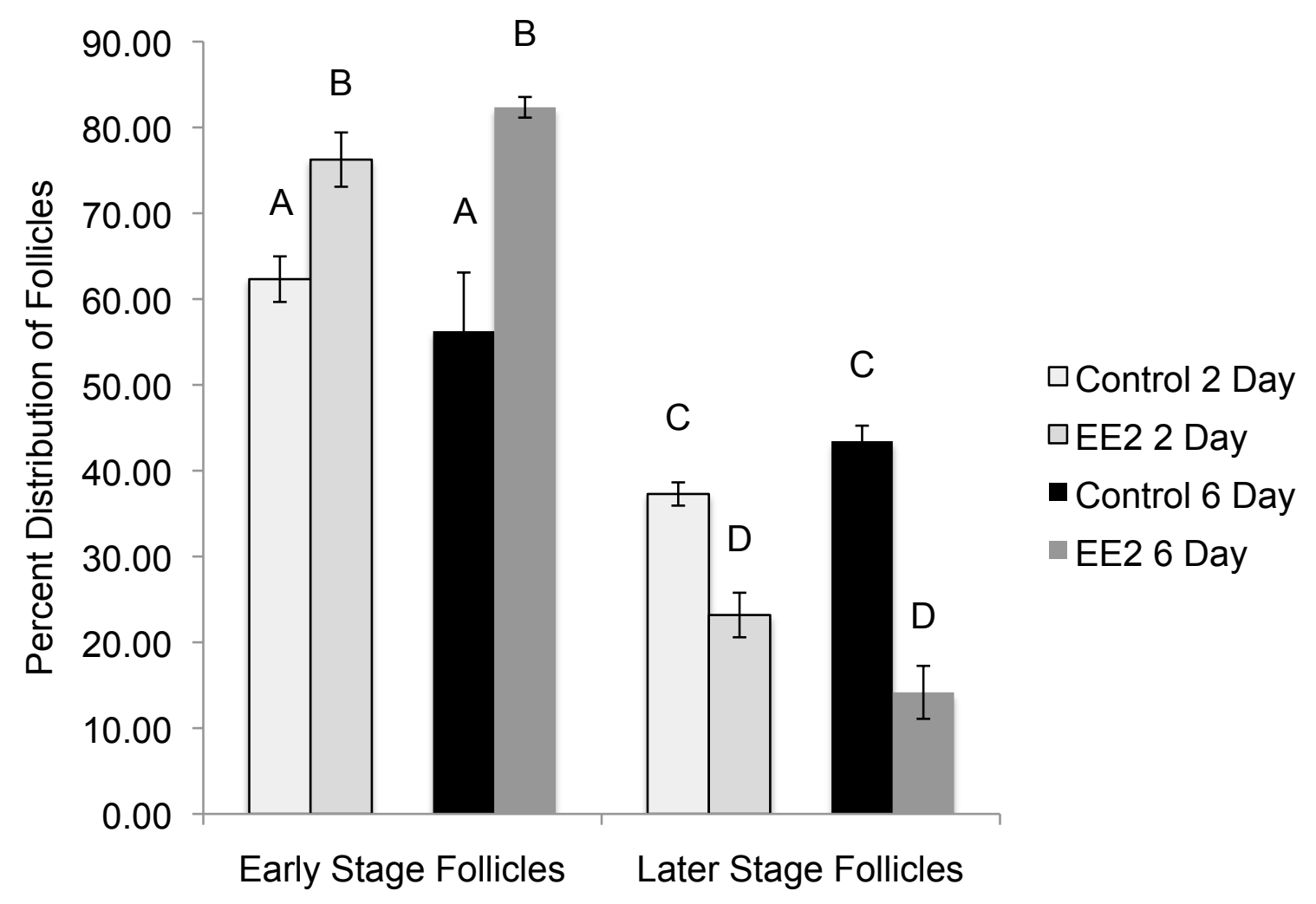

Figure 13: Percent distribution of early stage (primary growth) follicles and later stage follicles (cortical alveolus, vitellogenic and mature) in ovarian tissue of fish exposed to $\mathrm{EE}_{2}(25 \mathrm{ng} / \mathrm{L})$ or ethanol (control) and sampled at 05:00 on the morning of the $2^{\text {nd }}$ and $6^{\text {th }}$ day of treatment. Data represents mean \pm S.E.M of 9 individuals per treatment. Different letters indicate a significant difference between time and treatments $(p<0.05$; ANOVA, Tukey's) 
a)

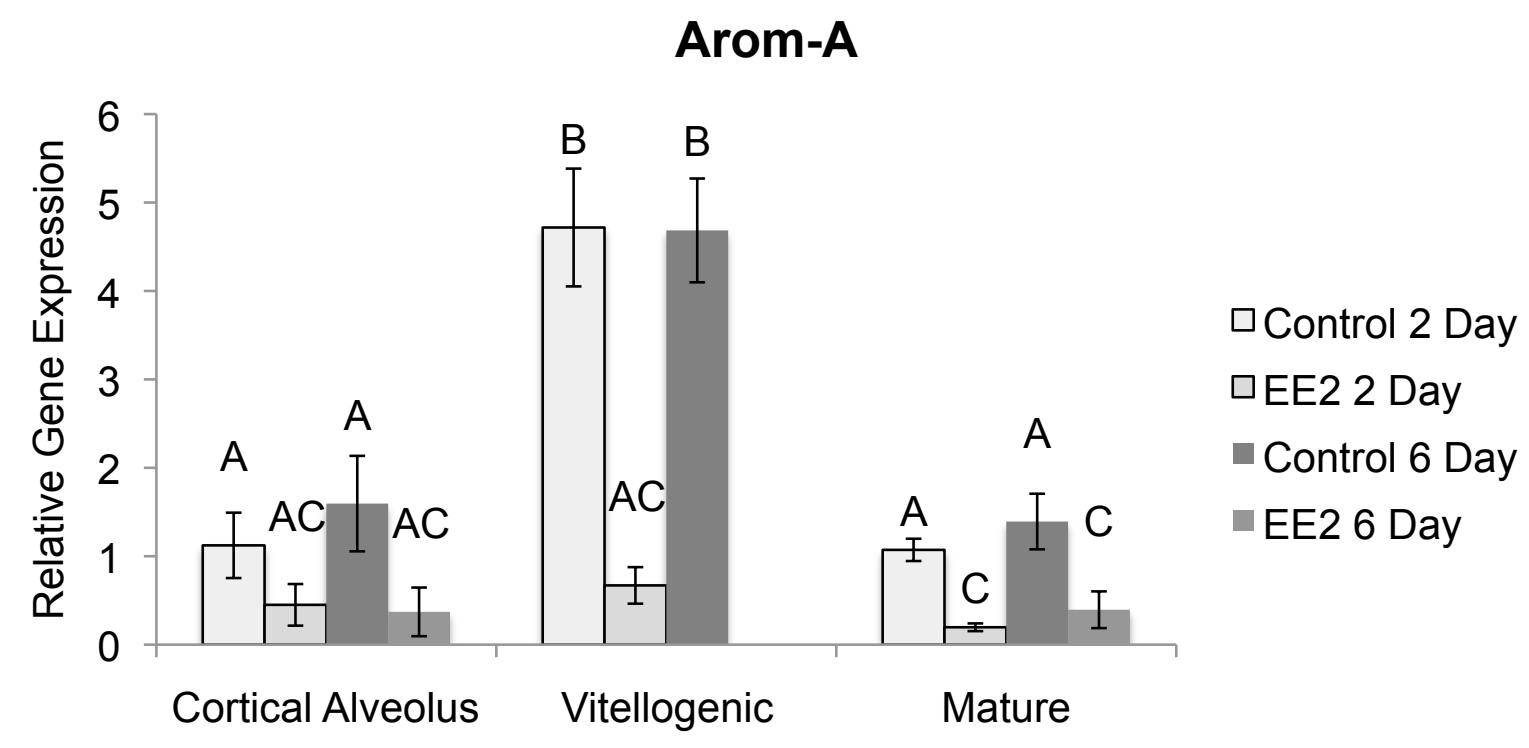

b)

LHr

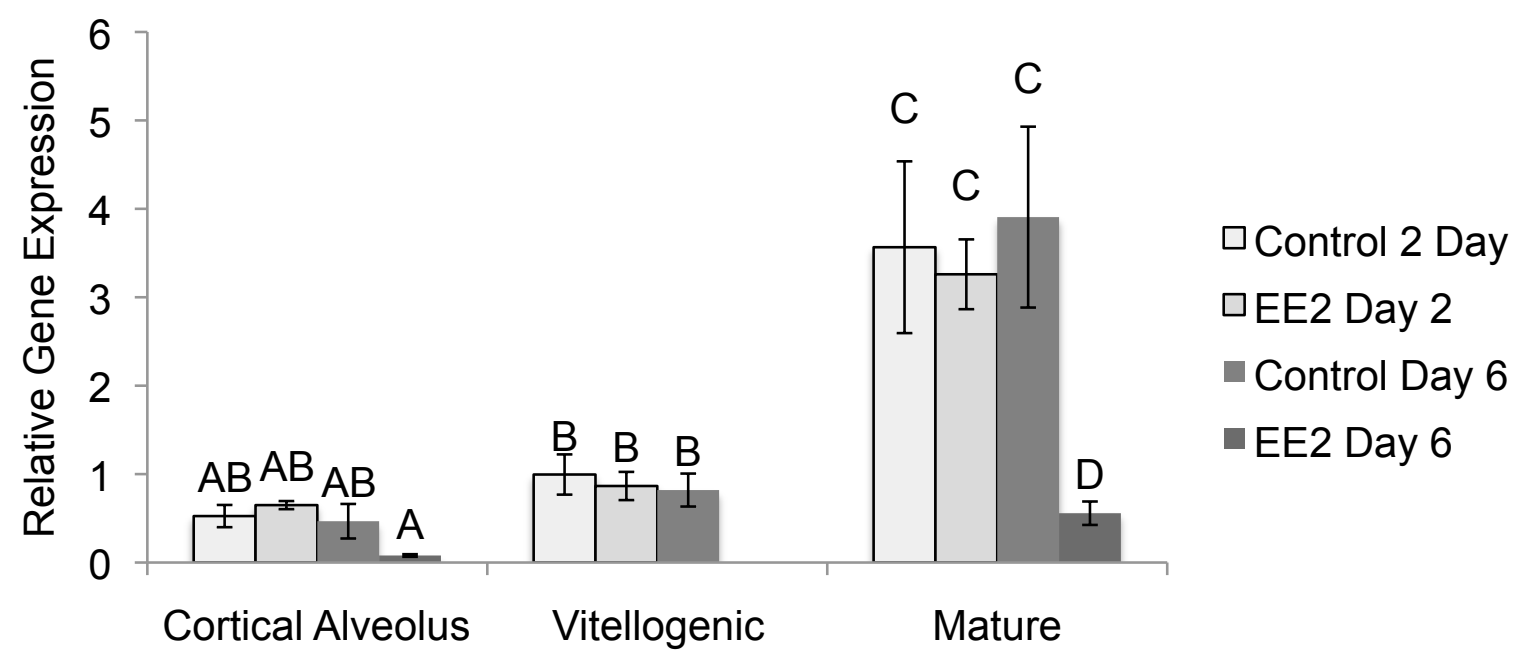


c)

\section{cPLA 2}

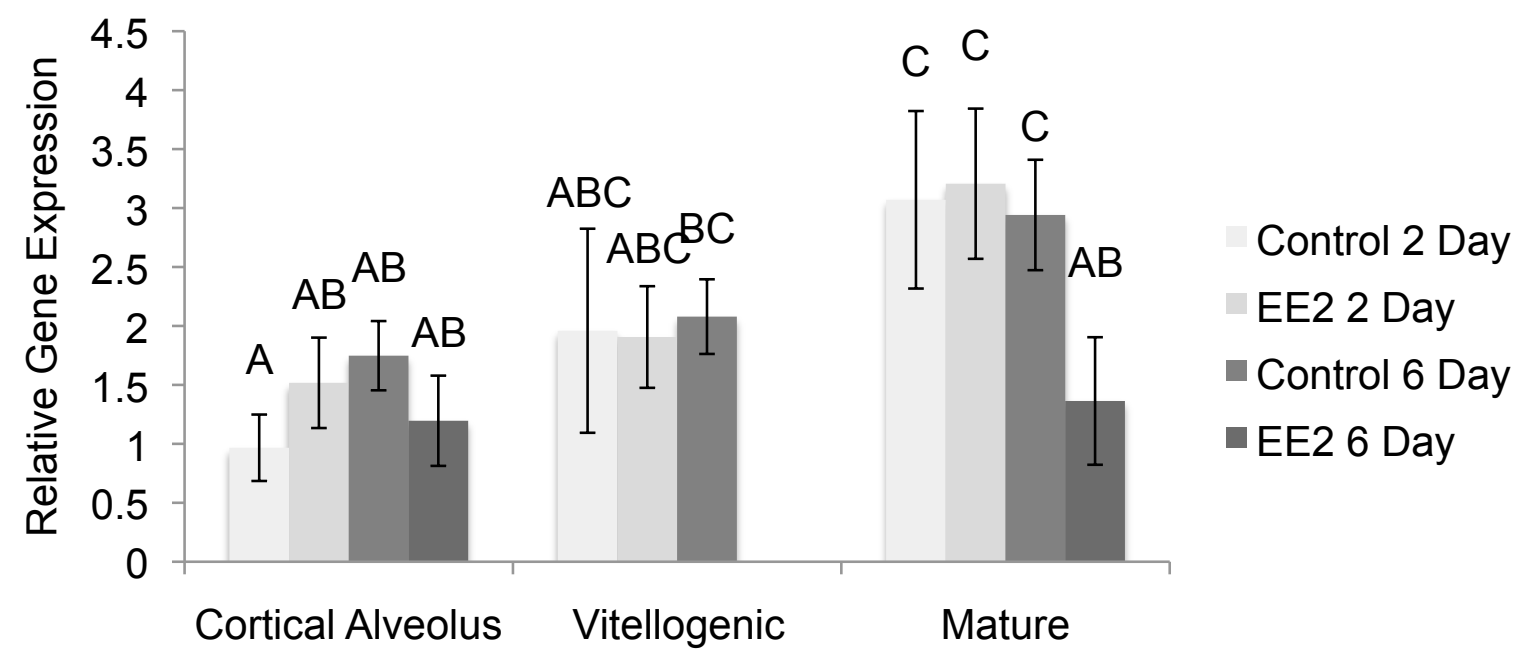

d)

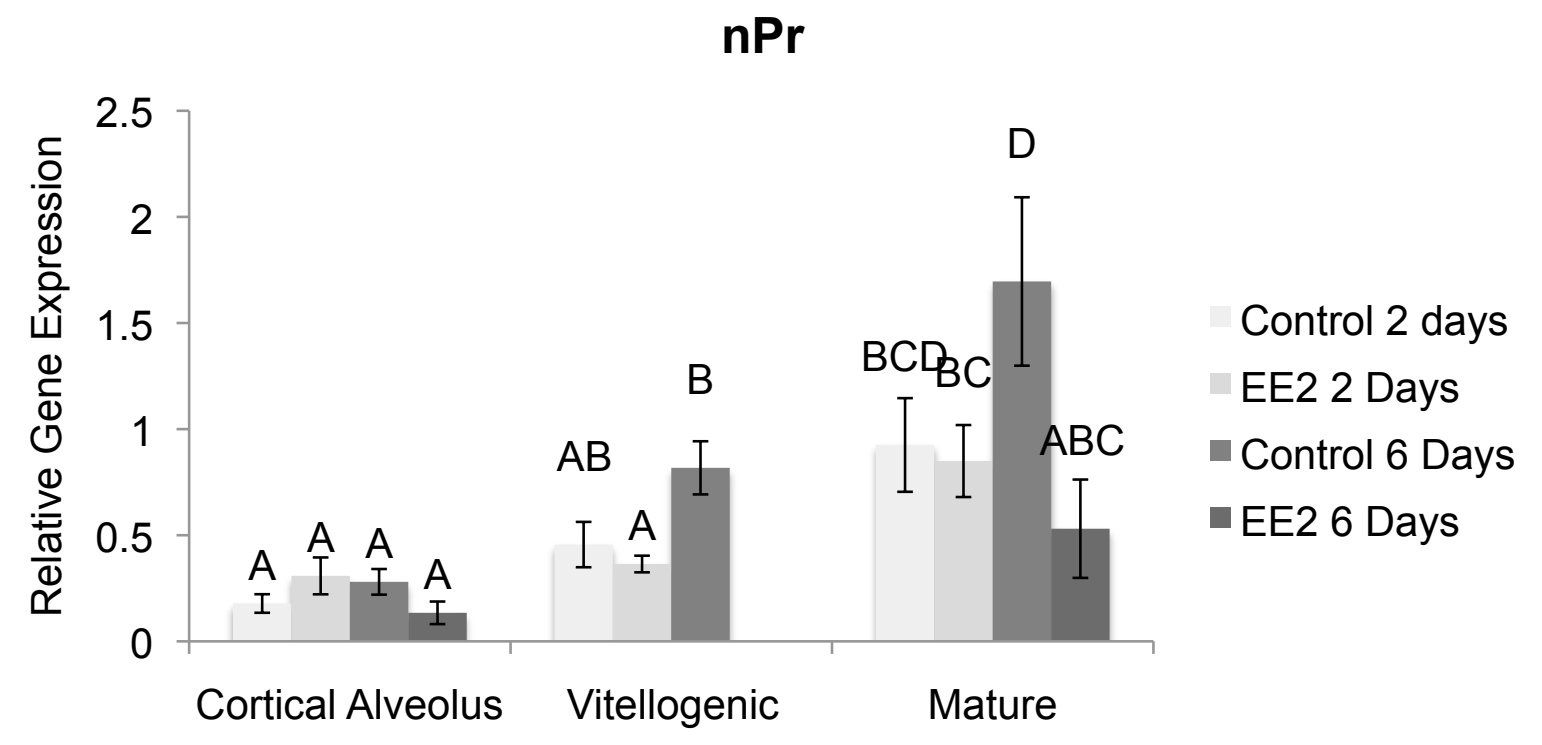


Figure 14: Relative expression of (a) aromatase (Arom-A) (b) luteinizing hormone receptor (LHr) (c) cytosolic phospholipase $\mathrm{A}_{2}\left(\mathrm{CPLA}_{2}\right)$ and (d) nuclear progestin receptor (nPR) in cortical alveolus, vitellogenic and mature follicles from fish exposed to $25 \mathrm{ng} / \mathrm{L}$ of $\mathrm{EE}_{2}$ for 2 and 6 days and sampled at 05:00. Data represents the mean \pm S.E.M. of 3 tanks per treatment. Different letters denote statistical significance $(p<0.05$; ANOVA, Tukey's) 
a)

\section{Arom-A}

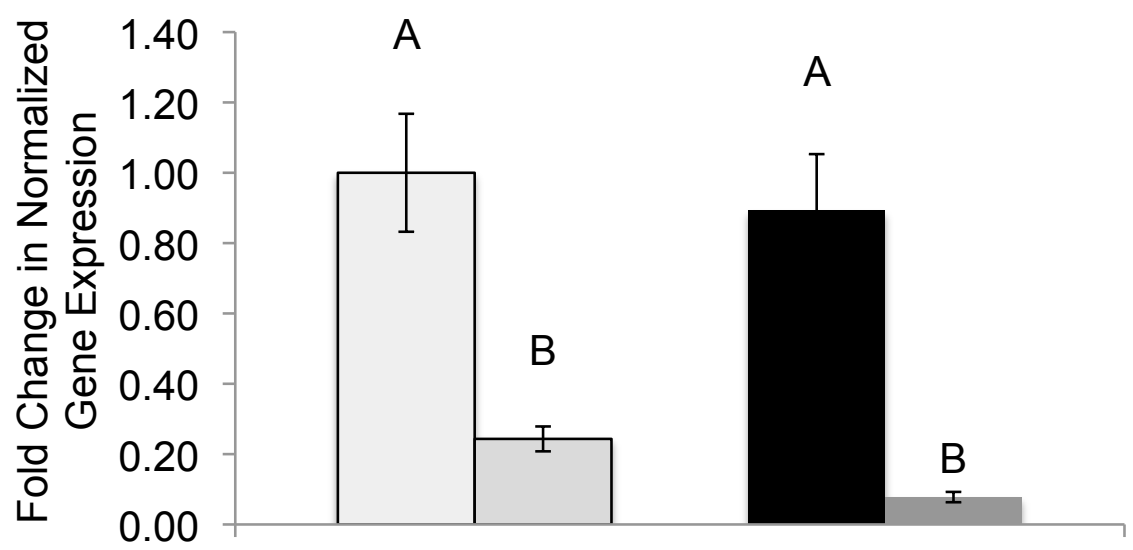

$\square$ Control 2 day $\square$ EE2 2 day - Control 6 day EE2 6 day

b)

\section{LHr}

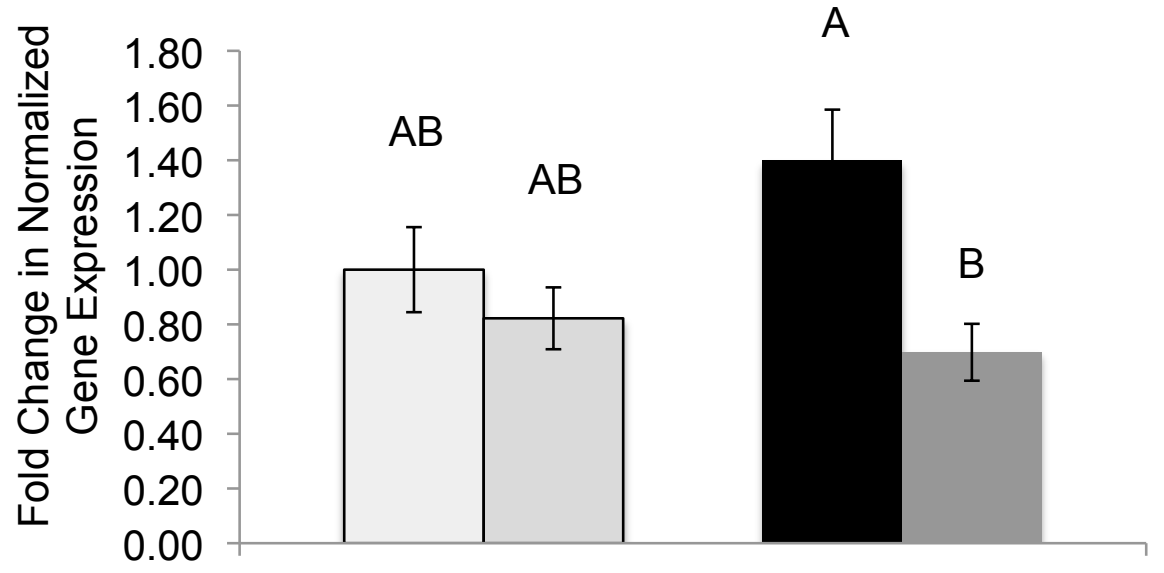

$\square$ Control 2 Day 口EE2 2 Day - Control 6 Day EE2 6 Day 
c)

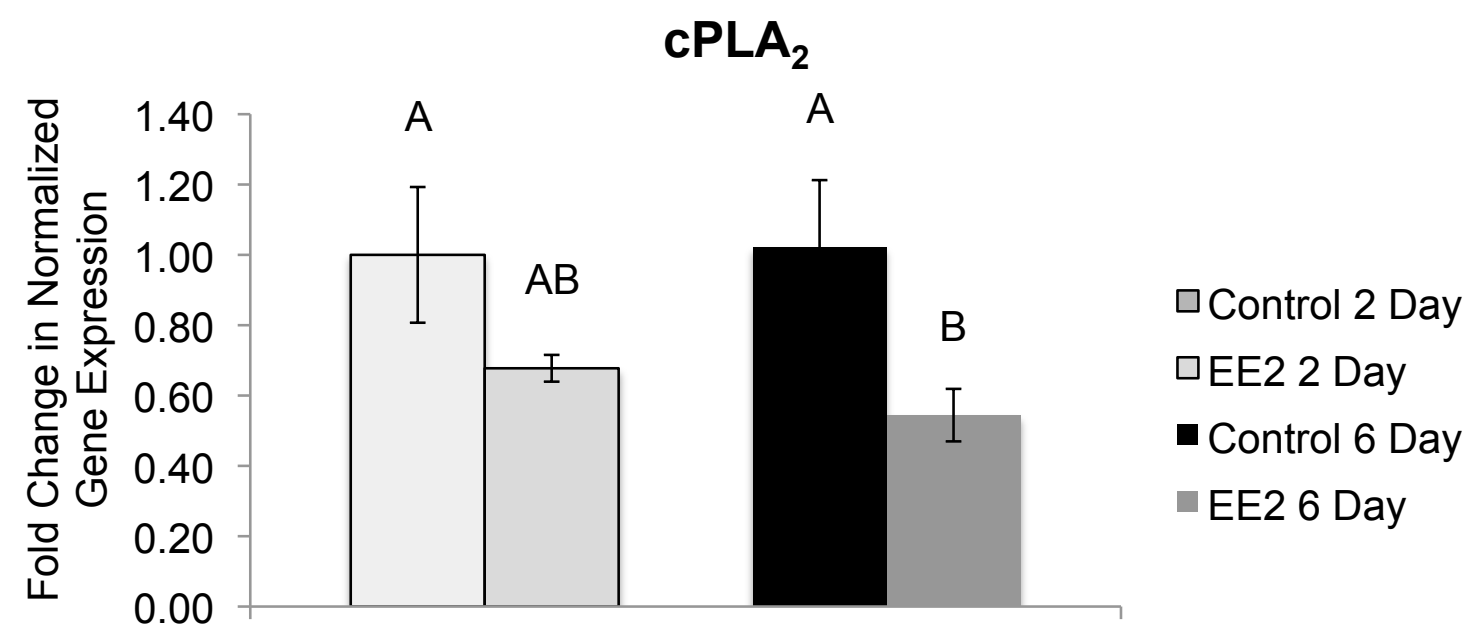

d)

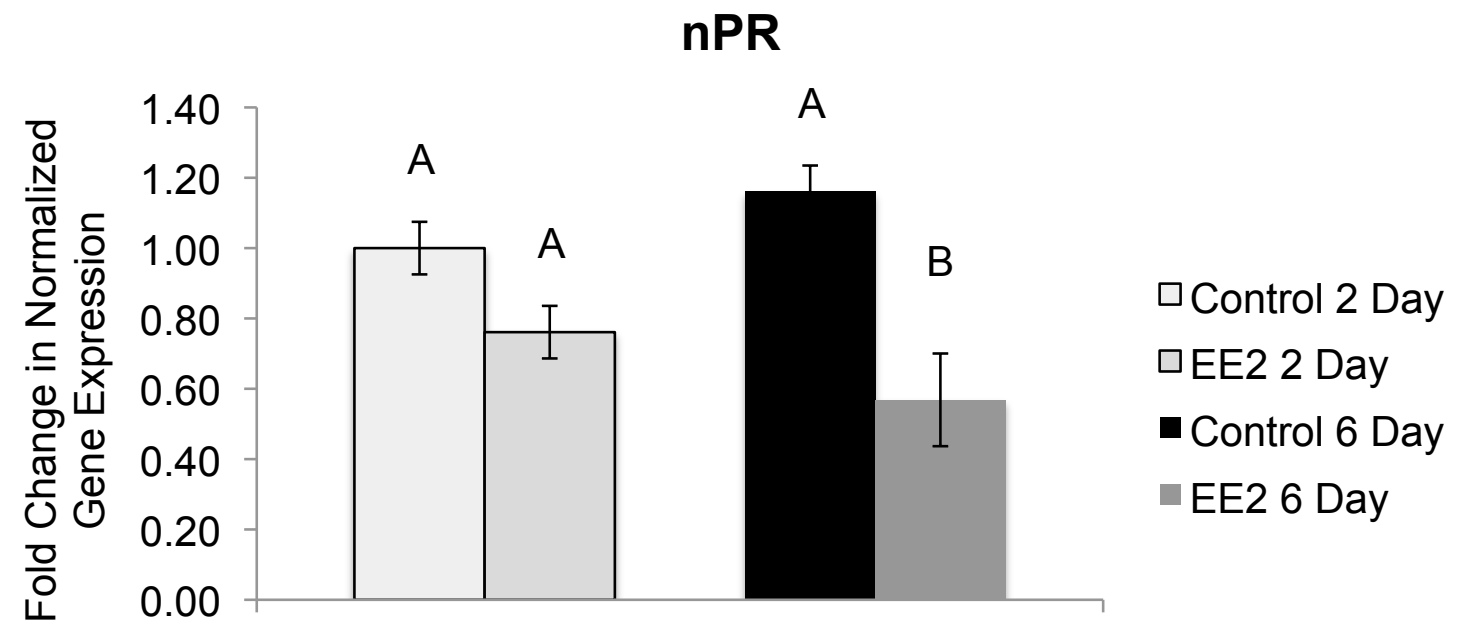


Figure 15: Ovarian expression of (a) aromatase (Arom-A) (b) luteinizing hormone receptor (LHr) (c) cytosolic phospholipase $\mathrm{A}_{2}\left(\mathrm{CPLA}_{2}\right)$ and (d) nuclear progestin receptor (nPR) in fish exposed to $\mathrm{EE}_{2}(25 \mathrm{ng} / \mathrm{L})$ or ethanol (control) for 2 and 6-days and sampled at 05:00. Data represents the mean \pm S.E.M. of 3 tanks per treatment. Different letters indicate a significant difference between time and treatments $(p<0.05$; ANOVA, Tukey's). 
Table 1. List of primers and their sequences used in this study

\begin{tabular}{|c|c|c|c|}
\hline Gene & \multicolumn{2}{|c|}{ Sequence $\left(5^{\prime}-3^{\prime}\right)$} & Source \\
\hline ef1a & $\begin{array}{l}\text { Forward } \\
\text { Reverse }\end{array}$ & $\begin{array}{l}\text { GATCACTGGTACTTCTCAGGCTGA } \\
\text { GGTGAAAGCCAGGAGGGC }\end{array}$ & Lister et al., 2009 \\
\hline cpla2 & $\begin{array}{l}\text { Forward } \\
\text { Reverse }\end{array}$ & $\begin{array}{l}\text { TGCTCTTGGAAGTTTGCGC } \\
\text { AGCAGTCCAACTCGATGCATC }\end{array}$ & Lister et al., 2009 \\
\hline Ihr & $\begin{array}{l}\text { Forward } \\
\text { Reverse }\end{array}$ & $\begin{array}{l}\text { ACCTGACCTCCATCTTCTCCC } \\
\text { TGGATGGTACTGAGCGCAGA }\end{array}$ & Lister et al., 2009 \\
\hline ptgs 1 & $\begin{array}{l}\text { Forward } \\
\text { Reverse }\end{array}$ & $\begin{array}{l}\text { AAGGTCTGGGTCACGGAGTG } \\
\text { TCTGCGTGTCTGCATGAACAG }\end{array}$ & Lister \& Van Der Kraak, 2008 \\
\hline ptgs2 & $\begin{array}{l}\text { Forward } \\
\text { Reverse }\end{array}$ & $\begin{array}{l}\text { GTTAAAAGATGGAAAGCTTAAATACCAGG } \\
\text { CAAGAGAATCTCCATAAATGTGTCCA }\end{array}$ & Lister \& Van Der Kraak, 2008 \\
\hline Arom-A & $\begin{array}{l}\text { Forward } \\
\text { Reverse }\end{array}$ & $\begin{array}{l}\text { AGTTCAACTGGCACACGCAG } \\
\text { AGCTCTCCATGGCTCTGAGC }\end{array}$ & Ings \& Van Der Kraak, 2006 \\
\hline mpra & $\begin{array}{l}\text { Forward } \\
\text { Reverse }\end{array}$ & $\begin{array}{l}\text { GGCCATCAGATCTTCCATGTG } \\
\text { TCTCTCTGTGTAATCCAGTCGAACA }\end{array}$ & Nelson \& Van Der Kraak, 2010 \\
\hline$n P R$ & $\begin{array}{l}\text { Forward } \\
\text { Reverse }\end{array}$ & $\begin{array}{l}\text { GGATCACCTTTCTGCGCT } \\
\text { GACAACCAGAAGCCTC }\end{array}$ & Hanna et al., 20120 \\
\hline gpr30 & $\begin{array}{l}\text { Forward } \\
\text { Reverse }\end{array}$ & $\begin{array}{l}\text { CATCGGCCTGTTTCTCTCAT } \\
\text { GTAGCACAGGCCGATAAT }\end{array}$ & Pang \& Thomas, 2010 \\
\hline bax & $\begin{array}{l}\text { Forward } \\
\text { Reverse }\end{array}$ & $\begin{array}{l}\text { GGCTATTTCAACCAGGGTTCC } \\
\text { TGCGAATCACCAATGCTGT }\end{array}$ & Tang et al., 2007 \\
\hline$p 53$ & $\begin{array}{l}\text { Forward } \\
\text { Reverse }\end{array}$ & $\begin{array}{l}\text { GGGCAATCAGCGAGCAAA } \\
\text { ACTGACCTTCCTGAGTCTCCA }\end{array}$ & Soares et al., 2012 \\
\hline$b c / 2$ & $\begin{array}{l}\text { Forward } \\
\text { Reverse }\end{array}$ & $\begin{array}{l}\text { AGGAAAATGGAGGTTGGGATG } \\
\text { TGTTAGGTATGAAAACGGGTGGA }\end{array}$ & Jin et al., 2010 \\
\hline$v t g$ & $\begin{array}{l}\text { Forward } \\
\text { Reverse }\end{array}$ & $\begin{array}{l}\text { TGCGTGAAGTTGTCATGCTTG } \\
\text { GATCTCGTGGATGGGCCTG }\end{array}$ & \\
\hline arp & $\begin{array}{l}\text { Forward } \\
\text { Reverse }\end{array}$ & $\begin{array}{l}\text { CCAGAACACCGGGCTCG } \\
\text { TTGATAAGCTGAACGTCACTCAAGA }\end{array}$ & Ings \& Van Der Kraak, 2006 \\
\hline hprt & $\begin{array}{l}\text { Forward } \\
\text { Reverse }\end{array}$ & $\begin{array}{l}\text { ATCAGCGAAACAGGAAAGGAG } \\
\text { CTGCGGTGAGCTGCACTACT }\end{array}$ & Tang et al., 2007 \\
\hline
\end{tabular}




\section{DISCUSSION}

Experiment 1 and 2 examined cellular and organ level aspects of the different reproductive processes that contribute to spawning and although QUIN and $\mathrm{EE}_{2}$ both inhibit spawning, this outcome was mediated through distinct AOPs. The results of these experiments suggest that QUIN inhibits spawning by interrupting the ovulatory pathway, with no significant effects seen at the organ level (histology or GSI). In comparison $\mathrm{EE}_{2}$ had an impact on all the reproductive processes examined with responses recorded at the both the cellular and organ level (Table 2). The time course used in Experiment 1 and 2 assisted in elucidating gene expression results and identified time points that provided useful information about impacts on the reproductive processes examined. The results of Experiment 3 provided more details about $\mathrm{EE}_{2}$ 's $\mathrm{AOP}$ and the linkages between cellular and organ responses. Although $\mathrm{EE}_{2}$ alters the proportion of follicle stages within the ovary, the downregulation of gene expression as a consequence of $E_{2}$ exposure was primarily due to a decrease in expression of the genes of interest in vitellogenic and mature follicles. The time course in this experiment demonstrated the progression of effects of $\mathrm{EE}_{2}$ at the cellular, whole organ and organism level. 
Table 2: Adverse outcome pathways of QUIN and $E E_{2}$ that result in the inhibition of spawning in zebrafish.

\begin{tabular}{|c|c|c|}
\hline & Quinacrine & $\mathrm{EE}_{2}$ \\
\hline \multicolumn{3}{|l|}{ Spawning } \\
\hline \# of eggs produced/female/day & $\downarrow$ & $\downarrow$ \\
\hline \multicolumn{3}{|l|}{ Steroidogenesis/Follicular Recruitment } \\
\hline $\begin{array}{l}\text { - } E_{2} \text { levels } \\
\text { - GSI }\end{array}$ & $\begin{array}{l}\text { No Change } \\
\text { No Change }\end{array}$ & No Change \\
\hline \multicolumn{3}{|l|}{-Proportion of Follicle Stages } \\
\hline $\begin{array}{l}\text { Early Stage (primary growth) } \\
\text { Later Stage (cortical alveolus, vitellogenic, mature) } \\
\text { - Arom-A expression }\end{array}$ & $\begin{array}{l}\text { No Change } \\
\text { No Change } \\
\text { No Change }\end{array}$ & $\underset{\downarrow}{\downarrow}$ \\
\hline \multicolumn{3}{|l|}{ Maturation } \\
\hline $\begin{array}{l}\text { - 17a,20ß-P levels } \\
\text { - LHr expression * }\end{array}$ & $\begin{array}{c}\downarrow \\
\text { No Change }\end{array}$ & No Change \\
\hline \multicolumn{3}{|l|}{ Ovulation } \\
\hline $\begin{array}{l}\text { - PGF } 2 a \text { levels } \\
\text { - cPLA } A_{2} \text { expression } \\
\text { - COX-2 expression } \\
\text { - nPR expression }\end{array}$ & $\begin{array}{c}\text { No Change } \\
\text { No Change } \\
\downarrow \\
\text { No Change }\end{array}$ & $\begin{array}{c}\text { No Change } \\
\Downarrow \\
\text { No Change } \\
\downarrow\end{array}$ \\
\hline \multicolumn{3}{|l|}{ Estrogenic } \\
\hline -Male liver vtg expression & No Change & $\uparrow$ \\
\hline
\end{tabular}

*The surge of LH responsible for switching the steroidogenic pathway to the production of $17 \alpha, 20 \beta-\mathrm{P}$ is a defining event in the maturation, which is why $\mathrm{LHr}$ expression is categorized under maturation in the AOP, however it should be noted that LHr also plays a role in follicular recruitment, steroidogenesis and possibly ovulation (Kwok et al., 2005). 


\section{Follicular Recruitment}

Histological examination of the ovarian tissue showed that fish exposed to $\mathrm{EE}_{2}$ had a higher percentage of smaller early stage follicles and lower percentage of larger later stage follicles than the fish in the control or the QUIN group. This altered ovarian histology was also found in other studies that looked at the proportion of follicles in the ovary after $E_{2}$ exposure (Van den Belt et al., 2002; Van den Belt at al., 2001, Weber, Hill, \& Janz, 2003). These results indicate that $\mathrm{EE}_{2}$ may be interrupting follicular recruitment; preventing follicles from reaching the mature stage or potentially stimulating atresia once follicles reach the later stages. It has been proposed that $E_{2}$ may inhibit folliclular recrutiment by reducing gonadotropin levels through negative feedback mechanisms (Van den Belt et al., 2002). A decrease in gonadotropin levels and/or an imbalance of sex steroids is also believed to increase the incidence of folliclular atresia, another mechanism by which $\mathrm{EE}_{2}$ could possibly be impacting the proportion of follicle stages within the ovary. No vitellogenic follicles were found in the ovarian portions removed from the fish exposed to $\mathrm{EE}_{2}$ for six days, however follicles from all four stages were found in every fish sampled in other tanks. This provides further evidence that $\mathrm{EE}_{2}$ inhibits further recruitment or prevents follicular development past this stage. The altered ovarian histology was observed after only two days of treatment, demonstrating that altered follicular recruitment is a rapid response to $E_{2}$ exposure. The presence of the few mature follicles that were found in the ovaries of the fish exposed to $E_{2}$ for six days may be explained by the fact that it takes approximately ten days for follicles to proceed through the development stages (Wang \& Ge, 2002, 2004). The vitellogenic follicles present in the ovary before treatment with $\mathrm{EE}_{2}$ may have been able to progress 
through to the later development stages without obstruction during the first few days of $\mathrm{EE}_{2}$ exposure.

The fish exposed to $\mathrm{EE}_{2}$ also demonstrated a reduced GSI when compared to the fish exposed to QUIN and the control group, which is consistent with the findings of studies that examined the effects of $\mathrm{EE}_{2}$ on the zebrafish ovary (Van den Belt et al., 2001; Van den Belt, et al., 2002; Versonnen \& Janssen, 2004). Generally, the major fraction of ovarian volume is made up of the larger later stage follicles, a lack of these follicle stages in the ovaries of the $\mathrm{EE}_{2}$ fish could explain the decreased GSI observed.

\section{Steroidogenesis}

Aroma-A is responsible for the aromatization of testosterone to $E_{2}$, the hormone that initiates vitellogenin production in the liver and consequently follicular growth (Cheshenko, Pakdel, Segner, Kah, \& Eggen, 2008; Hinfray, Palluel, \& Turies, 2006). Expression of Arom-A is highest in vitellogenic follicles, when they are undergoing vitellogenesis, then declines in mature follicles (Goto-Kazeto et al., 2004). Fish exposed to QUIN demonstrated decreased expression of Arom-A at only one of the four sampling timepoints in Experiment 2, in contrast, downregulation of Arom-A was observed at all four timepoints in fish exposed to $\mathrm{EE}_{2}$. In addition, the results of the histological examination demonstrated that the ovaries of fish exposed to QUIN had a comparable proportion of follicle stages as the controls. Taking these results into account, the decrease in Aroma-A expression at one timepoint in the QUIN group does not suggest a major effect of QUIN exposure on the steroidogenic pathway.

The downregulation of Arom-A observed in the $\mathrm{EE}_{2}$ group is consistent with other studies looking at zebrafish exposed to $\mathrm{EE}_{2}$ (Cheshenko et al., 2008; Hinfray et al., 
2006; Urbatzka et al., 2012). A decrease in expression of Arom-A could inhibit estradiol production, resulting in an inhibition of follicle growth (Cheshenko et al., 2008). A decline in expression of Arom-A was observed in vitellogenic follicles (two-day treatment) and mature follicles (two and six-day treatment). No vitellogenic follicles were found in the fish that has been exposed to $\mathrm{EE}_{2}$ for 6 days, so the expression of Arom-A in these follicles could not be measured. This rapid effect observed after treatment with $\mathrm{EE}_{2}$ is consistent with the impacts observed on follicular recruitment, indicating that both these pathways are sensitive to exposure.

\section{Maturation}

$\mathrm{LH}$ is responsible for priming follicles to produce $17 \alpha, 20 \beta-\mathrm{P}$, which is the first step in releasing follicles from Stage 1 prophase arrest. Expression of LHr increases with follicle stage and the highest level of expression is seen in mature follicles (Kwok, et al., 2005). Fish exposed to QUIN demonstrated an increase in ovarian levels of $\mathrm{LHr}$ at 09:00. It is possible that the mature follicles that are not ovulated and/or spawned are responsible for the increased levels of LHr observed at 09:00 as this follicle stage demonstrates the highest level of expression (Kwok et al., 2005). This possibility is supported by the histological data as the proportion of mature follicles present in the ovaries of fish exposed to QUIN was similar to the control group; however, fewer eggs were being spawned in the QUIN group.

A decrease in ovarian and mature follicle stage expression of $\mathrm{LHr}$ was observed in fish exposed to $\mathrm{EE}_{2}$ for eight and six-days respectively, confirming the results of other $\mathrm{EE}_{2}$ exposure studies (Carnevali et al., 2010; Liu et al., 2013). Low expression of LHr may indicate that $\mathrm{EE}_{2}$ is inhibiting the action of $\mathrm{LH}$. A decrease in receptors indicates 
that LH may have little to no effect on follicles, preventing these follicles from undergoing maturation (Clelland \& Peng, 2009). This could also explain the lack of larger mature follicles noted in the histological examination of fish exposed to $\mathrm{EE}_{2}$.

\section{Ovulation}

Possible triggers for ovulation in zebrafish include prostaglandins, a product of the AA pathway (Lister \& Van Der Kraak, 2008) and $17 \alpha, 20 \beta-P$, acting through nPRs (Nagahama \& Yamashita, 2008). A decrease in levels of COX-2 was observed in fish exposed to QUIN in experiment 1 at one timepoint, 06:00. COX-2 is one of the enzymes involved in the production of prostaglandins, which are thought to be involved in the initiation of ovulation (Lister \& Van Der Kraak, 2008). In experiment 2, however, there was no impact of QUIN exposure observed on COX-2 expression at any of the four sampling timepoints. This may be explained by the change in experimental design in that experiment 1 had a larger sample size than experiment 2 and consequently the power of the statistical analysis in experiment 2 was weaker and potentially unable to detect significance. A reduction in ovarian levels of $17 \alpha, 20 \beta-P$ was also detected in the QUIN treatment group in experiment 1. This evidence suggests that QUIN may interrupt pathways involved in ovulation. Though QUIN is a phospholipase A2 inhibitor, exposure had no effect on $\mathrm{CPLA}_{2}$ expression levels. However, the mode of action of QUIN is to inhibit (Nagahama \& Yamashita, 2008) the activity of $\mathrm{CPLA}_{2}$ and does not seem to have an effect on transcription (Ehsanian et al., 2011). It was surprising that there was no effect seen on levels of $\mathrm{PGF}_{2 a}$, as a decrease in COX-2 suggests an interruption in the pathway responsible for the production of prostaglandins. One explanation for this is the sampling time, a study by Lister Van Der Kraak (2008) noted higher levels of $\mathrm{PGF}_{2_{a}}$ in 
spawning vs non-0spawning females at 08:00, which is when the lights came on in the experimental chamber. The fish in the current study were sampled at 06:00 in order to capture female fish in the midst of the ovulatory process, which occurs a couple of hours before spawning. Therefore it is possible that the window where levels of $P G_{2 a}$ were increased was missed with this earlier sampling time.

A decline in ovarian and mature follicle expression of $\mathrm{CPLA}_{2}$ and $\mathrm{nPR}$ was observed in fish exposed to $\mathrm{EE}_{2}$ for eight and six-days respectively. A decrease in $\mathrm{cPLA}_{2}$ suggests an interruption in the pathway responsible for the production of prostaglandins (Lister \& Van Der Kraak, 2008). $17 \alpha, 20 \beta-\mathrm{P}$ is thought to bind to nPRs to induce ovulation (Nagahama \& Yamashita, 2008) and low expression of this receptor suggests that $17 \alpha, 20 \beta-P$ is unable to act on the follicle, preventing the egg from being expelled from the follicle. This decrease in ovulatory genes could explain why the later stage follicles present in the ovary are not being spawned.

\section{Estrogenicity}

An upregulation of liver vtg expression in male fish is a recognized molecular indicator of estrogenic activity (Hutchinson, Ankley, Segner, \& Tyler, 2005), therefore hepatic vtg levels were measured to determine the potential estrogenic qualities of QUIN and $\mathrm{EE}_{2}$. There was no change in levels of expression between treatment or timepoints in the female fish. In the male fish there was no significant difference in expression between the control and the QUIN group, however the males exposed to $\mathrm{EE}_{2}$ demonstrated significantly higher levels of expression, which is consistent with results from other studies (Versonnen \& Janssen, 2004). 


\section{Conclusions}

This study demonstrated that the AOP framework was useful in determining how QUIN and $E_{2}$ inhibit spawning and allowed for connections to be drawn between the effects on primary reproductive pathways leading to spawning and impacts on cellular and organ responses (Table 2). The results of this study suggests that QUIN inhibits spawning by interupting the ovulatory pathway as the only impact of QUIN exposure was a decrease in genes and hormones involved in ovulation. There was no difference in ovary appearance or composition (proportion of follicles) when compared to the control, providing further evidence that QUIN is only impacting ovulation as there was no observed effect on follicular recruitment or maturation at the cellular or organ level. The AOP for $\mathrm{EE}_{2}$ demonstrates that $\mathrm{EE}_{2}$ inhibits spawning in two ways. Initially a decrease in Arom-A expression was detected, which may be responsible for preventing follicles from developing past the cortical alveolus stage. These effects of follicular recruitment were consistent with the reduced GSI and altered proportion of follicles in $E_{2}$ exposed fish. A decline in expression of $\mathrm{LHr}, \mathrm{cPLA} \mathrm{A}_{2}$ and $\mathrm{nPR}$ in mature follicles prevents the few later stage follicles present in the ovary from undergoing maturation and ovulation and those follicles are therefore unable to be spawned.

In conclusion the AOP framework was useful in identifying the reproductive pathways affected by $\mathrm{EE}_{2}$ and QUIN that led to an inhibition of spawning in zebrafish. Connections between responses observed at the molecular/cellular and organ level allowed for a comprehensive description of how each EDC affected spawning success. 


\section{CHAPTER 3}

\section{GENERAL DISCUSSION}

The present study evaluated whether an AOP framework can be effective at discriminating the effects of two model toxicants on spawning success in zebrafish. Specifically we have shown that QUIN and $\mathrm{EE}_{2}$ both inhibit spawning and identified potential AOPs responsible for this effect. In this study aspects of follicular recruitment, steroidogenesis, oocyte maturation and ovulation were examined using a variety of approaches: histology, EIAs and qPCR to identify cellular and organ responses to toxicant exposure.

The data obtained from the histological examination was useful in characterizing a change in the proportion of follicle stages present in the ovary and in determining the effects on follicular recruitment. When used in combination with measurement of GSI, the histological assessment facilitates the basis of understanding effects on ovarian size. When examining aspects of the pathways of steroidogenesis and follicular recruitment, maturation and ovulation, impacts on the expression of Arom-A, $\mathrm{LHr}$, $\mathrm{cPLA}_{2}, \mathrm{COX}-2$ and nPRs contributed valuable information in describing the toxicants' AOPs. The gene expression profiles of the exposed fish allowed for the identification of the reproductive pathways affected. Ovarian levels of $17 \alpha, 20 \beta-P$ did provide some

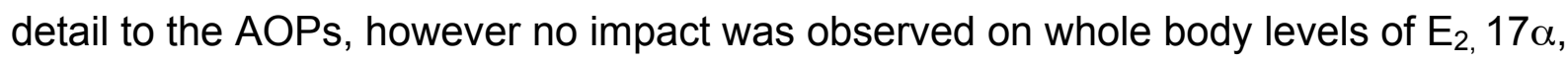
$20 \beta-P$ and $\mathrm{PGF}_{2 \star}$ and, in this study, whole body measurements did not assist in understanding how $\mathrm{EE}_{2}$ and QUIN were affecting reproduction.

The results of the histological analysis and gene expression provided valuable information in establishing the AOPs of QUIN and $\mathrm{EE}_{2}$ while the measurement of 
reproductive hormones levels did not. The rapid and dynamic nature of changes in hormone levels that occur during the periovulatory period may explain why only a few impacts on the hormones of interest were detected (Clelland \& Peng, 2009). The results of this study suggests that hormones, especially at the whole body level, may not be the most practical endpoint when trying to ascertain a toxicant's AOP on reproductive success.

\section{Further questions}

AOPs are useful in understanding the mode of action of a single substance, however, in real world circumstances, organisms are more likely to be exposed to a mixture rather than a single toxicant (Cleuvers, 2004). The more details added to the AOP of a toxicant, the greater the likelihood of discovering biomarkers related to an adverse effect that have value diagnostically in detecting the initiating event of exposure. This information also has the potential to assist in identifying the harmful component(s) of an unknown mixture and approximate the possible effects of exposure (Ankley et al., 2010).

While histology and gene expression provided useful information in this study, these aspects by no means represent the complete AOP of QUIN and $E_{2}$. The use of other tools may be useful in establishing a complete AOP of toxicants on the reproductive processes. While gene expression is helpful in identifying the pathways affected by toxicant exposure, especially ones that require synthesis of new mRNA, it does not provide an accurate representation of protein levels (Guo et al., 2008). The concentration of proteins and their interactions can be integral causative forces behind the success of reproductive processes (Guo et al., 2008); therefore, impacts on protein 
levels have the potential to provide valuable information regarding a toxicant's AOP. It is possible that aspects of the AOP for QUIN or $\mathrm{EE}_{2}$ were overlooked because there was no effect seen in the expression of mRNA. Measuring protein levels would provide a more complete description of a toxicant's AOP and may supplement or discount impacts described by gene expression results.

The impacts of QUIN and $E_{2}$ on the reproductive pathways indicated what processes are being interrupted and allowed for connections to be drawn to the apical endpoint of spawning inhibition. Determining the ability of the follicles to proceed through the maturation stage would provide additional details concerning the AOPs and would assist in establishing a connection between an impact on the cellular level and functionality. Zebrafish follicles can undergo spontaneous maturation in vitro (Pang \& Ge, 1999), testing the ability of the follicles of exposed fish to mature would provide information as to whether a toxicant's impact on maturation at the cellular level actually signifies a shutdown of this pathway.

The investigation of pathways not directly related to spawning may also provide information regarding AOPs associated with reproduction. Many studies have found an alteration in ovarian structure after exposure to $\mathrm{EE}_{2}$ and in this study a decrease in Arom-A provides a plausible explanation for the lack of later stage follicles. Other studies have suggested that increased events of follicular atresia are responsible for this change in the proportion of follicle stages (Van den Belt et al., 2002; Weber et al., 2003). Follicular atresia is a hormonally controlled apoptotic process that can be brought on by a number of stressors, including an imbalance of hormones (Miranda, Bazzoli, Rizzo, \& Sato, 1999). The current study did examine the expression levels of 
pro-apoptotic genes and apoptotic genes but there was no significant change in expression with $E_{2}$ treatment $A$ histological evaluation of the ovaries of zebrafish exposed to $\mathrm{EE}_{2}$ using terminal deoxynucleotidyl transferase (TdT)-mediated dUTP nick end labeling (TUNEL) would provide more accurate count of the number of atretic follicles present than counting from H\&E slides (Drevnick, Sandheinrich, \& Oris, 2006).

\section{Conclusions}

This thesis identified the AOPs of QUIN and $\mathrm{EE}_{2}$ and though both EDCs inhibit spawning they do so by affecting different reproductive pathways. Examination of the primary pathways involved in reproduction provided a means to successfully detect how a toxicant was affecting reproduction and identified which aspects provided the most useful information regarding a toxicants AOP. This study demonstrates the usefulness of AOPs in defining the impacts of different toxicants at the cellular, organ and whole organism level and how connections between these impacts and to the endpoint of spawning inhibition can be drawn. Further evidence is also provided regarding the value of the AOP framework as a tool in investigating the mode of action of toxicants on reproductive success and its potential to be utilized in real world situations. 


\section{REFERENCES}

Al-Ansari, A. M., Saleem, A., Kimpe, L. E., Sherry, J. P., McMaster, M. E., Trudeau, V. L., \& Blais, J. M. (2010). Bioaccumulation of the pharmaceutical $17 \alpha-$ ethinylestradiol in shorthead redhorse suckers (Moxostoma macrolepidotum) from the St. Clair River, Canada. Environmental Pollution, 158(8), 2566-71.

Alsop, D., Brown, S., \& Van Der Kraak, G. (2007). The effects of copper and benzo[a]pyrene on retinoids and reproduction in zebrafish. Aquatic Toxicology, 82(4), 281-95.

Ankley, G. T., Bencic, D. C., Breen, M. S., Collette, T. W., Conolly, R. B., Denslow, N. D., ... Watanabe, K. H. (2009). Endocrine disrupting chemicals in fish: developing exposure indicators and predictive models of effects based on mechanism of action. Aquatic Toxicology, 92(3), 168-78.

Ankley, G. T., Bennett, R. S., Erickson, R. J., Hoff, D. J., Hornung, M. W., Johnson, R. D., ... Villeneuve, D. L. (2010). Adverse outcome pathways: a conceptual framework to support ecotoxicology research and risk assessment. Environmental Toxicology and Chemistry / SETAC, 29(3), 730-41.

Ankley, G. T., Brooks, B., Huggett, D., \& Sumpter, J. P. (2007). Repeating history: Pharmaceuticals in the environment. Environmental Science \& Technology, 41, $8211-8217$.

Berndtson, A K., \& Goetz, F. W. (1986). Investigations on the control of in vitro spontaneous brook trout (Salvelinus fontinalis) ovulation. General and Comparative Endocrinology, 61(1), 134-141.

Blanco-Vives, B., \& Sánchez-Vázquez, F. J. (2009). Synchronisation to light and feeding time of circadian rhythms of spawning and locomotor activity in zebrafish. Physiology \& Behavior, 98(3), 268-75.

Carnevali, O., Tosti, L., Speciale, C., Peng, C., Zhu, Y., \& Maradonna, F. (2010). DEHP impairs zebrafish reproduction by affecting critical factors in oogenesis. PloS One, $5(4), 1-7$.

Cheshenko, K., Pakdel, F., Segner, H., Kah, O., \& Eggen, R. I. L. (2008). Interference of endocrine disrupting chemicals with aromatase CYP19 expression or activity, and consequences for reproduction of teleost fish. General and Comparative Endocrinology, 155(1), 31-62.

Clelland, E., \& Peng, C. (2009). Endocrine/paracrine control of zebrafish ovarian development. Molecular and Cellular Endocrinology, 312(1-2), 42-52. 
Cleuvers, M. (2004). Mixture toxicity of the anti-inflammatory drugs diclofenac, ibuprofen, naproxen, and acetylsalicylic acid. Ecotoxicology and Environmental Safety, 59(3), 309-315.

Drevnick, P. E., Sandheinrich, M. B., \& Oris, J. T. (2006). Increased ovarian follicular apoptosis in fathead minnows (Pimephales promelas) exposed to dietary methylmercury. Aquatic Toxicology, 79(1), 49-54.

Ehsanian, R., Van Waes, C., \& Feller, S. M. (2011). Beyond DNA binding - a review of the potential mechanisms mediating quinacrine's therapeutic activities in parasitic infections, inflammation, and cancers. Cell Communication and Signaling, 9, 1-18.

Espey, L. L., Stein, V. I., \& Dumitrescu, J. (1982). Survey of antiinflammatory agents and related drugs as inhibitors of ovulation in the rabbit. Fertility and Sterility, 38(2), 238-247.

Goto-Kazeto, R., Kight, K. E., Zohar, Y., Place, A. R., \& Trant, J. M. (2004). Localization and expression of aromatase mRNA in adult zebrafish. General and Comparative Endocrinology, 139(1), 72-84.

Guo, Y., Xiao, P., Lei, S., Deng, F., Xiao, G. G., Liu, Y., ... Deng, H. (2008). How is mRNA expression predictive for protein expression? A correlation study on human circulating monocytes. Acta Biochimica et Biophysica Sinica, 40(5), 426-436.

Hanna, R., Daly, S., Pang, Y., Anglade, I., Kah, O., Thomas, P., \& Zhu, Y. (2010). Characterization and expression of the nuclear progestin receptor in zebrafish gonads and brain. Biology of Reproduction, 122(April 2009), 112-122.

Heberer, T. (2002). Occurrence, fate, and removal of pharmaceutical residues in the aquatic environment: a review of recent research data. Toxicology Letters, 131(12), 5-17.

Hill, A. J., Teraoka, H., Heideman, W., \& Peterson, R. E. (2005). Zebrafish as a model vertebrate for investigating chemical toxicity. Toxicological Sciences : An Official Journal of the Society of Toxicology, 86(1), 6-19.

Hinfray, N., Palluel, O., Turies, C., Cousin, C., Porcher, J. M., \& Brion, F. (2006). Brain and Gonadal Aromatase as Potential Targets of Endocrine Disrupting Chemicals in a Model Species, the Zebrafish (Danio rerio), Environmental Toxicology, 21(4), 332-337.

Hutchinson, T. H., Ankley, G. T., Segner, H., \& Tyler, C. R. (2005). Screening and Testing for Endocrine Disruption in Fish-Biomarkers As "Signposts," Not "Traffic Lights," in Risk Assessment. Environmental Health Perspectives, 114(S-1), 106114. 
Ings, J. S., \& Van Der Kraak, G. (2006). Characterization of the mRNA expression of StAR and steroidogenic enzymes in zebrafish ovarian follicles. Molecular Reproduction and Development, 73, 943-954.

Jin, Y., Zhang, X., Shu, L., Chen, L., Sun, L., Qian, H., ... Fu, Z. (2010). Oxidative stress response and gene expression with atrazine exposure in adult female zebrafish (Danio rerio). Chemosphere, 78(7), 846-52.

Katzeto, Y., Goto-Kazeto, R., Trant, J.M. (2005). Membrane-bound progestin receptors in channel catfish ad zebrafish ovary: changes in gene expression associated with the reproductive cycles and hormonal reagents. General and Comparative Endocrinology. 142, 204-211

Kagawa, H., Tanaka, H., Okuzawa, K., \& Kobayashi, M. (1998). GTH II but not GTH I induces final maturation and the development of maturational competence of oocytes of red seabream in vitro. General and Comparative Endocrinology, 112(1), 80-88.

Kidd, K. A, Blanchfield, P. J., Mills, K. H., Palace, V. P., Evans, R. E., Lazorchak, J. M., \& Flick, R. W. (2007). Collapse of a fish population after exposure to a synthetic estrogen. Proceedings of the National Academy of Sciences of the United States of America, 104(21), 8897-8901.

Kramer, V. J., Etterson, M. A, Hecker, M., Murphy, C. A, Roesijadi, G., Spade, D. J., Ankley, G. T. (2011). Adverse outcome pathways and ecological risk assessment: brid. Environmental Toxicology and Chemistry / SETAC, 30(1), 64-76.

Kohli, G., Clelland, E., \& Peng, C. (2005). Potential targets of transforming growth factor-beta1 during inhibition of oocyte maturation in zebrafish. Reproductive Biology and Endocrinology, 3, 53.

Kwok, H.F., So, W.K., Wang, Y., \& Ge, W. (2005). Zebrafish gonadotropins and their receptors: I. Cloning and characterization of zebrafish follicle-stimulating hormone and luteinizing hormone receptors--evidence for their distinct functions in follicle development. Biology of Reproduction, 72(6), 1370-1381.

Laale, H. W. (1977). The biology and use of zebrafish, Brachydanio rerio in fisheries research: A literature review. Journal of Fish Biology, 10(2), 121-173.

Lange, A., Paull, G. C., Coe, T. S., Katsu, Y., Urushitani, H., Iguchi, T., \& Tyler, C. R. (2009). Sexual reprogramming and estrogenic sensitization in wild fish exposed to ethinylestradiol. Environmental Science \& Technology, 43(4), 1219-1225. 
Lister, A., \& Van Der Kraak, G. (2008). An investigation into the role of prostaglandins in zebrafish oocyte maturation and ovulation. General and Comparative Endocrinology, 159(1), 46-57.

Lister, A., Regan, C., Van Zwol, J., \& Van Der Kraak, G. (2009). Inhibition of egg production in zebrafish by fluoxetine and municipal effluents: a mechanistic evaluation. Aquatic Toxicology, 95(4), 320-329.

Liu, K., Wu, R. S. S., \& Ge, W. (2013). Luteinizing hormone receptor (Ihcgr) as a marker gene for characterizing estrogenic endocrine-disrupting chemicals in zebrafish ovarian follicle cells. General and Comparative Endocrinology, 192, 89-94.

Lydon, J. P., DeMayo, F. J., Funk, C. R., Mani, S. K., Hughes, A R., Montgomery, C. A, ... O'Malley, B. W. (1995). Mice lacking progesterone receptor exhibit pleiotropic reproductive abnormalities. Genes \& Development, 9(18), 2266-2278.

Melynk, N., Van Der Kraak, G. (2011). Regulation of prostaglandin synthesis in the zebrafish ovary. (dissertation).

Metcalfe, C. D., Kleywegt, S., Letcher, R. J., Topp, E., Wagh, P., Trudeau, V. L., \& Moon, T. W. (2013). A multi-assay screening approach for assessment of endocrine-active contaminants in wastewater effluent samples. Science of the Total Environment, 455, 132-140.

Mills, L. J., \& Chichester, C. (2005). Review of evidence: are endocrine-disrupting chemicals in the aquatic environment impacting fish populations? The Science of the Total Environment, 343(1-3), 1-34.

Miranda, A. C., Bazzoli, N., Rizzo, E., \& Sato, Y. (1999). Ovarian follicular atresia in two teleost species: a histological and ultrastructural study. Tissue \& Cell, 31(5), 480488.

Nagahama, Y., \& Yamashita, M. (2008). Regulation of oocyte maturation in fish. Development, Growth \& Differentiation, 50 Suppl 1, 195-219.

Nagahama, Y., Yoshikuni, M., Yamashita, M., Tanaka, M. (1994). Regulation of oocyte maturation in fish In: Sherwood N.M. Hew, C.L. (Eds), Fish physiology. Academic Press Inc., New York, pp. 393-439

Nagahama, Y., Yoshikuni, M., Yamashita, M., Tokomoto, T., Katsu, Y.(1995). Regulation of oocyte growth and maturation in fish. Current Topics in Developmental Biology, 30, 103-145.

Nelson, S. N., \& Van Der Kraak, G. (2010). Characterization and regulation of the insulin-like growth factor (IGF) system in the zebrafish (Danio rerio) ovary. General and Comparative Endocrinology, 168(1), 111-20. 
Niimi, A. J., \& LaHam, Q. N. (1974). Influence of breeding time interval on egg number, mortality, and hatching of the zebra fish Brachydanio verio. Canadian Journal of Zoology, 52(4), 515-7.

Ogiwara, K., Takano, N., Shinohara., M., Murakimu, M., Takahashi, T. (2005). Gelatinase A and membrane-type matrix metalloproteinases 1 and 2 are responsible for follicle rupture during ovulation in the medaka. Proceedings of the Natural Academy of Sciences U.S.A. 102, 8442-8447

Pang, Y., Dong, J., \& Thomas, P. (2008). Estrogen signaling characteristics of Atlantic croaker G protein-coupled receptor 30 (GPR30) and evidence it is involved in maintenance of oocyte meiotic arrest. Endocrinology, 149(7), 3410-3426.

Pang, Y., \& Ge, W. (1999). Activin stimulation of zebrafish oocyte maturation in vitro and its potential role in mediating gonadotropin-induced oocyte maturation. Biology of Reproduction, 61(4), 987-992.

Pang, Y., \& Ge, W. (2002a). Gonadotropin and activin enhance maturational competence of oocytes in the zebrafish (Danio rerio). Biology of Reproduction, 66(2), 259-265.

Pang, Y., \& Ge, W. (2002b). Gonadotropin regulation of activin betaA and activin type IIA receptor expression in the ovarian follicle cells of the zebrafish, Danio rerio. Molecular and Cellular Endocrinology, 188(1-2), 195-205.

Pang, Y., \& Thomas, P. (2010). Involvement of estradiol-17B and its membrane receptor, G protein coupled receptor 30 (GPR30) in regulation of oocyte maturation in zebrafish, Danio rerio. General and Comparative Endocrinology, 161(1), 58-61.

Parker, W. J., Pileggi, V., Seto, P., Chen, X., Ogunlaja, M., Van Der Kraak, G., \& Parrott, J. (2014). Impact of activated sludge configuration and operating conditions on in vitro and in vivo responses and trace organic compound removal. The Science of the Total Environment, 490C, 360-369.

Parrott, J. L., \& Blunt, B. R. (2005). Life-cycle exposure of fathead minnows (Pimephales promelas) to an ethinylestradiol concentration below $1 \mathrm{ng} / \mathrm{L}$ reduces egg fertilization success and demasculinizes males. Environmental Toxicology, 20(2), 131-41.

Patiño, R., \& Sullivan, C. V. (2003). Ovarian follicle growth, maturation and ovulation in teleost fish. Fish Physiology and Biochemistry, (1986), 57-70.

Patiño, R., Yoshizaki, G., Thomas, P., \& Kagawa, H. (2001). Gonadotropic control of ovarian follicle maturation: the two-stage concept and its mechanisms. 
Comparative Biochemistry and Physiology. Part B, Biochemistry \& Molecular Biology, 129(2-3), 427-439.

Patiño, R., \& Thomas, P. (1990). Effects of gonadotropin on ovarian intrafollicular processes during the development of oocyte maturational competence in a teleost, the Atlantic croaker: evidence for two distinct stages of gonadotropin control of final oocyte maturation. Biology of Reproduction, 43(5), 818-827.

Rahman, M. F., Yanful, E. K., \& Jasim, S. Y. (2009). Endocrine disrupting compounds (EDCs) and pharmaceuticals and personal care products (PPCPs) in the aquatic environment: implications for the drinking water industry and global environmental health. Journal of Water and Health, 7(2), 224-243.

Segner, H., Caroll, K., Fenske, M., Janssen, C. R., Maack, G., Pascoe, D., ... Wenzel, A. (2003). Identification of endocrine-disrupting effects in aquatic vertebrates and invertebrates : report from the European IDEA project, 54, 302-314.

Selderslaghs, I. W. T., Van Rompay, A. R., De Coen, W., \& Witters, H. E. (2009). Development of a screening assay to identify teratogenic and embryotoxic chemicals using the zebrafish embryo. Reproductive Toxicology, 28(3), 308-320.

Selman, K., Wallace, R. A., \& Sarka, A. (1993). Stages of Oocyte Development in the Zebrafish, Brachydanio rerio. Journal of Morphology, 224, 203-224.

Soares, J., Castro, L. F. C., Reis-Henriques, M. a, Monteiro, N. M., \& Santos, M. M. (2012). Zebrafish (Danio rerio) life-cycle exposure to chronic low doses of ethinylestradiol modulates p53 gene transcription within the gonads, but not NER pathways. Ecotoxicology, 21(5), 1513-1522.

Söffker, M., \& Tyler, C. R. (2012). Endocrine disrupting chemicals and sexual behaviors in fish--a critical review on effects and possible consequences. Critical Reviews in Toxicology, 42(8), 653-668.

Spence, R., Fatema, M. K., Reichard, M., Huq, K., Wahab, M., Ahmed, Z. F., \& Smith, C. (2006). The distribution and habitat preferences of the zebrafish in Bangladesh. Journal of Fish Biology, 69(5), 1435-1448.

Stacey, N., Chojnacki, A., Narayanan, A., Cole, T., \& Murphy, C. (2003). Hormonally derived sex pheromones in fish: exogenous cues and signals from gonad to brain. Canadian Journal of Physiology and Pharmacology, 341(81(4), 329-341.

Tan, Q., Zagrodny, A., Bernaudo, S., \& Peng, C. (2009). Regulation of membrane progestin receptors in the zebrafish ovary by gonadotropin, activin, TGF-beta and BMP-15. Molecular and Cellular Endocrinology, 312(1-2), 72-79. 
Tang, R., Dodd, A., Lai, D., Mcnabb, W. C., \& Love, D. R. (2007). Validation of Zebrafish (Danio rerio) Reference Genes for Quantitative Real-time RT-PCR Normalization. Acta Biochimica et Biophysica Sinica, 39(5), 384-390.

Teraoka, H., Dong, W., \& Hiraga, T. (2003). Zebrafish as a novel experimental model for developmental toxicology. Congenital Anomalies, 43(2), 123-32.

Tokumoto, T., Tokumoto, M., \& Nagahama, Y. (2005). Induction and inhibition of oocyte maturation by EDCs in zebrafish. Reproductive Biology and Endocrinology, 3, 1-9.

Urbatzka, R., Rocha, E., Reis, B., Cruzeiro, C., Monteiro, R., \& Rocha, M. J. (2012). Effects of ethinylestradiol and of an environmentally relevant mixture of xenoestrogens on steroidogenic gene expression and specific transcription factors in zebrafish. Environmental Pollution, 164, 28-35.

Van den Belt, K., Verheyen, R., \& Witters, H. (2001). Reproductive effects of ethynylestradiol and 4t-octylphenol on the zebrafish (Danio rerio). Archives of Environmental Contamination and Toxicology, 41(4), 458-467.

Van den Belt, K., Wester, P. W., Van der Ven, L. T. M., Verheyen, R., \& Witters, H. (2002). Effects of ethynylestradiol on the reproductive physiology in zebrafish (Danio rerio): time dependency and reversibility. Environmental Toxicology and Chemistry/SETAC, 21(4), 767-775.

Van den Heuvel, M. R., Martel, P., Kovacs, T. G., MacLatchy, D., Van Der Kraak, G., Parrott, J. L., ... Hewitt, L. M. (2010). Evaluation of short-term fish reproductive bioassays for predicting effects of a Canadian bleached kraft mill effluent. Water Quality Research Journal of Canada, 45(2), 175-186.

Van Der Kraak, G. (2009). The GnRH System and the Neuroendocrine Regulation of Reproduction. Fish Neuroendocrinology, 28, 115-149.

Versonnen, B. J., \& Janssen, C. R. (2004). Xenoestrogenic effects of ethinylestradiol in zebrafish (Danio rerio). Environmental Toxicology, 19(3), 198-206.

Vogtherr, M., Grimme, S., Elhorst, B., Jacobs, D., Fiebig, K., Griesinger, C., \& Zhan, R. (2003). Antimalarial drug quinacrine binds to C-terminal helix of cellular prion protein. Journal of Medicinal Chemistry, 227(46), 3563-3564.

Vosges, M., Braguer, J.C., \& Combarnous, Y. (2008). Long-term exposure of male rats to low-dose ethinylestradiol (EE2) in drinking water: effects on ponderal growth and on litter size of their progeny. Reproductive Toxicology, 25(2), 161-168.

Wang, H., Tan, J. T., Emelyanov, A., Korzh, V., \& Gong, Z. (2005). Hepatic and extrahepatic expression of vitellogenin genes in the zebrafish, Danio rerio. Gene, $356,91-100$. 
Wang, H., Yan, T., Tan, J. T., \& Gong, Z. (2000). A zebrafish vitellogenin gene (vg3) encodes a novel vitellogenin without a phosvitin domain and may represent a primitive vertebrate vitellogenin gene. Gene, 256 (1-2), 303-310.

Wang, Y., \& Ge, W. (2002). Cloning of zebrafish ovarian carbonyl reductase-like 20ßhydroxysteroid dehydrogenase and characterization of its spatial and temporal expression. General and Comparative Endocrinology, 127(3), 209-216.

Wang, Y., \& Ge, W. (2004). Developmental profiles of activin betaA, betaB, and follistatin expression in the zebrafish ovary: evidence for their differential roles during sexual maturation and ovulatory cycle. Biology of Reproduction, 71(6), 2056-2064.

Weber, L. P., Hill, R. L., \& Janz, D. M. (2003). Developmental estrogenic exposure in zebrafish (Danio rerio): II. Histological evaluation of gametogenesis and organ toxicity. Aquatic Toxicology, 63(4), 431-446.

Werner, J., Palace, V. P., Wautier, K. G., Mills, K. H., Chalanchuk, S. M., \& Kidd, K. A. (2006). Reproductive fitness of lake trout (Salvelinus namaycush ) exposed to environmentally relevant concentrations of the potent estrogen ethynylestradiol (EE2) in a whole lake exposure experiment. Scientia Marina (October), 59-66.

World Health Organization, International Programme on Chemical Safety (WHO-IPCS). Global Assessment of the State-of-the-Science of Endocrine Disrupters. Damstra, T., Barlow, S., Bergman, A., Kavlock, R., Van Der Kraak, G., eds. 2002.

Wu, T., Patel, H., Mukai, S., Melino, C., Garg, R., Ni, X., ... Peng, C. (2000). Activin , Inhibin, and Follistatin in Zebrafish Ovary : Expression and Role. Biology of Reproduction, 1592(62), 1585-1592.

Yaron, Z. \& Siva, B. (2006). Reproduction. In: Evans, D., Clairborne, J. (eds), The Physiology of Fishes, third ed. CRC Press, Boca Raton, Florida, pp.343-386.

Yin, G. G., Kookana, R. S., \& Ru, Y. J. (2002). Occurrence and fate of hormone steroids in the environment. Environment International, 28(6), 545-551.

Zha, J., Wang, Z., Wang, N., \& Ingersoll, C. (2007). Histological alternation and vitellogenin induction in adult rare minnow (Gobiocypris rarus) after exposure to ethynylestradiol and nonylphenol. Chemosphere, 66(3), 488-495.

Zhang, C., Willett, C., \& Fremgen, T. (2003). Zebrafish: an animal model for toxicological studies. Current Protocols in Toxicology, 1-18. 
Zuo, Y., Zhang, K., \& Zhou, S. (2013). Determination of estrogenic steroids and microbial and photochemical degradation of $17 \alpha$-ethinylestradiol (EE2) in lake surface water, a case study. Environmental Science. Processes \& Impacts, 15(8), 1529-1535. 